\title{
Supporting Calculations for Submerged Bed Scrubber Condensate Disposal Preconceptual Study
}

Author Name:

\section{A. Pajunen}

AEM Consulting, LLC

Richland, WA 99352

U.S. Department of Energy Contract DE-AC27-08RV14800

\author{
EDT/ECN: DRF UC: \\ Cost Center: Charge Code: \\ B\&R Code: Total Pages: 105
}

Key Words: Submerged Bed Scrubber, LAW Facility, Low Activity Waste, Off-Site Disposal, Direct Disposal, Wiped-Film Evaporator

Abstract: This document provides supporting calculations for the preparation of the Submerged Bed Scrubber Condensate Disposal Preconceptual Study report. The supporting calculations include equipment sizing, Hazard Category determination, and LAW Melter Decontamination Factor Adjustments.

TRADEMARK DISCLAIMER. Reference herein to any specific commercial product, process, or service by trade name, trademark, manufacturer, or otherwise, does not necessarily constitute or imply its endorsement, recommendation, or favoring by the United States Government or any agency thereof or its contractors or subcontractors.

APPROVED

By G. E. Bratton at $8: 29$ am, Sep 18, 2012

Date

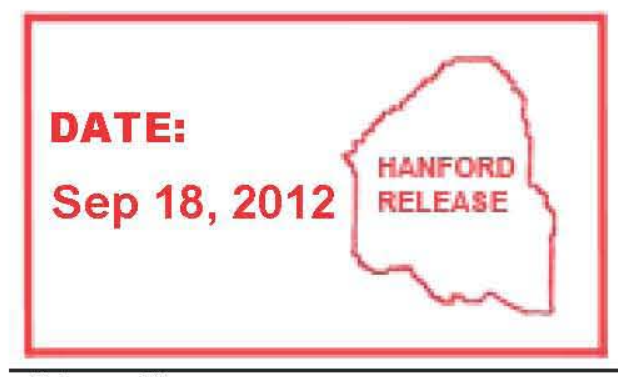

Release Stamp

\section{Approved For Public Release}




\title{
SUPPORTING CALCULATION FOR SUBMERGED BED SCRUBBER CONDENSATE DISPOSAL PRECONCEPTUAL STUDY
}

\author{
June 2012 \\ prepared by: \\ G.R. Golcar \\ A.L. Pajunen \\ P. Johnson \\ A E M Consulting, LLC \\ 1201 Jadwin Avenue, Suite 203 \\ Richland, Washington 99352 \\ (509) 946-3685
}

prepared for:

Washington River Protection Solutions, LLC 


\section{CONTENTS}

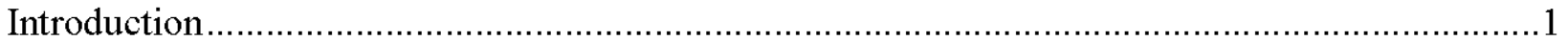

References

\section{APPENDICES}

Appendix A - Calculation AEM-WRPS-2012-CN-012, Alternative 1 Equipment Sizing Estimates ...................................................................................... A

Appendix B - Calculation AEM-WRPS-2012-CN-013, Alternative 2 Equipment Sizing Estimates ....................................................................................... B-i

Appendix C - Calculation AEM-WRPS-2012-CN-014, Alternative 3 Equipment Sizing

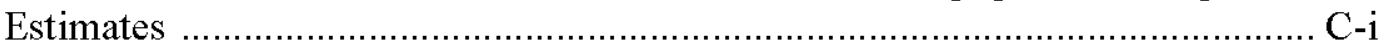

Appendix D - Calculation AEM-WRPS-2012-CN-015, Low-Activity Waste Melter Decontamination Factor Adjustments .................................................... D-i

Appendix E - Calculation AEM-WRPS-2012-CN-017 Hazard Category Calculation for Submerged Bed Scrubber Condensate Direct Disposal ....................................E-i

FIGURE

Figure 1. Submerged Bed Scrubber Condensate Direction Disposal Alternatives ................. 1 


\section{INTRODUCTION}

The submerged bed scrubber (SBS) condensate direct disposal alternatives were developed in RPP-RPT-52321, Submerged Bed Scrubber Condensate Disposal Preconceptual Engineering Study. To support the development of these alternatives, supporting calculations were prepared and are included herein.

The three SBS condensate direct disposal alternatives identified in RPP-RPT-52321 are used as the basis for these supporting calculations. Figure 1 provides a graphical depiction of the SBS condensate direct disposal alternatives included in RPP-RPT-52321.

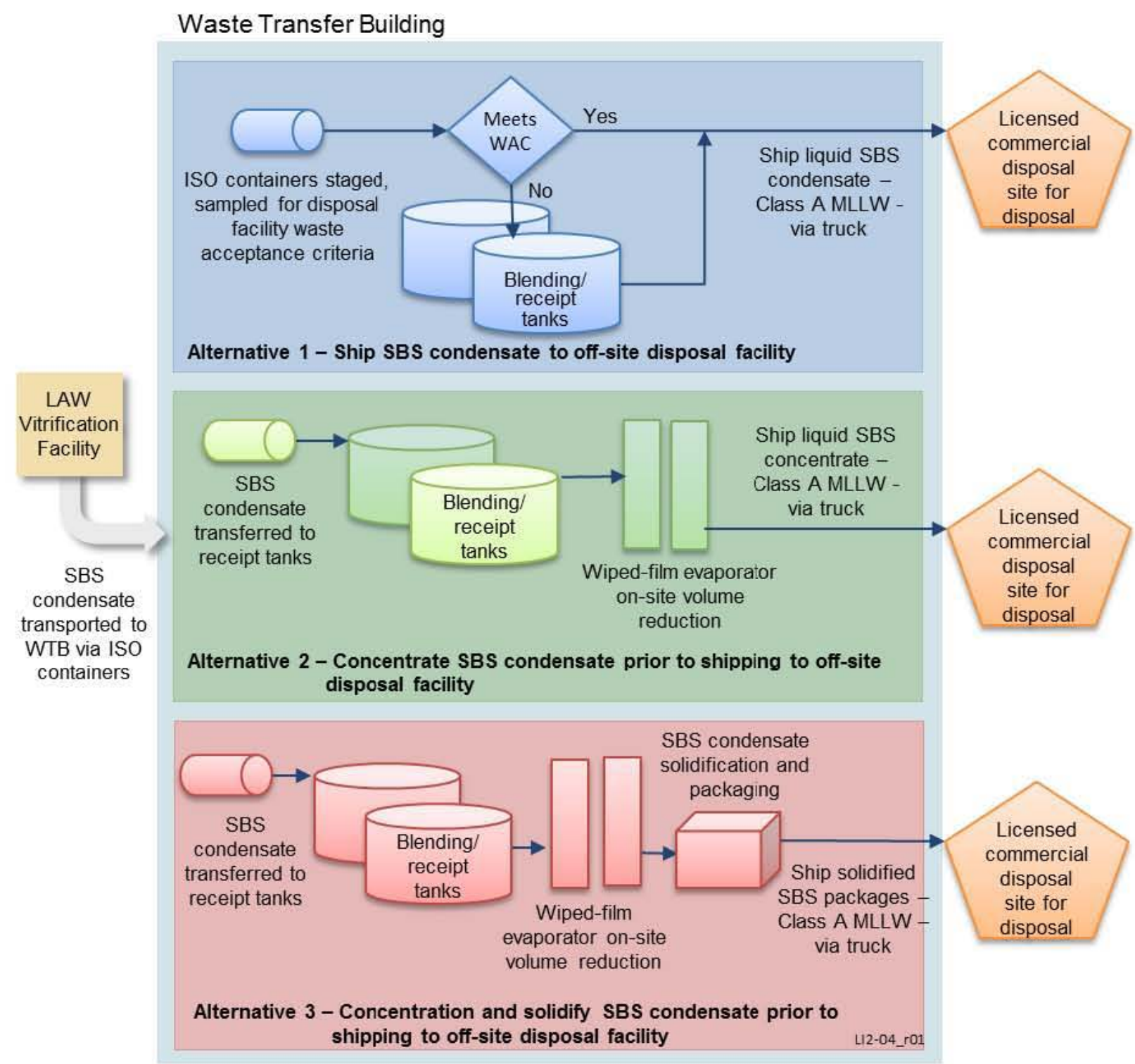

Figure 1. Submerged Bed Scrubber Condensate Direction Disposal Alternatives 
The following supporting calculations are included in this document.

- Calculation AEM-WRPS-2012-CN-012, Rev. 0, provides the Alternative 1 equipment sizing estimates (Appendix A)

- Calculation AEM-WRPS-2012-CN-013, Rev. 0, provides the Alternative 2 equipment sizing estimates (Appendix B)

- Calculation AEM-WRPS-2012-CN-014, Rev. 0, provides the Alternative 3 equipment sizing estimates (Appendix C)

- Calculation AEM-WRPS-2012-CN-015, Rev. 0, provides the LAW Melter Decontamination Factor Adjustments (Appendix D)

- Calculation AEM-WRPS-2012-CN-017, Rev. 0, provides the Hazard Category Calculation for SBS condensate direct disposal (Appendix E).

\section{REFERENCES}

RPP-RPT-52321, 2012, Submerged Bed Scrubber Condensate Disposal Preconceptual Engineering Study, Rev. 0, Washington River Protection Solutions, LLC, Richland, Washington. 
Appendix A

CALCULATION AEM-WRPS-2012-CN-012, ALTERNATIVE 1 EQUIPMENT SIZING ESTIMATES 
Subcontractor Calculation Review Checklist

Subject: AEM-WRPS-2012-CN-012, Alternative 1 Equipment Sizing Estimates

The subject document has been reviewed by the undersigned.

The reviewer reviewed and verified the following items as applicable.

Documents Reviewed: AEM-WRPS-2012-CN-012, Alternative 1 Equipment Sizing Estimates Analysis Performed By: AEM Consulting, LLC

- Design Input

- Basic Assumption

- Approach/Design Methodology

- Consistency with item or document supported by the calculation

- Conclusion/Results Interpretation

- Impact on existing requirements

Reviewer (printed name, signature, and date) P. E. Peistrup

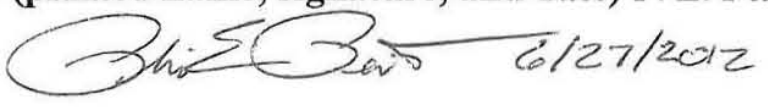

Organizational Manager (printed name, signature, and date) Martin Wheeler

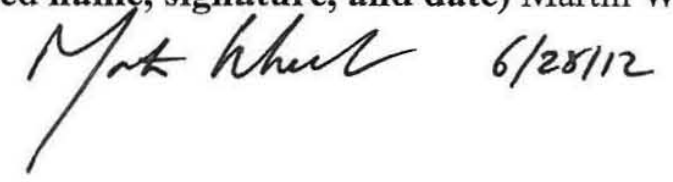




\begin{tabular}{|c|c|c|c|}
\hline \multirow{2}{*}{$\begin{array}{l}\text { A E M Consulting, LLC. } \\
\text { Calculation Note and } \\
\text { Peer Review }\end{array}$} & \multicolumn{2}{|c|}{$\begin{array}{l}\text { Calculation Set No. } \\
\text { AEM-WRPS-2012-CN-012 }\end{array}$} & $\begin{array}{l}\text { ev No. } \\
0\end{array}$ \\
\hline & \multicolumn{3}{|c|}{ End Use: Pre-conceptual Design } \\
\hline $\begin{array}{l}\text { Project: WRPS } 48504 \text { Line Item 2-SBS Direct Disposal } \\
\text { Alternatives. }\end{array}$ & \multicolumn{3}{|c|}{ Sheet 1 of 9} \\
\hline Discipline: Process & \multicolumn{3}{|c|}{ Contract No: WRPS 48504 Line Item 2} \\
\hline Structure or System: NA & \multicolumn{3}{|c|}{ Reserved } \\
\hline \multicolumn{4}{|l|}{ Subject: Alternative 1 Equipment Sizing Estimates } \\
\hline \multicolumn{2}{|c|}{ Completed by: G. R. Golcar Cailé, Ban } & Date & \\
\hline \multirow{2}{*}{\multicolumn{2}{|c|}{ 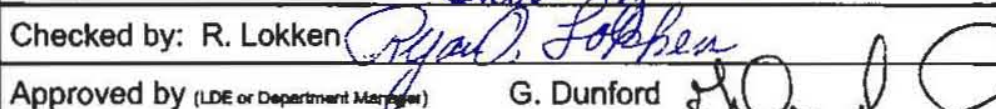 }} & Date & \\
\hline & & Date $6 / 2$ & \\
\hline \multicolumn{4}{|l|}{ Distribution: NA } \\
\hline \multirow[t]{2}{*}{$\begin{array}{l}\text { Reason for Revision: } \\
\text { Not applicable, initial release. }\end{array}$} & & \multicolumn{2}{|c|}{$\begin{array}{l}\text { Total number of sheets in this } \\
\text { issue: } 9\end{array}$} \\
\hline & & \multicolumn{2}{|c|}{$\begin{array}{l}\text { Sheets revised, added or deleted: } \\
\text { NA }\end{array}$} \\
\hline \multicolumn{4}{|c|}{$\begin{array}{l}\text { Problem Statement: } \\
\text { Estimate the size of major equipment pieces for the configuration associated with the Alternative-1, which } \\
\text { transfers the "As Generated" SBS condensate directly to the disposal site. Also, the annual sample load is } \\
\text { estimated. }\end{array}$} \\
\hline \multicolumn{4}{|c|}{$\begin{array}{l}\text { Surnmary Conclusions: } \\
\text { The feed to Alternative-1 is the SBS condensate transferred in International Standard Organization (ISO) tanks } \\
\text { from WTP vessel RLD-VSL-00005. The analysis uses seven days of storage as an assumed allocation for poor } \\
\text { weather condition and the design throughput of } 7500 \text { gallons per operating day for the SBS condensate flow rate } \\
\text { at peak generation documented in SVF-2440 SBS Disposal PreConcept Alts. as the basis for sizing. }\end{array}$} \\
\hline \multicolumn{4}{|c|}{$\begin{array}{l}\text { - A maximum of } 65,600 \text { gallons (rounded) tank volume size for each tank in a two tank storage } \\
\text { configuration is required }\end{array}$} \\
\hline \multicolumn{4}{|c|}{$\begin{array}{l}\text { - The size of each storage tank was reduced to } 31,300 \text { gallons (rounded) by considering the use of ISO } \\
\text { tanks in combination with tank that provide additional storage capacity at the waste transfer facility in the } \\
\text { holding period. }\end{array}$} \\
\hline \multicolumn{4}{|c|}{$\begin{array}{l}\text { The reduced storage tank system feed receipt and blending tanks are sized for blending off-normal SBS } \\
\text { condensate and storage for the sampling analysis to comply with the waste acceptance criteria. }\end{array}$} \\
\hline \multicolumn{4}{|c|}{$\begin{array}{l}\text { Design Basis: } \\
\text { The Alternative-1 SBS condensate feed throughput documented in SVF- } 2440 \text { Rev } 0 \text { at } 7500 \text { gallon per day. }\end{array}$} \\
\hline
\end{tabular}


RPP-RPT-52796, Rev. 0

A E M Consulting, LLC. Calculation Set No. AEM-WRPS-2012-CN-012 Rev No. 0

Sheet 2 of 9

\section{Contents}

$\begin{array}{ll}1.0 & \text { Objective/Purpose } \\ 2.0 & \text { Input Data } \ldots \ldots \ldots \ldots \ldots \ldots \ldots \ldots\end{array}$

\subsection{Objective/Purpose}

A pre-conceptual engineering study is being developed to compare three alternative configurations for disposal of the Submerged Bed Scrubber (SBS) condensate from the WTP LAW Vitrification facility. The objective of this calculation is to estimate the size of major equipment pieces for the configuration associated with the Alternative-1, which transfers the "As Generated" SBS condensate directly to the disposal site. In addition, the annual sample load is estimated. Alternative- 1 contains feed receipt and blending tanks to meet the feed storage capacity for an assumed holding period prior to shipment to an off site disposal site. The process stream for Alternative-1 is SBS condensate transferred in International Standard Organization (ISO) tanks from the WTP vessel RLD-VSL-00005. The calculation considers the holding time to conduct and prepare Record Control (RC) waste analysis, storing liquid in ISO tanks used for transferring the liquid while performing RC analysis before offsite shipment, and/or blending SBS condensate in the storage tanks followed by RC sampling before loading in ISO tanks for disposal shipment.

Figure 1 provides a simplified view of the Alternative-1 configuration. SBS condensate from the WTP vessel RLD-VSL-00005 is received at the waste transfer facility in the ISO tanks. An RC sample from the RLD-VSL-00005 before loading ISO tanks determines if the SBS condensate batch complies with transportation and disposal waste acceptance criteria (WAC). If the ISO tank content complies with the WAC then the container is stored at the waste transfer facility for shipment to a licensed disposal site. SBS condensate that fails to comply with WAC is transferred to one of two SBS condensate storage tanks located in the waste transfer building and blended with complying batches. The tank content is then RC sampled and, if determined to be compliant, prepared for loading into ISO tanks for offsite transportation.

\subsection{Input Data}

- The WTP vessel RLD-VSL-00005 SBS condensate output is used as the input feed stream to the Alternative-1 evaluation.

- The analysis uses the throughput documented in SVF-2440, SBS Disposal PreConcept Alts. Rev 0 (worksheet Eqpt DesignAlt-1) as the basis for sizing. The equipment sizing is based on receiving 7500 gallons per operating day (SBS condensate flow rate at peak generation). This rate is defined as "DesignRateStream1" in the calculation described in Section 4.0, and is referred to as "Stream1, SBS feed condensate" in SVF-2440 (Eqpt DesignAlt-1 worksheet).

- The mission average daily rate at $4540.6 \mathrm{gal} /$ day described in SVF-2440 (worksheet Mission Avg-Alt 1) is used to calculate the minimum sampling load required for RC sampling analysis performed at WTP on the RLD-VSL-00005 content prior to transferring the waste in ISO tanks.

- The batch volume of 16,000 gallons for vessel RLD-VSL-00005 described in 24590-WTP-RPT-PT-02-005, Flow sheet Bases, Assumptions, and Requirements, Rev 6, page B-4 is used to estimate the minimum annual sampling load for Alternative-1 configuration (see Figure 1 for RC sampling point).

File: AEM-WRPS-2012-CN-012 Rev 0.xmcd 
- Equipment sizing is based on a peak processing rate such that operating efficiency adjustments are not required (overall Total Operating Efficiency (TOE) of 100\%).

- An ISO tank is used to transfer SBS condensate from the WTP to the Waste Transfer Building (WTB). The ISO tanks provide additional storage capacity at the WTB, and are used for transportation of SBS condensate to a licensed commercial disposal site (see Figure 1).

\section{Input Calculation Constants:}

Facility Design Basis :

Overall Operating Efficiency:

Days per year:
DesignRate $_{\text {Stream1 }}:=7500 \quad$ gal condensate/Operating day

$\mathrm{TOE}:=1 \quad$ Operating days/Calendar days

Days : $=365$

Calendar days/Calendar yr

Input Feed Volumetric Flow Rate at Peak Generation: $\quad Q_{\text {Feedin }}:=$ DesignRate $_{\text {Stream1 }} \cdot{ }^{\mathrm{TOE}}$

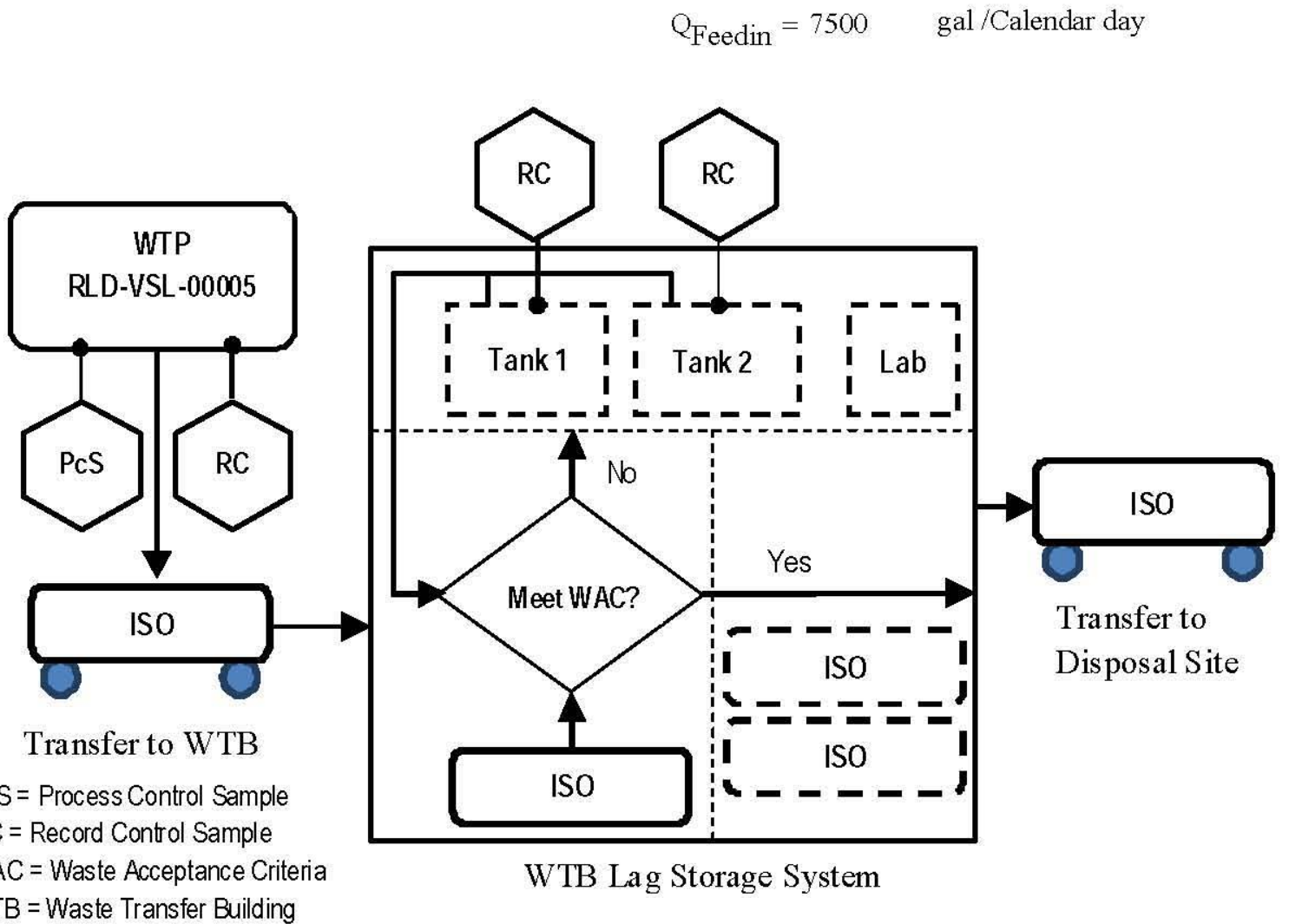

Figure 1 Alternative-1 Configuration and Sampling 


\subsection{Assumptions}

For Alternative-1 the following assumptions apply:

1. ISO tanks of 5000 gallon volumetric capacity are assumed for the SBS condensate transportation and storage in the WTB lag storage system. At a least twelve ISO tanks and ISO tank positions are available to support lag storage.

2. A two day Record Control (RC) sample analysis turnaround time is assumed to verify compliance with the transportation and disposal site waste acceptance criteria (WAC). This assumes analysis and data package preparation activities similar to that described for sample point PT-27 in 24590-WTP-PL-PR-04-0001, Integrated Sampling and Analysis Requirements Document (ISARD), which characterized waste transfers from RLD-TK-0006A/B for comparison with the Liquid Effluent Retention Facility/Effluent Treatment Facility $\mathrm{WAC}$, and is assumed similar to sample requirements for this application. The RC sampling is performed on the SBS condensate vessel batches transferred from the WTP and stored in ISO tanks at the WTB facility and, if necessary, on the SBS condensate stored in the lag storage tanks after blending operation (see Figure 1).

3. The lag storage system is sized to hold condensate for seven days, which is an assumed allocation for poor weather condition along transport routes. This logic implicitly includes the two-day hold time for tank sampling analysis turnaround prior to loading condensate for transport.

4. In order to meet seven day criteria needed as the basis for the tank storage capacity, it is assumed a combination of ISO tanks and the feed receipt and blending tanks can be used to satisfy the storage period. A design margin of $80 \%$ volumetric fill capacity is used to estimate the two feed storage tanks volumes as an enabling assumption.

6. The feed receipt and blending storage tanks are assumed to be cylindrical, above ground vessels.

7. A 1:1 aspect ratio for each tank diameter and height is used as an enabling assumption.

Assumption Calculation Constants:

Hold time before Transfer:

Design Margin of Tank Volume Filled by Feed:

Tank Height to Diameter Aspect Ratio:

$$
\begin{aligned}
& \mathrm{t}_{\text {HoldMax }}:=7 \text { day } \\
& \text { Fill }_{\mathrm{DM}}:=0.8 \\
& \mathrm{AR}:=1 \quad \text { Dimensionless }
\end{aligned}
$$

\subsection{Method of Analysis}

This calculation begins by constructing the Alternative-1 configuration and sampling schematic shown in Figure 1. The seven days of storage and the design throughput of 7500 gallons per operating day for the SBS condensate flow rate, at peak generation, are used as the sizing basis. These inputs calculate the maximum storage capacity required for the Alternative-1 configuration using a system of two storage tanks. The peak generation rate provides a conservative margin in sizing. The calculated maximum storage capacity is then applied as the basis to estimate a reduced storage tank volume, when it is assumed a combination of the ISO tanks and reduced storage tanks satisfy the seven days storage criteria. In this case the SBS condensate tanks are sized for blending off-normal SBS condensate and storage for the RC sampling to comply with the WAC.

The sample load is estimated for the maximum number of samples to be analyzed if enough waste received at the WTB facility was out of WAC specification such that all waste need to be routed to the storage tanks for blending.

File: AEM-WRPS-2012-CN-012 Rev 0.xmcd 


\section{Storage Vessel Sizing:}

The storage tanks are assumed cylindrical, above ground atmospheric-pressure storage tanks. The calculation for a two tank configuration is presented in this section.

\section{Maximum Required Tank Size:}

The maximum volume of each tank is sized to accommodate storing seven days of SBS condensate, generated at the peak rate, when $80 \%$ full. The two storage tank system is arranged such that one tank is always available to receive liquid from WTP vessel RLD-VSL-00005 without stopping the upstream process flow. Based on the described cycling scheme, the needed tank volume capacity and size is calculated.

$$
\text { Number of Lag Storage Tanks: } \quad \operatorname{Num}_{2 \mathrm{~T}}:=2 \quad \text { Tanks Configuration }
$$

Hold Time before Transfer for Two lag Storage System: $\quad t_{\text {Hold2T }}:=t_{\text {HoldMax }}$

Feed Volume per Storage Tank: $\quad \mathrm{V}_{2 \mathrm{TFeed}}:=\mathrm{Q}_{\text {Feedin }} \cdot \mathrm{t}_{\mathrm{H}} \mathrm{Hold} 2 \mathrm{~T}$

$$
\mathrm{V}_{2 \mathrm{TFeed}}=52500 \quad \mathrm{gal} \mathrm{Feed} / \text { Storage Tank }
$$

Design Margin of Tank Volume Filled by Feed: $\quad$ Fill $_{\mathrm{DM}}=0.8$

Actual Tank Volume to achieve $80 \%$ Storage Capacity: $\quad \mathrm{V}_{2 \mathrm{TSize}}:=\frac{\mathrm{V}_{2 \mathrm{TFeed}}}{\text { Fill }_{\mathrm{DM}}}$

$$
\mathrm{V}_{2 \mathrm{TSize}}=65625 \quad \text { gallons Capacity/ Storage Tank }
$$

or

$$
\mathrm{V}_{2 \mathrm{Tft} 3}:=\frac{\mathrm{V}_{2 \mathrm{TSize}}}{7.4805} \quad \mathrm{~V}_{2 \mathrm{Tft} 3}=8773 \quad \mathrm{ft}^{3}
$$

Using a 1:1 aspect ratio for tank diameter and height, diameter for each storage tank dimensions:

$$
\begin{aligned}
& \text { Tank Height to Diameter Aspect Ratio: } \quad \mathrm{AR}=1 \\
& \text { Storage Tank Diameter: } \quad \mathrm{D}_{2 \mathrm{~T}}:=\left[\frac{\mathrm{V}_{2 \mathrm{Tft} 3}}{\left(\frac{\pi}{4}\right) \mathrm{AR}}\right]^{\frac{1}{3}} \quad \mathrm{D}_{2 \mathrm{~T}}=22.4 \quad \mathrm{ft} \\
& \text { Storage Tank Height: } \quad \mathrm{H}_{2 \mathrm{~T}}:=\mathrm{D}_{2 \mathrm{~T}} \cdot \mathrm{AR} \quad \mathrm{H}_{2 \mathrm{~T}}=22.4 \quad \mathrm{ft}
\end{aligned}
$$

\section{Reduced Size Based on Allocating Storage to ISO Tanks:}

The volume of the feed receipt and blend tank in the lag storage configuration can be reduced when a portion of the storage requirement is allocated to ISO tanks. Assuming at least twelve ISO tank storage positions are available to support lag storage system volume for 7 days of storage, which is assigned between a reduced tank

File: AEM-WRPS-2012-CN-012 Rev 0.xmcd 
capacity and a fraction of allocated ISO tanks. To decide on reduced tank capacity, the volume of seven days of storage in equivalent numbers of ISO tank is determined.

Volume of an ISO Tank:

$$
\mathrm{V}_{\text {ISO.Tank }}:=5000 \quad \text { gallons/ ISO Tank }
$$

Volume of Feed for Seven Days of Storage Equivalent to ISO Tanks:

$$
\begin{aligned}
& \mathrm{V}_{\text {FeedEQISO }}:=\frac{\mathrm{V}_{\text {2TFeed }}}{\mathrm{V}_{\text {ISO.Tank }}} \\
& \mathrm{V}_{\text {FeedEQISO }}=10.5 \quad \text { Equivalent ISO Tanks }
\end{aligned}
$$

The reduced tank sizing is simplified by assigning tank storage volume equivalent to integer numbers of ISO tanks volume.

Assigned Number of ISO Tanks for Each Reduced Storage Tank Capacity in ISO tank increments:

$$
\mathrm{N}_{\text {ISOTank }}:=5 \quad \text { ISO Tanks/ Tank Capacity }
$$

Reduced Feed Volume per Storage Tank:

$$
\begin{gathered}
\mathrm{V}_{\text {2TReduced }}:=\mathrm{V}_{\text {ISO.Tank }} \cdot \mathrm{N}_{\text {ISOTank }} \\
\mathrm{V}_{\text {2TReduced }}=25000 \quad \text { gal Feed } / \text { Storage Tank }
\end{gathered}
$$

Design Margin of Tank Volume Filled by Feed: $\quad$ Fill $_{\mathrm{DM}}=0.8$

Tank Volume to achieve $80 \%$ Storage Capacity: $\quad \mathrm{V}_{2 \text { TReducedSize }}:=\frac{\mathrm{V}_{2 \mathrm{TRe}} \text {.uced }}{\text { Fill }_{\mathrm{DM}}}$

$$
\mathrm{V}_{\text {2TReducedSize }}=31250 \text { gallons Capacity/Storage Tank }
$$

or

$$
\begin{gathered}
\mathrm{V}_{\text {2TReducedft3 }}:=\frac{\mathrm{V}_{\text {2TReducedSize }}}{7.4805} \\
\mathrm{~V}_{\text {2TReducedft3 }}=4178 \quad \mathrm{ft}^{3}
\end{gathered}
$$

Using a 1:1 aspect ratio for tank diameter and height, each storage tank dimensions become:

$$
\text { Tank Height to Diameter Aspect Ratio: } \quad \mathrm{AR}=1
$$

Storage Tank Reduced Diameter: $\quad \mathrm{D}_{2 \text { TReduced }}:=\left[\frac{\mathrm{V}_{\text {2TReducedft3 }}}{\left(\frac{\pi}{4}\right) \mathrm{AR}}\right]^{\frac{1}{3}} \quad \mathrm{D}_{2 \mathrm{TReduced}}=17.5 \quad \mathrm{ft}$

Storage Tank Reduced Height: $\quad \mathrm{H}_{2 \mathrm{TRe}}$ duced $:=\mathrm{D}_{2 \mathrm{TRe}}$ duced $\mathrm{AR} \quad \mathrm{H}_{2 \mathrm{TRe}} \quad \mathrm{ft}$ 
Remaining Volume of SBS condensate allocated to ISO Tanks:

$$
\begin{aligned}
& \mathrm{V}_{\text {FeedinISO }}:=\mathrm{V}_{2 \text { TFeed }}-\mathrm{V}_{2} \text { TReduced } \\
& \mathrm{V}_{\text {FeedinISO }}=27500 \quad \text { gal of SBS Condensate allocated to ISO tanks }
\end{aligned}
$$

Number of ISO Tanks Needed to Add to the Reduced Tank Storage:

$$
\begin{aligned}
& \mathrm{N}_{\text {ISOTankNeed }}:=\frac{\mathrm{V}_{\text {FeedinISO }}}{\mathrm{V}_{\text {ISO.Tank }}} \\
& \mathrm{N}_{\text {ISOTankNeed }}=5.5 \quad \text { Number of ISO Tanks for balance SBS condensate } \\
& \text { RoundN }_{\text {ISOTankNeed }}:=\operatorname{round}\left(\mathrm{N}_{\text {ISOTankNeed }}\right)
\end{aligned}
$$

Number of ISO Tanks (Rounded) Used for 7 Days of SBS Condensate Storage per Reduced Storage Tank.

$$
\text { RoundN }_{\text {ISOTankNeed }}=6 \quad \text { ISO tanks } / \text { Reduced Storage Tank }
$$

Number of ISO Tanks (Rounded) Used for 7 Days of SBS Condensate Storage per Reduced Two Storage Tank Fully Filled for Offsite Transportation.

$$
\begin{gathered}
\mathrm{N}_{\text {ISOTankFull }}:=\mathrm{N}_{\text {ISOTankNeed }} \cdot \mathrm{Num}_{2 \mathrm{~T}} \quad \text { ISO tanks/ Reduced Two Storage Tank Configuration } \\
\mathrm{N}_{\text {ISOTankFull }}=11 \quad \text { ISO tanks } / \text { Reduced Two Storage Tank Configuration }
\end{gathered}
$$

\section{Sample Load Estimate:}

Based on the assumption for sampling scheme shown on of Figure 1, a Record Control sample is taken from the RLD-VSL-00005 at WTP before transferring the content to an ISO tank for transport to the WTB. The average SBS condensate rate at $4540.6 \mathrm{gal} /$ day, in SVF-2440 (Mission Avg-Alt 1 worksheet), and RLD-VSL-00005 batch volume of 16,000 gallons are used to estimate the minimum RC sampling load. The minimum is based on no additional RC samples at the WTB. The maximum number of RC samples is estimated when enough SBS condensate batches received at the WTB are assumed out of WAC compliance, and routed to the storage tanks for blending, such that all SBS condensate passes through the storage tanks.

\section{Minimum Record Control Sampling Load:}

Mission Average Daily Rate:

RLD-VSL-00005 Batch Volume:

$$
\begin{array}{ll}
Q_{\text {Mission.S1 }}:=4540.6 & \text { gal /day } \\
V_{\text {VSL.00005 }}:=16000 & \text { gallons }
\end{array}
$$


Number of RC Samples per Year per Vessel RLD-VSL-00005 RCSample VSL.00005 $_{=} \frac{\mathrm{Q}_{\text {Mission.S1 }} \cdot \text { Days }}{\mathrm{V}_{\text {VSL.00005 }}}$

$$
\begin{aligned}
& \text { RoundRCSample }_{\text {VSL.00005 }}:=\operatorname{round}\left(\text { RCSample }_{\text {VSL.00005 }}\right) \\
& \text { RoundRCSample }_{\text {VSL.00005 }}=104 \text { Alternative-1 Minimum Samples } / y r
\end{aligned}
$$

Maximum Record Control Sampling Load:

Number of RC Samples per Year per Reduced Two Storage Tank System :

$$
\begin{aligned}
& \text { RCSample }_{2 \mathrm{~T}}:=\frac{\mathrm{Q}_{\text {Feedin }} \cdot \text { Days }}{\mathrm{V}_{2 \mathrm{TReduced}}} \\
& \text { RoundRCSample }_{2 \mathrm{~T}}:=\operatorname{round}\left(\text { RCSample }_{2 \mathrm{~T}}\right) \\
& \text { RoundRCSample }_{2 \mathrm{~T}}=110 \quad \text { Samples } / \mathrm{yr}
\end{aligned}
$$

Maximum Number Number of RC Samples for Alternative-1 Configuration:

$$
\begin{aligned}
& \text { Alt1 }_{\text {MaxRCSamples }}:=\text { RoundRCSample }_{2 \mathrm{~T}}+\text { RoundRCSample }_{\text {VSL.00005 }} \\
& \text { Alt1 }_{\text {MaxRCSamples }}=214 \quad \text { Alternative-1 Maximum Samples } / \mathrm{yr}
\end{aligned}
$$

\subsection{Use of Computer Software}

This calculation was performed using Mathcad, version 13.0 (Mathsoft Engineering \& Education, Inc.)

\subsection{Results}

The Maximum Tank Volume Required for a Two Tank Storage System Configuration is:

$$
\mathrm{V}_{2 \mathrm{TSize}}=65625 \quad \text { gallons } / \text { Storage Tank }
$$

When a minimum of twelve ISO tanks are allocated to support lag storage, the tanks provided in a Two Tank Storage System configuration can be reduced to :

$$
\mathrm{V}_{2 \mathrm{TReducedSize}}=31250 \quad \text { gallons } / \text { Reduced Size Storage Tank }
$$

The Diameter and Height of Each Storage Tank (Supported by ISO Tank Storage):

$$
\mathrm{D}_{2 \text { TReduced }}=17.5 \mathrm{ft} \quad \text { and } \quad \mathrm{H}_{2} \text { TReduced }=17.5 \mathrm{ft}
$$

Minimum Record Control Sampling Load:

$$
\text { RoundRCSample }_{\text {VSL. } .00005}=104 \text { RC Samples } / \text { yr }
$$

Maximum Record Control Sampling Load:

$$
\mathrm{Alt1}_{\text {MaxRCSamples }}=214 \quad \text { RC Samples } / \mathrm{yr}
$$

File: AEM-WRPS-2012-CN-012 Rev 0.xmcd 


\subsection{Conclusions}

The Alternative-1 equipment sizing was performed using the throughput documented in SVF-2440 Rev 0 at 7500 gallon per day. The size of the feed receipt and blending vessels in a two lag storage configuration is reduced by approximately $50 \%$ in volume by including the ISO tanks in combination with the storage vessels to hold SBS content prior to transportation.

\subsection{References}

24590-WTP-RPT-PT-02-005, 201 1, Flow sheet Bases, Assumptions, and Requirements, Rev 6.0, Bechtel National Inc., Richland, Washington.

24590-WTP-PL-PR-04-0001, 2008, Integrated Sampling and Analysis Requirements Document (ISARD), Rev 2, Bechtel National Inc., Richland, Washington.

SVF-2440, 2012, SBS Disposal PreConcept Alts. Rev 0. Washington River Protection Solutions LLC, Richland, Washington 
Appendix B

CALCULATION AEM-WRPS-2012-CN-013, ALTERNATIVE 2 EQUIPMENT SIZING ESTIMATES 


\section{Subcontractor Calculation Review Checklist}

Subject: AEM-WRPS-2012-CN-013, Alternative 2 Equipment Sizing Estimates

The subject document has been reviewed by the undersigned.

The reviewer reviewed and verified the following items as applicable.

Documents Reviewed: AEM-WRPS-2012-CN-013, Alternative 2 Equipment Sizing Estimates Analysis Performed By: AEM Consulting, LLC

- Design Input

- Basic Assumption

- Approach/Design Methodology

- Consistency with item or document supported by the calculation

- Conclusion/Results Interpretation

- Impact on existing requirements

Reviewer (printed name, signature, and date) P. E. Peistrup

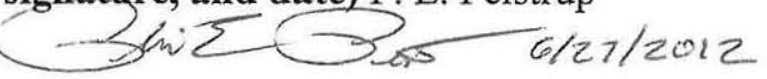

Organizational Manager (printed name, signature, and date) Martin Wheeler

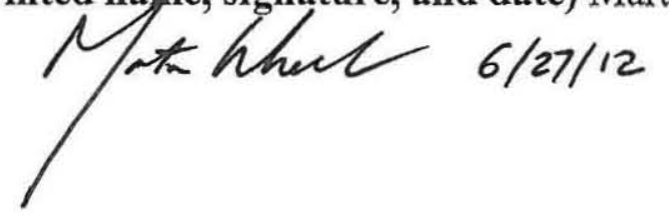




\begin{tabular}{|c|c|c|c|}
\hline & \multicolumn{2}{|c|}{$\begin{array}{l}\text { Calculation Set No. } \\
\text { AEM-WRPS-2012-CN-013 }\end{array}$} & $\begin{array}{l}\text { ev No. } \\
0\end{array}$ \\
\hline & \multicolumn{3}{|c|}{ End Use: Pre-conceptual Design } \\
\hline $\begin{array}{l}\text { Project: WRPS } 48504 \text { Line Item 2-SBS Direct Disposal } \\
\text { Altematives. }\end{array}$ & \multicolumn{3}{|c|}{ Sheet 1 of 16} \\
\hline Discipline: Process & \multicolumn{3}{|c|}{ Contract No: WRPS 48504 Line Item 2} \\
\hline Structure or System: NA & \multicolumn{3}{|c|}{ Reserved } \\
\hline \multicolumn{4}{|l|}{ Subject: Alternative 2 Equipment Sizing Estimates } \\
\hline \multicolumn{2}{|c|}{ Completed by: G.R. Golcar Gule Mru Lu } & Date & \\
\hline \multirow{2}{*}{\multicolumn{2}{|c|}{ Checked by: R. Lokken fefjom O. Jrhthew }} & Date & \\
\hline & & Date $6(2$ & \\
\hline \multicolumn{4}{|l|}{ Distribution: NA } \\
\hline \multirow[t]{2}{*}{$\begin{array}{l}\text { Reason for Revision: } \\
\text { Not applicable, initial release. }\end{array}$} & & \multicolumn{2}{|c|}{$\begin{array}{l}\text { Total number of sheets in this } \\
\text { issue: } 16\end{array}$} \\
\hline & & \multicolumn{2}{|c|}{$\begin{array}{l}\text { Sheets revised, added or deleted: } \\
\text { NA }\end{array}$} \\
\hline \multicolumn{4}{|c|}{$\begin{array}{l}\text { Problem Statement: } \\
\text { Determine equipment sizes to support evaluation of Alternative-2 configuration. The subject equipment is: a) feed } \\
\text { staging tanks, b) Wiped Film evaporator (WFE), c) WFE condensate storage tanks, d) WFE condensate storage } \\
\text { tanks, and f) heat exchanger to condensate WFE overhead vapor stream. The calculation uses the throughput } \\
\text { documented in SVF-2440, SBS Disposal PreConcept Alts. at } 7500 \text { gallon per day, and seven days of assumed } \\
\text { holding period prior to transferring the WFE concentrate for offsite disposal and shipment of the WFE condensate } \\
\text { to the effluent treatment facility (ETF). }\end{array}$} \\
\hline \multicolumn{4}{|c|}{ 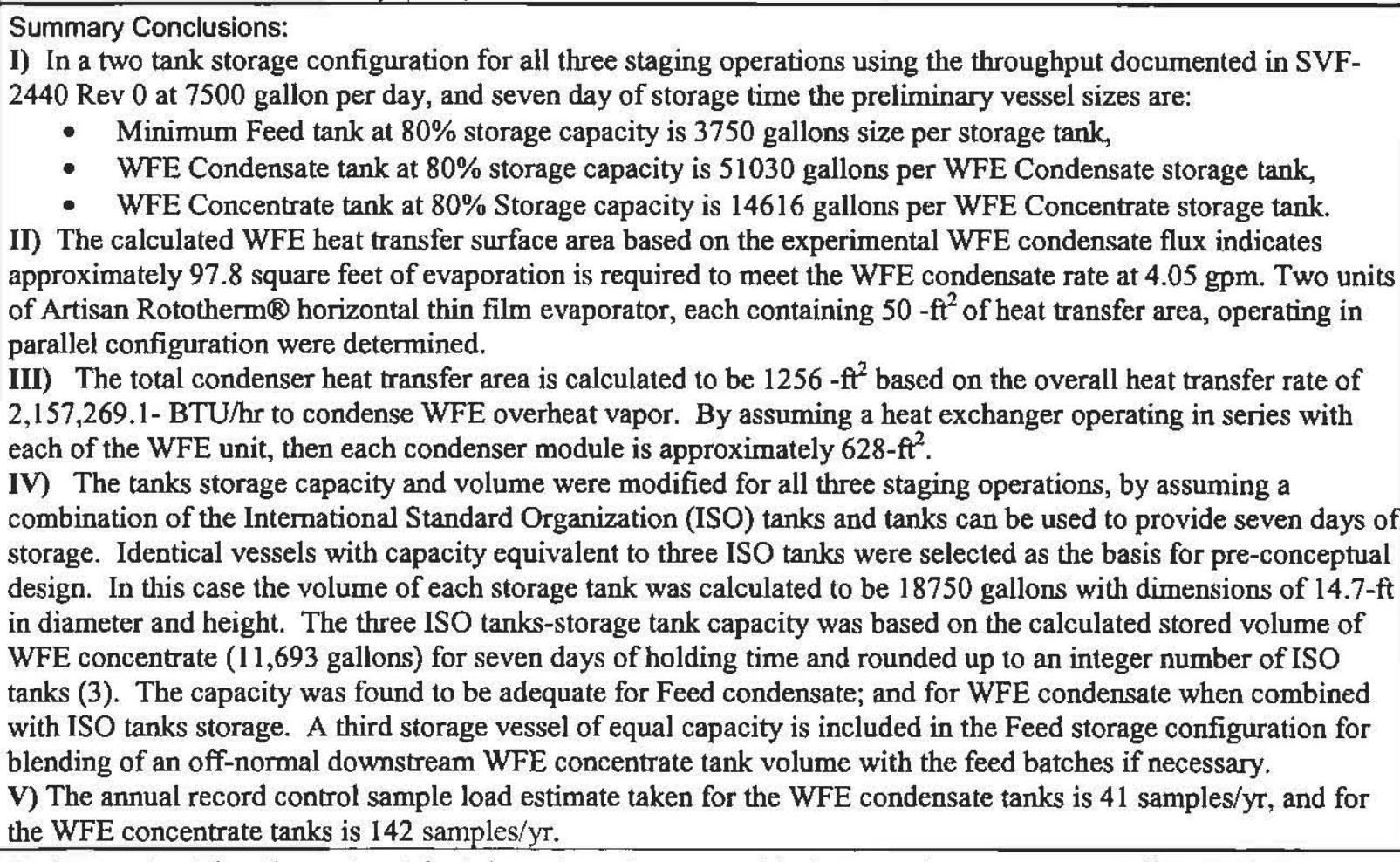 } \\
\hline
\end{tabular}


RPP-RPT-52796, Rev. 0

\section{Contents}

$\begin{array}{ll}1.0 & \text { Objective/Purpose } \\ 2.0 & \text { Input Data } \ldots \ldots \ldots \ldots \ldots \ldots \ldots \ldots \ldots\end{array}$

\subsection{Objective/Purpose}

A pre-conceptual engineering study is being developed to compare three alternative configurations for disposal of the Submerged Bed Scrubber (SBS) condensate from the WTP LAW Vitrification facility. The objective of this calculation is to estimate the size of major equipment pieces for the configuration associated with the Alternative-2, which transfers SBS condensate to the disposal site after concentration. In addition, the annual sample load is estimated. A Wiped Film evaporator (WFE) is used for the concentration process. The subject equipment in Alternative-2 are: a) feed staging tanks, b) Wiped Film evaporator, c) WFE condensate storage tanks, d) WFE concentrate tanks, and e) heat exchanger to condense WFE overhead vapor. The equipment are sized to satisfy an input throughput rate, and an assumed holding period prior to shipment to an off site disposal site. The turnaround time to perform the required Record Control (RC) sampling analysis prior to shipment is factored into the calculation.

The Alternative- 2 process schematic and sampling are shown in Figure 1. The SBS condensate in the WTP vessel RLD-VSL-00005 is process control sampled $(\mathrm{PcS})$ and received at the waste transfer facility in the international standard organization (ISO) tanks. The Feed tanks function to receive WTP condensate and if needed, blend non-complying downstream WFE concentrate with other SBS condensate batches. The SBS condensate is evaporated by a WFE and the resulting WFE condensate and WFE concentrate are RC sampled. WFE condensate is shipped to the effluent treatment facility (ETF), and the WFE concentrate is transported to a licensed disposal site. ISO tanks are used for all liquid shipments.

\subsection{Input Data}

- $\quad$ The WTP vessel RLD-VSL-00005 SBS condensate output is used as the input feed stream to the Alternative-2 evaluation.

- The analysis uses the throughput documented in SVF-2440, SBS Disposal PreConcept Alts. Rev 0 (worksheet Eqpt DesignAlt-2) as the basis for sizing. The equipment sizing is based on receiving 7500 gallons per operating day of the SBS condensate at peak generation. The rate is defined as "DesignRateStream2" in Section 4.0 calculation, and referred as "Stream2, WFE Feed" in the Eqpt DesignAlt-2 worksheet.

- Equipment sizing is based on a peak processing rate such that operating efficiency adjustments are not required (overall Total Operating Efficiency (TOE) of 100\%).

- An ISO tank is used to transfer SBS condensate from the WTP to the Waste Transfer/ Building (WTB). The ISO tanks provide additional storage capacity at the WTB, and are used for transportation of SBS condensate to a licensed commercial disposal site (see Figure 1).

File: AEM-WRPS-2012-CN-013 Rev 0.xmcd 


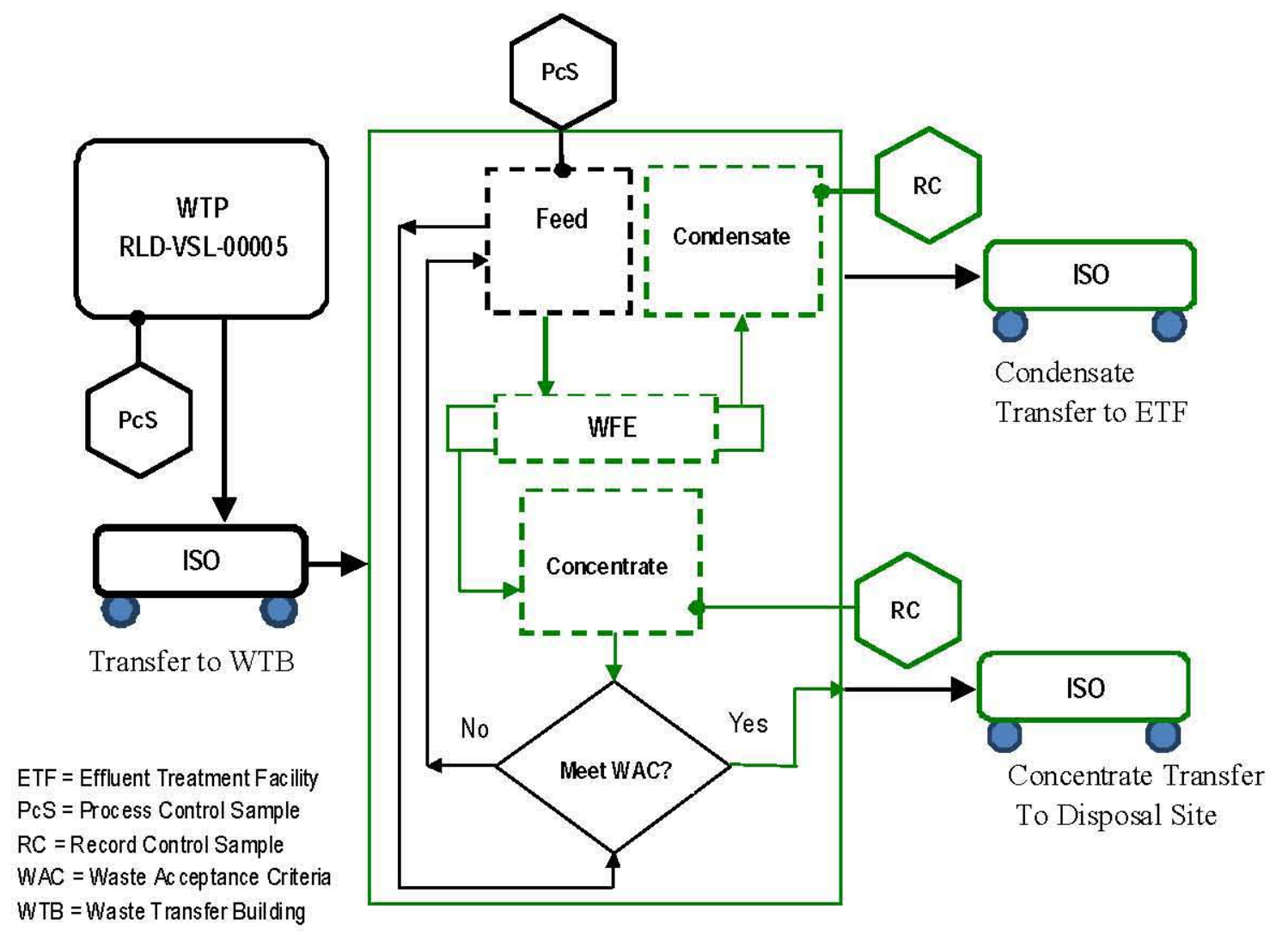

WTB Concentration System

Figure 1 Alternative-2 Configuration and Sampling

- The Wiped Film Evaporator size is based on experimental WFE condensate generation rates using an Artisan Rototherm ${ }^{\circledR}$ horizontal thin film evaporator containing 50 square feet of heat transfer area. The WFE testing was conducted using AN-105 liquid simulant and documented in RPP-RPT-47443, Wiped Film Evaporator Full- Scale Demonstration System Test Report. The WFE condensate rates are shown in Table 1, as reported in Table 6-1 of RPP-RPT-47443.

- The "Stream 8 WFE Condensate" of the SVF-2440 Eqpt DesignAlt-2 worksheet at 4.05 gpm is used to size WFE condensate storage vessels. The WFE condensate rate is defined as "QStream8" in Section 4.0.

- The "Stream 3 WFE Concentrate" of the SVF-2440 Eqpt DesignAlt-2 worksheet at $1.16 \mathrm{gpm}$ is the basis for the WFE concentrate storage vessels sizing, and is defined as "QStream3" in Section 4.0.

- The SVF-2440 Eqpt DesignAlt-2 worksheet "Stream 10 Cooling Water Supply" heat transfer rate across the heat exchange is $2,157,269.1 \mathrm{BTU} / \mathrm{hr}$. It condenses the overhead WFE water vapor at $125^{\circ} \mathrm{F}$ to liquid water at $82{ }^{\circ} \mathrm{F}$ and is used to determine heat exchanger $/ \mathrm{s}$ heat transfer area. 
Table 1 Experimental Average Condensate Production Rate (RPP-RPT-47443, Rev 0, Table 6-1)

\begin{tabular}{|c|c|c|c|c|c|c|c|c|}
\hline $\begin{array}{l}\text { Test } \\
\text { Run }\end{array}$ & $\begin{array}{l}\text { Average } \\
\text { Feed } \\
\text { Rate } \\
\text { [UT-001] } \\
\text { (gpm) }\end{array}$ & $\begin{array}{c}\text { Average } \\
\text { WFE } \\
\text { Operating } \\
\text { Pressure } \\
\text { [DPT-305] } \\
\text { torr } \\
\text { absolute }\end{array}$ & $\begin{array}{c}\text { Average } \\
\text { Steam } \\
\text { Pressure } \\
\text { [PT502] } \\
\text { (psig) }\end{array}$ & $\begin{array}{l}\text { Feed Starting } \\
\text { SpG [UT-001] }\end{array}$ & $\begin{array}{c}\text { Feed Starting } \\
\text { Temp [UT-001] } \\
\left.\text { ( }{ }^{\circ} \mathrm{F}\right)\end{array}$ & $\begin{array}{c}\text { Feed Ending SpG } \\
\text { [UT-001] }\end{array}$ & $\begin{array}{c}\text { Feed } \\
\text { Ending } \\
\text { Temp } \\
\text { [UT-001] } \\
\left({ }^{\circ} \mathrm{F}\right)\end{array}$ & $\begin{array}{c}\text { Average } \\
\text { Condensate } \\
\text { FT-401 } \\
\text { Flow Rate } \\
\text { (gal/min) } \\
\text { [lb/hr] }\end{array}$ \\
\hline 1 & 8.6 & 110 & 24 & 1.17 & 77 & 1.23 & 116.4 & $\begin{array}{c}2.071 \\
{[1037]}\end{array}$ \\
\hline 2 & 10 & 110 & 24 & 1.17 & 100 & 1.25 & 126.1 & $\begin{array}{c}2.185 \\
{[1094]}\end{array}$ \\
\hline 3 & 10 & 90 & 24 & 1.17 & 102.3 & 1.27 & 121.8 & $\begin{array}{c}2.363 \\
{[1183]}\end{array}$ \\
\hline 4 & 8 & 90 & 24 & 1.17 & 100.9 & 1.28 & 118.0 & $\begin{array}{c}2.312 \\
{[1157]}\end{array}$ \\
\hline 5 & 8 & 110 & 37 & 1.17 & 96.9 & 1.28 & 124.1 & $\begin{array}{c}2.514 \\
{[1258]}\end{array}$ \\
\hline 6 & 10 & 110 & 33 & 1.17 & 100.2 & 1.28 & 126.0 & $\begin{array}{c}2.479 \\
{[1241]}\end{array}$ \\
\hline 7 & 10 & 90 & 31 & 1.17 & 102.4 & 1.31 & 120.7 & $\begin{array}{c}2.599 \\
{[1301]}\end{array}$ \\
\hline 8 & 8 & 90 & 29 & 1.17 & 97.1 & 1.27 & 118.3 & $\begin{array}{c}2.473 \\
{[1238]}\end{array}$ \\
\hline
\end{tabular}

- The overall heat transfer coefficient for a Service value Stain less Steel $316 \mathrm{~L}$ shell and tube heat exchanger at 105.56 BTU/(hr. $\mathrm{ft}^{2}{ }^{\circ} \mathrm{F}$ ) documented in Appendix 10 of RPP-RPT-47433, Rev0 pages A10-51 is applied in the heat exchanger area calculation.

- The SVF-2440 Eqpt Design Alt-2 work sheet fluid temperatures for: "Stream 4 WFE vapor" at $125^{\circ} \mathrm{F}$, "Stream 8 WFE Condensate" at $82^{\circ} \mathrm{F}$, "Stream 10 Cooling Water Supply" at $77^{\circ} \mathrm{F}$, and "Stream 11 Cooling Water Return" at $87^{\circ} \mathrm{F}$ are inputs to calculate the log mean temperature difference (LMTD), $\Delta \mathrm{T}_{1 \mathrm{~m}}$. A countercurrent flow heat exchanger is selected for applying LMTD as the mean temperature difference in heat exchanger design equation.

\section{Input Calculation Constants:}

Facility Design Basis :

Overall Operating Efficiency:

Days per year:

$$
\text { DesignRate }_{\text {Stream } 2}:=7500 \text { gal condensate/Operating day }
$$

$$
\mathrm{TOE}:=1 \quad \text { Operating days/Calendar day }
$$

Days : $=365$

Daily Input Feed Volumetric Flow Rate:

$$
\mathrm{Q}_{\text {Feedin }}:=\text { DesignRate }_{\text {Stream2 }} \cdot \mathrm{TOE} \quad \mathrm{Q}_{\text {Feedin }}=7500 \mathrm{gal} / \text { Calendar day }
$$

File: AEM-WRPS-2012-CN-013 Rev 0.xmcd 


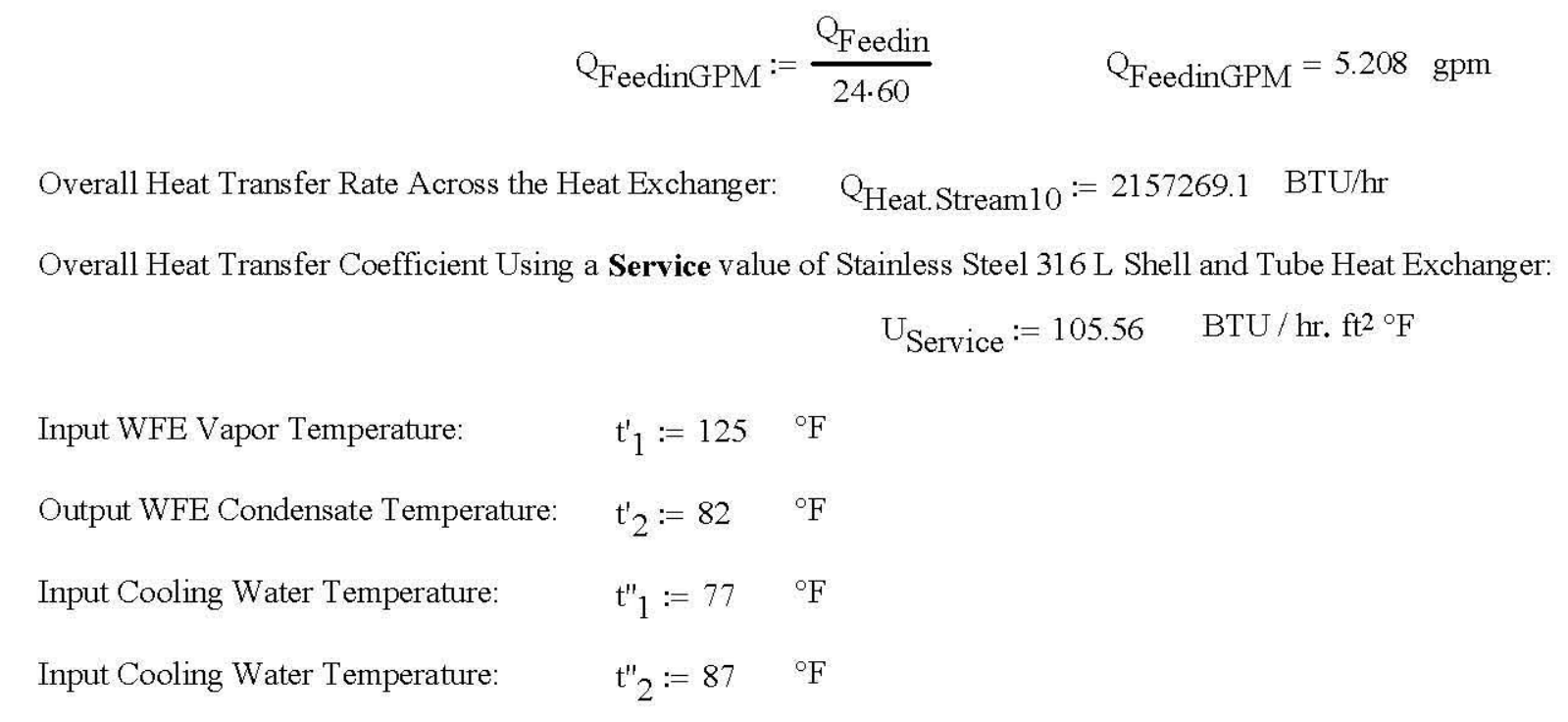

\subsection{Assumptions}

For Alternative-2 the following assumptions apply:

1. ISO tanks of 5000 gallon volumetric capacity are assumed for the SBS condensate transportation and storage in the WTB lag storage system as an enabling assumption. A minimum twelve ISO tanks and ISO tank positions are available to support lag storage.

2. A two-tank storage configuration is selected for storage and processing of the SBS Feed condensate, WFE condensate, and WFE concentrate that support sampling.

3. The two-tank storage configuration is arranged such that one tank is always available to receive liquid from the ISO tanks or the upstream process without stopping the processing demand.

4. An additional third Feed tank is included to be used in the blending of off-normal downstream WFE concentrate with feed batches.

5. A two day Record Control (RC) sample analysis turnaround time is assumed to verify compliance with the transportation and disposal site waste acceptance criteria (WAC). This assumes analysis and data package preparation activities similar to that described for sample point PT-27 in 24590-WTP-PL-PR-04-0001, Integrated Sampling and Analysis Requirements Document (ISARD), which characterized waste transfers from RLD-TK-0006A/B for comparison with the Liquid Effluent Retention Facility/Effluent Treatment Facility WAC, and is assumed similar to sample requirement for this application. The RC sampling is performed on the WFE condensate, and on the WFE concentrate stored in the lag storage tanks prior to off site shipment (see Figure 1).

6. A 0.4 day Process Control ( $\mathrm{PcS}$ ) sample turnaround time to monitor processing is assumed. Unlike the RC sampling, the $\mathrm{PcS}$ is assumed as a monitoring verification step and thereby no alternating between the feed vessels is required. This assumes analysis and data package preparation activities similar to that described for sample point PT-35 in 24590-WTP-PL-PR-04-0001, and is assumed similar to sample requirement for this application. The PcS sampling is performed on the SBS condensate vessel batches transferred from the WTP and stored in ISO tanks at the WTB facility, and the SBS condensate feed at the WTB as illustrated on Figure 1.

7. Process knowledge and/or process control sampling is assumed sufficient for loading the content of the RLD-VSL-00005 vessel into ISO tanks, and transfer to WTB facility as an enabling assumption.

8. The WFE condensate and WFE concentrate storage tanks in combination with ISO tanks are sized to hold liquid for seven days of storage before transferring to offsite. The assumption is allocated for poor weather condition along transport routes. This logic implicitly includes the two-day hold point for tank sampling analysis turnaround prior to loading condensate on a transport.

File: AEM-WRPS-2012-CN-013 Rev 0.xmcd 
9. The SBS Feed condensate tanks are assumed to function as staging vessels prior to concentration process. The sizing of these vessels are assumed unconstrained by seven days of storage as assumed for WFE condensate and WFE concentrate storage tanks. The PcS monitoring residence time of the feed tanks is assumed as sizing criteria for these vessels in a preliminary analysis.

10. A design margin of $80 \%$ volumetric fill capacity is used to estimate the two feed storage tanks volumes as an enabling assumption.

11. The storage tanks are assumed to be cylindrical, above ground vessels.

12. A 1:1 aspect ratio for each tank diameter and height is used as an enabling assumption.

13. The heat exchangers are considered to be Stainless Steel $316 \mathrm{~L}$ shell and tube heat exchanger operating in a countercurrent flow as an enabling assumption.

Assumption Calculation Constants:

Residence Time For SBS Condensate Feed before Downstream WFE Concentration

Residence Time for Feed Process Control Sample Analysis: $\quad t_{\mathrm{PcS}}:=0.4 \quad$ Day

Storage Hold Time before Transfer for the WFE Concentrate Or WFE Condensate Storage Tanks:

Hold time before Transfer:

Design Margin of Tank Volume Filled by Feed:

$$
\begin{aligned}
& \mathrm{t}_{\text {HoldMax }}:=7 \text { day } \\
& \text { Fill }_{\mathrm{DM}}:=0.8 \\
& \mathrm{AR}:=1 \quad \text { Dimensionless }
\end{aligned}
$$

Tank Height to Diameter Aspect Ratio:

\subsection{Method of Analysis}

The Alternative-2 configuration and sampling schematic is shown in Figure 1. A preliminary vessel sizing is performed to estimate the volume constraint (minimum volume for feed tank, and maximum volume for downstream storage tanks) when $80 \%$ full. The calculation uses a residence time of 0.4 days for PcS monitoring and the input rate of 7500 gallons per operating day at peak generation to estimate a minimum feed tank size, since the feed vessel functions as an interim vessel before concentration. The volumetric flow rate for the WFE condensate and WFE concentrate, documented in SVF-2440, and seven days of storage are used to calculate the maximum storage required in this case.

In the second phase of vessel sizing, the calculated maximum storage capacity for the WFE condensate and concentrate storage tanks are applied as the basis to estimate a reduced storage tank volume, when it is assumed a combination of the ISO tanks and reduced storage tanks satisfy the seven days storage criteria. An additional third Feed tank is included to be used in the blending of off-normal downstream WFE concentrate with the feed batches. The vessel sizing and facility layout was further simplified by assuming an identical vessel size for all seven tanks used in the Alternative-2 configuration. Furthermore, the complexity associated with sorting ISO tanks allocated for liquid storage by WFE condensate or WFE concentrate streams is decreased, when the selection of a reduced tanks size selection is conservatively based on the initial WFE concentrate storage capacity that is equivalent to the capacity in units of ISO tanks. The reduced tank sizing is not constrained by the feed tank volume since the residence time for the feed tanks is less than one day as compared to seven day of storage for WFE condensate and WFE concentrate.

The Wiped Film evaporator is sized to meet the design WFE condensate rate at $4.05 \mathrm{gpm}$. The calculation described below uses the experimental WFE condensate production flux provided by a 50 square feet heat transfer area (RPP-RPT-47433). The WFE scale up is simplified by assuming the overall heat transfer coefficient for the Alternative-2 WFE to be the same as the tested system without postulating a scaling factor for the overall heat transfer. The calculation assume WFE units of 50 square feet heat transfer area that are identical to the tested WFE to operate in parallel configuration in meeting the design condensate production rate.

File: AEM-WRPS-2012-CN-013 Rev 0.xmcd 
The system heat exchanger area size is based on the calculated heat removal rate to generate WFE water condensate from the WFE overhead vapor. The heat exchanger area is calculated using an overall heat transfer coefficient based on the service value of stainless for a steel shell and tube heat exchanger. A countercurrent flow heat exchanger is assumed when applying LMTD as the mean temperature difference in heat exchanger design equation.

\section{Alternative-2 Tank Storage Sizing:}

For all three staging operations a two tank storage configuration is used. The two storage tank system is arranged such that one tank is always available to receive a liquid stream without stopping the upstream production flow. Each tank volume is sized using a design margin of $80 \%$ fill capacity. A preliminary sizing calculation for: a) Feed, b) WFE condensate, and c) WFE concentrate storage is based on the assumed throughput and the storage time is performed to establish the design based storage capacities requirement. The PcS sampling is assumed to not be a holding point to alternate between the tanks for the feed tanks .

The tank storage capacities are then modified to reach a storage volume applicable for all three staging operations by incorporating the use of the ISO tanks at each stage with the storage vessels in a two tank storage system that meet the initially calculated capacities. An additional third Feed tank is included to be used in blending of off-normal downstream WFE concentrate with the feed batches.

\section{Alternative -2 Preliminary Feed Tank Sizing}

The output flow rate from the Feed vessel, "Stream 2 WFE Feed" in the Eqpt DesignAlt-2 worksheet, which is the WTP vessel RLD-VSL-00005 condensate and the PcS sampling residence time for the Feed process control is used.

Feed Output Volumetric Flow Rate to the WFE:

$$
\begin{aligned}
& Q_{\text {FeedoutGPM }}:=Q_{\text {FeedinGPM }} \\
& Q_{\text {FeedoutGPM }}=5.208 \quad \text { gpm } \\
& Q_{\text {FeedGPH }}:=Q_{\text {FeedoutGPM }} 60 \\
& Q_{\text {FeedGPH }}=312.5 \quad \text { GPH }
\end{aligned}
$$

Residence Time for Feed Process Control Sample Analysis: $\quad t_{\mathrm{PcS}}=0.4 \quad$ Day

$$
\mathrm{t}_{\mathrm{PcSHR}}:=\mathrm{t}_{\mathrm{PcS}} \cdot 24 \quad \mathrm{t}_{\mathrm{PcSHR}}=9.6 \quad \mathrm{hr}
$$

The minimum capacity for the Feed tank is to store 9.6 hours of material.

Minimum Feed Volume per Storage Tank:

Design Margin of Tank Volume Filled by Liquid:

Minimum Tank Volume at $80 \%$ Storage Capacity for Feed Storage:

$$
\mathrm{V}_{\text {FeedSize }}=3750
$$

$$
\begin{aligned}
& \mathrm{V}_{\text {Feed }}:=\mathrm{Q}_{\text {FeedGPH }}{ }^{\mathrm{t}} \mathrm{PcSHR} \\
& \mathrm{V}_{\text {Feed }}=3000 \quad \text { gal Feed } / \text { Storage Tank } \\
& \text { Fill }_{\mathrm{DM}}=0.8 \\
& \quad \mathrm{~V}_{\text {FeedSize }}:=\frac{\mathrm{V}_{\text {Feed }}}{\text { Fill }} \text { DM }_{\text {e }}
\end{aligned}
$$$$
\text { gallon Size Capacity/ Storage Tank }
$$

File: AEM-WRPS-2012-CN-013 Rev 0.xmcd 
or

$$
\mathrm{V}_{\text {FeedSizeft3 }}:=\frac{\mathrm{V}_{\text {FeedSize }}}{7.4805} \quad \mathrm{~V}_{\text {FeedSizeft } 3}=501 \quad \mathrm{ft}^{3} \text { Size Capacity/ Storage Tank }
$$

Alternative -2 Preliminary WFE Condensate Storage Tank Sizing

The vapor stream leaving the WFE flows into a condenser and the WFE condensate is collected in a WFE condensate storage vessel. The WFE condensate storage vessels are sized to meet: a) WFE condensate production rate of $4.05 \mathrm{gpm}$ described in Section 2.0 for the "Stream 8 WFE Condensate", and b) hold seven days of condensate storage. The assumed two days holding point analysis turnaround for the RC sampling is implicitly accounted in allow holding time.

Stream 8 WFE Condensate Volumetric Rate All WFE modules::

$$
\begin{aligned}
& Q_{\text {Stream8 }}:=4.05 \quad \mathrm{gpm} \\
& \mathrm{Q}_{\text {Stream8.Day }}:=\mathrm{Q}_{\text {Stream8 }} \cdot 60 \cdot 24 \\
& \mathrm{Q}_{\text {Stream8.Day }}=5.832 \times 10^{3} \mathrm{gal} / \text { day }
\end{aligned}
$$

In a Two Tank WFE Condensate storage, a WFE condensate tank is always available to receive WFE condensate stream from the WFE vapor condensation without stopping the upstream WFE condensate production flow.

Number of WFE Condensate Storage Tanks:

Hold Time before Transfer from Two Tank WFE Condensate Storage System:

WFE Condensate Volume per Storage Tank:

$$
\mathrm{N}_{2 \mathrm{~T} . \text { Cond }}:=2 \quad \text { Tanks Configuration }
$$

$$
\mathrm{t}_{\text {Hold2T }}:=\mathrm{t}_{\text {HoldMax }} \quad \text { (7 days) }
$$

$$
\begin{gathered}
\mathrm{V}_{2 \mathrm{~T} . \text { Cond }}:=\mathrm{Q}_{\text {Stream8.Day }}{ }^{\mathrm{t}_{\text {Hold}} \mathrm{T}} \\
\mathrm{V}_{2 \mathrm{~T} \text {.Cond }}=40824 \quad \text { gal WFE Condensate/ Storage Tank }
\end{gathered}
$$

Design Margin of Tank Volume Filled by Liquid: $\quad$ Fill $_{\mathrm{DM}}=0.8$

Tank Volume to Meet the Design Criteria and $80 \%$ Storage Capacity: $\quad V_{2 T}$.Cond.Size $:=\frac{V_{2 T} \text {.Cond }}{\text { Fill }}$

$$
\mathrm{V}_{2 \mathrm{~T} . \text { Cond.Size }}=51030 \quad \text { gallon Size Capacity/ WFE Condensate Storage Tank }
$$

or

$$
\mathrm{V}_{2 \text { T.Cond.ft3 }}:=\frac{\mathrm{V}_{2 \mathrm{~T}} \text {.Cond.Size }}{7.4805} \quad \mathrm{~V}_{2 \mathrm{~T} \text {.Cond.ft } 3}=6822 \quad \mathrm{ft}^{3} \text { Size Capacity/ Storage Tank }
$$

\section{Alternative -2 Preliminary WFE Concentrate Storage Tank Sizing}

The WFE concentrate storage vessel system is sized to meet: a) WFF concentrate production rate of 1.16 gpm described in Section 2.0 for the "Stream 3 WFE Concentrate", and b) the seven days of storage time.

File: AEM-WRPS-2012-CN-013 Rev 0.xmcd 
Stream 3 WFE Concentrate Volumetric Rate from All WFE modules:

Stream 3 WFE Concentrate Volumetric Rate:

$$
\mathrm{Q}_{\text {Stream3 }}:=1.16 \quad \mathrm{gpm}
$$$$
\mathrm{Q}_{\text {Stream3.Day }}:=\mathrm{Q}_{\text {Stream3 }} \cdot 60 \cdot 24
$$

$$
\mathrm{Q}_{\text {Stream3.Day }}=1670.4 \quad \mathrm{gal} / \text { day }
$$

Number of WFE Concentrate Storage Tanks:

Hold Time before Transfer from Two Tank WFE Concentrate Storage System:

WFE Concentrate Volume per Storage Tank:

$$
\begin{array}{ll}
\mathrm{N}_{2 \mathrm{~T} . \text { Conc }}:=2 & \text { Tanks Configuration } \\
\mathrm{t}_{\mathrm{Hold} 2 \mathrm{~T}}=7 & \text { days }
\end{array}
$$

Design Margin of Tank Volume Filled by Liquid:

Fill $_{\mathrm{DM}}=0.8$

Tank Volume to Meet the Design Criteria and $80 \%$ Storage

Capacity:

$$
\mathrm{V}_{\text {2T.Conc.Size }}:=\frac{\mathrm{V}_{2 \mathrm{~T} . \text { Conc }}}{\text { Fill }_{\mathrm{DM}}}
$$

$$
\mathrm{V}_{2 \mathrm{~T} \text {.Conc.Size }}=14616
$$

gallon Size Capacity/ WFE Concentrate Storage Tank

or

$$
\mathrm{V}_{2 \mathrm{~T} . \text { Conc. } \mathrm{ft} 3}:=\frac{\mathrm{V}_{2 \mathrm{~T}} \text {.Conc.Size }}{7.4805} \quad \mathrm{~V}_{2 \mathrm{~T} . \text { Conc.ft3 }}=1954 \mathrm{ft}^{3} \text { Size Capacity/ Storage Tank }
$$

\section{Reduced Size Based on Allocating Storage to ISO Tanks:}

The WFE concentrate tanks are sized for seven days of holding are used as common tank size that can be supplemented by ISO tanks in different application. The tank storage capacity and volume calculations can be modified for all three staging operations when it is assumed a combination of the ISO tanks and storage tanks are available to satisfy the seven days storage criteria. An additional Feed tank is included for blending off-normal downstream WFE concentrate feed batches if needed. The vessel sizing and facility layout was further simplified by assuming an identical vessel size for all seven tanks used in the Alternative- 2 configuration. Furthermore, the complexity associated with sorting ISO tanks allocated for liquid storage by WFE condensate or WFE concentrate streams is decreased, when the tank size selection is conservatively based on the initial WFE concentrate storage capacity that is equivalent to the capacity in units of ISO tanks. The reduced tank sizing is not constrained by the feed tank volume since the residence time for the feed tanks is less than one day as compared to seven day of storage for WFE condensate and WFE concentrate.

The remaining volume of WFE condensate is allocated to ISO tanks. It is assumed that a modified WFE condensate tank is filled to capacity and an RC sample is taken. Then the tank content is transferred to ISO tanks for storage while analysis is performed.

The tank capacity is assumed to be used for the three feed and blending tanks that satisfy the tanks capacity above needed residence time. If needed, the full content of an off-normal WFE concentrate can be rerouted and 
blended with fresh SBS feed condensate.

Using the Preliminary Storage Volume for WFE Concentrate as Basis in Reduced Storage Tank Volumes per Seven Days of Storage:

WFE Concentrate Volume per Storage Tank:

Volume of an ISO Tank:

$$
\mathrm{V}_{2 \mathrm{~T} . \mathrm{Conc}}=11693 \quad \text { gal WFE Concentrate/ Storage Tank }
$$$$
\mathrm{V}_{\text {ISO.Tank }}:=5000 \quad \text { gallon/ ISO Tank }
$$

Equivalent Number of ISO Tanks for WFE Concentrate Volume:

$$
\begin{aligned}
\text { Num }_{\text {ISOTankEQ }}:= & \frac{V_{2 T} \text {.Conc }}{V_{\text {ISO.Tank }}} \\
\text { Num }_{\text {ISOTankEQ }} & =2.34 \text { Number of ISO Tanks for balance SBS condensate }
\end{aligned}
$$

Rounding Up to Next Integer for Number of ISO Tanks

$$
\begin{aligned}
& \text { RoundNum }_{\text {ISOTankEQ }}:=\left(\text { round( }\left(\text { Num }_{\text {ISOTankEQ }}\right)\right)+1 \\
& \text { RoundNum }_{\text {ISOTankEQ }}=3
\end{aligned}
$$

The Rounded Up Number of ISO tanks is Used For Each Modified Storage Capacity In a Two Tank Storage Configuration for All Processing Stages:

Using the Preliminary WFE Concentrate Storage:

Modified Volume per Storage Tank:

$$
\begin{aligned}
& \mathrm{V}_{\text {2TModified }}:=\mathrm{V}_{\text {ISO.Tank }} \cdot \text { RoundNum }_{\text {ISOTankEQ }} \\
& \mathrm{V}_{\text {2TModified }}=15000 \quad \text { gal Capacity/ Storage Tank }
\end{aligned}
$$

Design Margin of Tank Volume Filled by Liquid:

$$
\text { Fill }_{\mathrm{DM}}=0.8
$$

Using a 1:1 aspect ratio for tank diameter and height, each storage tank dimensions become:

File: AEM-WRPS-2012-CN-013 Rev 0.xmcd 
Tank Height to Diameter Aspect Ratio: $\quad$ AR $=1$

Storage Tank Reduced Diameter: $\quad \mathrm{D}_{\text {2TModified }}:=\left[\frac{\mathrm{V}_{\text {2TModifiedft } 3}}{\left(\frac{\pi}{4}\right) \mathrm{AR}}\right]^{\frac{1}{3}}$
$\mathrm{D}_{\text {2TModified }}=14.7 \mathrm{ft}$

Storage Tank Reduced Height:

$$
\begin{aligned}
& \mathrm{H}_{2 \text { TModified }}:=\mathrm{D}_{2} \text { TModified } \\
& \mathrm{H}_{2} \text { TRodified } \\
& =14.7
\end{aligned}
$$

Remaining Volume of WFE condensate allocated to ISO Tanks:

$$
\begin{aligned}
& \mathrm{V}_{2 \mathrm{~T} . \text { CondNeed }}:=\mathrm{V}_{2 \mathrm{~T} . \text { Cond }}-\mathrm{V}_{2 \mathrm{TM} \text { Modified }} \\
& \mathrm{V}_{2 \mathrm{~T} . \text { CondNeed }}=25824 \quad \text { gal WFE Condensate/ Storage Tank }
\end{aligned}
$$

Number of ISO Tanks Needed to Add to the Modified Tank Storage for WFE Condensate Storage:

$$
\begin{aligned}
& \mathrm{N}_{\text {ISOTankNeed }}:=\frac{\mathrm{V}_{\text {2T.CondNeed }}}{\mathrm{V}_{\text {ISO.Tank }}} \\
& \mathrm{N}_{\text {ISOTankNeed }}=5.2 \quad \begin{array}{l}
\text { Number of ISO Tanks for balance volume of WFE } \\
\text { condensate/Storage Tank }
\end{array}
\end{aligned}
$$

Rounding Up to Next Integer for Number of ISO Tanks Used for 7 Days of SBS Condensate Storage per Reduced Storage Tank.

$$
\begin{aligned}
& \text { RoundN } \mathrm{ISOTankNeed}_{\text {T }}:=\left(\operatorname{round}\left(\mathrm{N}_{\text {ISOTankNeed }}\right)\right)+1 \\
& \text { RoundN } \mathrm{ISOTankNeed}_{\text {ISO }}=6 \quad \text { ISO tanks/ Reduced Storage Tank }
\end{aligned}
$$

An additional 6- ISO tanks (rounded up) per each WFE condensate storage tank, or a total of 11- ISO tanks are needed to meet the storage required for the WFE Condensate.

Number of ISO Tanks (Rounded) Used for 7 Days of SBS Condensate Storage per Reduced Two Storage Tank approximately for ETF Transportation.

$$
\begin{aligned}
& \mathrm{N}_{\text {ISOTankFull }}:=\mathrm{N}_{\text {ISOTankNeed }} \cdot \mathrm{N}_{2 T} \text {.Cond } \quad \text { ISO tanks/ Reduced Two Storage Tank Configuration } \\
& \text { RoundN }_{\text {ISOTankFull }}:=\left(\text { round }\left(\mathrm{N}_{\text {ISOTankFull }}\right)\right)+1 \\
& \text { RoundN }_{\text {ISOTankFull }}=11 \quad \text { ISO tanks (Rounded up)/ Reduced Two Storage Tank Configuration }
\end{aligned}
$$

File: AEM-WRPS-2012-CN-013 Rev 0.xmcd 


\section{Alternative-2 Wiped Film Evaporator Sizing:}

The Wiped Film evaporator (WFE) is sized to meet the WFE condensate rate of $4.05 \mathrm{gpm}$ described in Section 2.0 for the "Stream 8 WFE Condensate". The sizing calculation is based on the WFE testing conducted using AN-105 liquid simulant documented in RPP-RPT-47443, Wiped Film Evaporator Full- Scale Demonstration System Test Report. Rev 0. The results for the WFE averaged condensate production rate listed in Table 6-1 of RPP-RPT-47443, and shown in Table 1 are used to determine the experimental condensate flux. The testing used an Artisan Rototherm horizontal thin film evaporator providing 50 square feet heat transfer area. To simplify WFE scale up, modules of Artisan Rototherm horizontal thin film evaporator containing 50 square feet heat transfer area are assumed to be used in parallel configuration for sizing the Alternative- 2 WFE. In this approach the WFE overall heat transfer coefficient, $\mathrm{U}$, is maintained constant and the resistances to the flow of heat from the heating medium to the product affecting the $\mathrm{U}$ determination (resistance of the inner product film, inner fouling factor, the metal wall of the evaporator vessel, the outer fouling factor and the outer heating medium film) are not changed and thereby no additional scaling factor to determine a scaled $\mathrm{U}$ is required in sizing the WFE.

The averaged condensate rate shown in Table 1 are ranges between $2.071 \mathrm{gal} / \mathrm{min}$ to $2.599 \mathrm{gal} / \mathrm{min}$. By using the minimum condensate production rate of $2.071 \mathrm{gal} / \mathrm{min}$ shown as the test run number 1 in Table 1 , the largest heat exchange surface area to meet the WFE design throughput is calculated.

$\underline{\text { Using minimum averaged condensate production rate at } 2.071 \mathrm{gal} / \mathrm{min} \text { of test run 1. Table 1: }}$

Heat Transfer Surface Area of Artisan Rototherm Horizontal Thin Film Evaporator used in Testing :

$$
\mathrm{A}_{\text {Rototherm }}:=50 \quad \mathrm{ft}^{2} \text { Heat exchange area }
$$

Minimum Averaged WFE Condensate Volumetric Rate: $\quad$ qWFE.cond.min $_{\text {W }}=2.071 \mathrm{gpm}$

Minimum WFE Condensate Volumetric Flux:

$$
\begin{aligned}
& \text { Flux }_{\text {WFE.cond.min }}:=\frac{\mathrm{q}_{\text {WFE.cond.min }}}{\mathrm{A}_{\text {Rototherm }}} \\
& \text { Flux }_{\text {WFE.cond.min }}=4.142 \times 10^{-2} \mathrm{gpm} / \mathrm{ft}^{2}
\end{aligned}
$$

Stream 8 WFE Condensate Volumetric Rate (see Section 2.0): $\mathrm{Q}_{\text {Stream8 }}=4.05 \mathrm{gpm}$

Required WFE Heating Surface Area for Minimum Condensate Rate: $\quad A_{\text {req1.WFE }}:=\frac{Q_{\text {Stream } 8}}{\text { Flux }_{\text {WFE.cond.min }}}$

$$
\mathrm{A}_{\text {req1.WFE }}=97.8 \quad \mathrm{ft}^{2}
$$

Required Number of Artisan Rototherm Evaporators;

$$
\begin{gathered}
\mathrm{N}_{\mathrm{WFE}}:=\frac{\mathrm{A}_{\text {req1.WFE }}}{\mathrm{A}_{\text {Rototherm }}} \\
\mathrm{N}_{\mathrm{WFE}}=1.96 \text { WFE Units } \\
\text { RoundN }_{\mathrm{WFE}}:=\text { round }\left(\mathrm{N}_{\mathrm{WFE}}\right) \\
\text { RoundN }_{\mathrm{WFE}}=2 \quad \text { WFE Units (Rounded) }
\end{gathered}
$$

The calculated WFE heat transfer surface area indicate 97.8 square feet of evaporation is required to produce 4.05

File: AEM-WRPS-2012-CN-013 Rev 0.xmcd 
gpm of WFE condensate. Therefore two-50 square feet of Artisan Rototherm evaporator units operating in parallel are needed to meet the design WFE condensate throughput.

\section{Alternative 2 - Heat Exchanger Sizing:}

The heat exchanger design equation is used to calculate the heat transfer surface area to condense the overhead WFE water vapor at $125^{\circ} \mathrm{F}$ to liquid water at $82^{\circ} \mathrm{F}$ at an overall heat transfer rate of $2,157,269.1 \mathrm{BTU} / \mathrm{hr}$ across the heat exchanger operating in countercurrent flow. As described in section 2.0 the overall heat transfer rate is calculated for "Stream 10 Cooling Water Supply" of SVF-2440 Eqpt Design Alt-2 worksheet. A countercurrent flow heat exchanger is selected for applying LMTD as the mean temperature difference in heat exchanger design equation. The heat exchanger is assumed to be a shell and tube exchanger. Initially an overall heat exchanger area is calculated. Then, since each WFE unit is configured to operate with a heat exchanger in series, the combination of each of the two-WFE unit and heat exchanger-modules operating in parallel produce the design WFE condensate rate and the heat transfer rate (of 2,157,269.1 BTU/hr).

An estimate of the number of heat exchanger tubes, etc. outlining a detailed heat exchanger design layout is differed to ore detailed studies.

Overall Heat Transfer Rate Across the Heat Exchanger: $\quad Q_{\text {Heat.Stream10 }}=2157269.1 \quad$ BTU/hr

Overall Heat Transfer Coefficient Using a Service value for Stainless Steel 316 L Shell and Tube Heat Exchanger

$$
\mathrm{U}_{\text {Service }}=105.56 \quad \mathrm{BTU} / \mathrm{hr} \mathrm{ft}^{\circ}{ }^{\circ} \mathrm{F}
$$

Input WFE Vapor Temperature: $\quad \mathrm{t}_{1}{ }_{1}=125 \quad{ }^{\circ} \mathrm{F}$

Output WFE Condensate Temperature: $\quad \mathrm{t}_{2}{ }_{2}=82 \quad{ }^{\circ} \mathrm{F}$

Input Cooling Water Temperature: $\quad \mathrm{t}_{1}=77 \quad{ }^{\circ} \mathrm{F}$

Input Cooling Water Temperature: $\quad \mathrm{t}_{2}=87 \quad{ }^{\circ} \mathrm{F}$

Countercurrent flow, Perry Eqn10-118a, 6th edition:

$$
\begin{aligned}
& \Delta \mathrm{T}_{1 \mathrm{~m}}:=\frac{\left(\mathrm{t}_{1}-\mathrm{t}_{2}^{\prime \prime}\right)-\left(\mathrm{t}_{2}-\mathrm{t}_{1}\right)}{\ln \left(\frac{\mathrm{t}_{1}{ }_{1}-\mathrm{t}_{2}{ }_{2}}{\mathrm{t}_{2}{ }_{2}-\mathrm{t}_{1}^{\prime \prime}}\right)} \\
& \Delta \mathrm{T}_{1 \mathrm{~m}}=16.27 \quad{ }^{\circ} \mathrm{F} \\
& \mathrm{A}_{\text {Heat.Transfer }}:=\frac{\mathrm{Q}_{\text {Heat.Stream } 10}}{\mathrm{U}_{\text {Service }} \cdot \Delta \mathrm{T}_{1 \mathrm{~m}}} \\
& \mathrm{~A}_{\text {Heat.Transfer }}=1256 \\
& \mathrm{ft}^{2}
\end{aligned}
$$

Total Heat Transfer Area:

Heat Transfer Area per WFE and Heat Exchanger Module: $\quad A_{\text {per.Module }}:=\frac{A_{\text {Heat.Transfer }}}{\text { RoundN }_{\text {WFE }}}$

$$
\mathrm{A}_{\text {per.Module }}=628 \mathrm{ft}^{2} / \text { Module of WFE and Heat Exchanger }
$$

File: AEM-WRPS-2012-CN-013 Rev 0.xmcd 


\section{Sample Load Estimate:}

Based on the sampling scheme shown on of Figure 1, RC samples are taken at the WTB form the WFE condensate tanks and WFE concentrate tanks .

\section{Number of RC Samples per Year per Modified Two Storage Tank WFE Concentrate Sample:}

$$
\begin{gathered}
\text { RCSample }_{2 \mathrm{~T}}:=\frac{\mathrm{Q}_{\text {Stream3.Day }} \cdot \text { Days }}{\mathrm{V}_{2 \mathrm{TModified}}} \\
\text { RoundRCSample }_{2 \mathrm{~T}}:=\operatorname{round}\left(\mathrm{RCSample}_{2 \mathrm{~T}}\right) \\
\text { RoundRCSample }_{2 \mathrm{~T}}=41 \quad \text { Samples WFE Concentrate/yr }
\end{gathered}
$$

Number of RC Samples per Year per Modified Two Storage Tank WFE Condensate Sample:

It is assumed that a modified WFE condensate tank is filled to capacity and an RC sample is taken. Then, the tank content is transferred to ISO tanks for storage while sampling analysis is performed.

$$
\begin{aligned}
& \text { RCSample }_{\text {WFECondensate }}:=\frac{\text { QStream8.Day }_{\text {Days }}}{\mathrm{V}_{\text {2TModified }}} \\
& \text { RCSample }_{\text {WFECondensate }}=142 \quad \text { Samples WFE Condensate/ yr }
\end{aligned}
$$

\subsection{Use of Computer Software}

This calculation was performed using Mathcad, version 13.0 (Mathsoft Engineering \& Education, Inc.)

\subsection{Results}

\section{Alternative-2 Tank Storage Sizing:}

In a two tank storage configuration using the design criteria the calculation indicate :

Minimum Feed Tank Volume at $80 \%$ Storage Capacity: $\quad V_{\text {FeedSize }}=3750$ gallons Size Capacity/ Storage Tank WFE Condensate Tank Volume at $80 \%$ Storage Capacity:

$$
\mathrm{V}_{2 \mathrm{~T} . \text { Cond.Size }}=51030 \quad \text { gallons Size Capacity } / \text { WFE Condensate Storage Tank }
$$

WFE Concentrate Tank Volume at 80\% Storage Capacity:

$$
\mathrm{V}_{2 \mathrm{~T} . \text { Conc. Size }}=14616 \quad \text { gallon Size Capacity/WFE Concentrate Storage Tank }
$$

The tanks storage capacity and volumes are modified for all three staging operations when a portion of (if needed) storage is supplied also by ISO tanks for the 7 days holding period. In this case each storage tank in a two tank storage system is assumed to hold the volumetric capacity of three ISO containers and thereby identical vessels are used for all stages of the Alternative- 2 processing.

File: AEM-WRPS-2012-CN-013 Rev 0.xmcd 
An additional third storage vessel of equal capacity is included in the Feed storage configuration for blending of the off-normal downstream WFE concentrate with the feed batches if necessary.

Modified Tank Volume at $80 \%$ Storage Capacity:

$$
\mathrm{V}_{2 \mathrm{TM} \text { difiedSize }}=18750 \quad \text { gallon Size Capacity/ Storage Tank }
$$

\section{Alternative-2 Wiped Film Evaporator Sizing:}

The Wiped Film evaporator (WFE) is sized to meet the WFE condensate rate of $4.05 \mathrm{gpm}$ by using 2 units of Artisan Rototherm ${ }^{\circledR}$ horizontal thin film evaporator containing 50 square feet of heat transfer area operating in parallel configuration.

\section{Alternative 2 - Heat Exchanger Sizing:}

The heat exchanger design equation is used to calculate the required heat transfer surface area to condensate the overhead WFE water vapor at $125^{\circ} \mathrm{F}$ to liquid water at $82^{\circ} \mathrm{F}$ at the overall heat transfer rate of $2,157,269.1 \mathrm{BTU} / \mathrm{hr}$. A countercurrent flow heat exchanger was selected for applying LMTD as the mean temperature difference in a basic heat exchanger design equation. The heat exchanger is assumed to be a shell and tube exchanger. It is configured that each WFE unit operating in series with a heat exchanger to produce a WFE condensate outflow. The combination of each of the two -WFE unit and heat exchanger- modules operating in parallel produce the design WFE condensate rate and the overall heat transfer rate.

$$
\begin{aligned}
& \text { Total Heat Transfer } \quad \mathrm{A}_{\text {Heat.Transfer }}=1256 \quad \mathrm{ft}^{2} \\
& \text { Area: }
\end{aligned}
$$

Heat Transfer Area per WFE and Heat Exchanger Module:

$$
\mathrm{A}_{\text {per.Module }}=628 \quad \mathrm{ft}^{2} / \text { Module of WFE and Heat Exchanger }
$$

\section{Alternative 2 - Sample Load Estimated:}

The annual sample load estimate for the record control samples taken at the WTB for the WFE condensate tanks and WFE concentrate tanks are:

Number of RC Samples per Year per Modified Two Storage Tank WFE Concentrate Sample :

$$
\text { RoundRCSample }_{2 \mathrm{~T}}=41 \quad \text { Samples WFE Concentrate } / \mathrm{yr}
$$

Number of RC Samples per Year per Modified Two Storage Tank WFE Condensate Sample:

$$
\text { RCSample } \text { WFECondensate }=142 \quad \text { Samples WFE Condensate } / \mathrm{yr}
$$

\subsection{Conclusions}

The Alternative-2 equipment sizing was performed using the the throughput documented in SVF-2440 at 7500 gallon per day. The calculated maximum storage capacity for the WFE concentrate storage tank is used as the basis to estimate a common storage tank volume for the feed, WFE condensate, and WFE concentrate storage, supplemented by ISO tank storage. An additional third storage vessel of equal capacity was included in the Feed storage configuration for blending of off-normal downstream WFE concentrate with the feed batches if necessary.

The size of WFE condensate storage in a two lag storage configuration is reduced by approximately $65 \%$ in

File: AEM-WRPS-2012-CN-013 Rev 0.xmcd 
volume by including the ISO tanks in combination with the storage vessels to hold WFE condensate content prior to transportation.

Two units of Artisan Rototherm ${ }^{\circledR}$ horizontal thin film evaporator, each providing 50 square feet of heat transfer area, operated in parallel satisfy the evaporation throughput. It is configured such that each WFE unit operating in series with a heat exchanger to produce a WFE condensate outflow. A heat transfer area of $628 \mathrm{ft}^{2}$ per each condenser module is estimated for each of the two -WFE unit and heat exchanger-modules operating in parallel to produce the design WFE condensate rate and the overall heat transfer rate.

\subsection{References}

24590-WTP-PL-PR-04-0001, 2008, Integrated Sampling and Analysis Requirements Document (ISARD), Rev 2, Bechtel National Inc., Richland, Washington.

Perry, R, 1984, Perry's Chemical Engineering Handbook, 6th edition, McGraw Book Company, New York, New York.

RPP-RPT-47443, 2011, Wiped Film Evaporator Full- Scale Demonstration System Test Report, Washington River Protection Solutions LLC, Richland, Washington.

SVF-2440, 2012, SBS Disposal PreConcept Alts. Rev 0, Washington River Protection Solutions LLC, Richland, Washington. 
Appendix C

CALCULATION AEM-WRPS-2012-CN-014, ALTERNATIVE 3 EQUIPMENT SIZING ESTIMATES 


\section{Subcontractor Calculation Review Checklist}

\section{Subject: AEM-WRPS-2012-CN-014, Alternative 3 Equipment Sizing Estimates}

The subject document has been reviewed by the undersigned.

The reviewer reviewed and verified the following items as applicable.

Documents Reviewed: AEM-WRPS-2012-CN-014, Alternative 3 Equipment Sizing Estimates Analysis Performed By: AEM Consulting, LLC

- Design Input

- Basic Assumption

- Approach/Design Methodology

- Consistency with item or document supported by the calculation

- Conclusion/Results Interpretation

- Impact on existing requirements

Reviewer (printed name, signature, and date) P. E. Peistrup

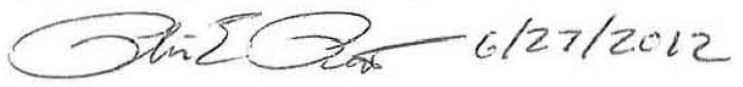

Organizational Manager (printed name, signature, and date) Martin Wheeler

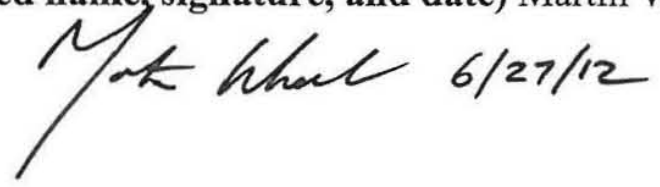


$\mathrm{ft}^{3}$ with the dimension of $5.5 \mathrm{ft}$ in diameter, $8.6 \mathrm{ft}$ is cylindrical section height, $7.6 \mathrm{ft}$ (rounded) in conical section height, and an overall $16.2 \mathrm{ft}$ tall.

V) A Horizontal Ribbon Blender with calculated full capacity of $135 \mathrm{ft}^{3}$ or 1010 gallon that is commercially available is estimated for mixing the Petroset-H dry solidification agent with the WFE concentrate.

VI) The pneumatic conveying system use a multistage centrifugal blower or a positive displacement rotary lobe blower, operating at volumetric air flow rate of approximately $320 \mathrm{ft}^{3} / \mathrm{min}$ (rounded) at $5.35 \mathrm{psig}$. The pipeline layout uses a $3.5 \mathrm{in}$. Sch 40 pipe with an ID=3.548 in., and consists of 50 -feet of horizontal length from the storage hopper solids feed-in, followed by a 30 -feet vertical elevation, and then a 50 -feet horizontal pipeline. A total pressure drop of the pneumatic conveying system was calculated to be $5.35 \mathrm{psig}$.

VII) The annual record control sample load estimate taken for the WFE condensate tanks is 41 samples/yr, and for the WFE concentrate tanks is 142 samples/yr.

Design Basis: The equipment sizing is based on equipment design mass balance of SVF-2440. 
RPP-RPT-52796, Rev. 0

\section{Contents}

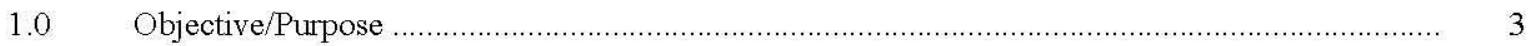

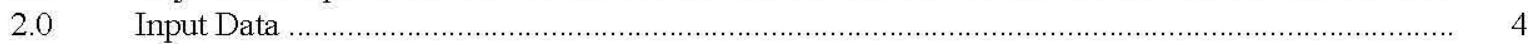

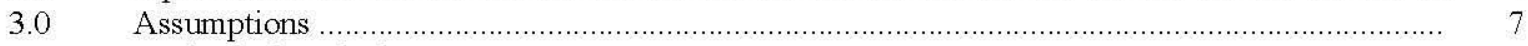

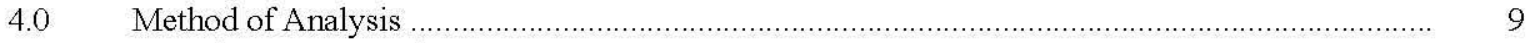

Use of Computer Software …

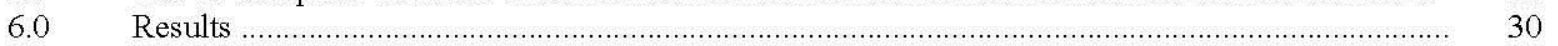

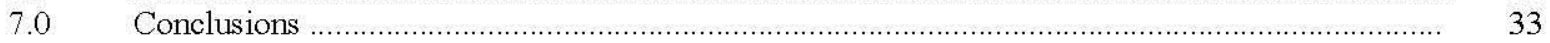

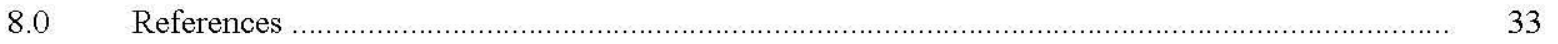

\subsection{Objective/Purpose}

Determine equipment sizes to support evaluation of Alternative-3 configuration. The subject equipment is:

- Feed staging and blending tanks.

- Wiped Film evaporator (WFE)

- WFE condensate storage tanks

- WFE concentrate storage tanks

- Heat exchanger to condensate WFE overhead vapor stream

- Pneumatic conveying system

- Solidification mixer

- Solidification agent powder storage silo and feed hopper.

Similar to Alternatives 1 and 2, the initial feed to the Alternative-3 is SBS liquid condensate transferred in the International Standard Organization (ISO) tanks from the WTP vessel RDL-VSL-00005. The turnaround time to perform the required Record Control (RC) sampling analysis prior to shipment, and the design based storage holding period are factored into calculations.

The Alternative- 3 process flow and sampling are shown in Figure 1. The SBS condensate in the WTP vessels are received at the waste transfer facility in the ISO containers. The Feed tanks function to receive WTP condensate and as needed blend the non-complying downstream WFE concentrate with WTP feed batches. The feed is evaporated by WFE and the resulting WFE condensate is RC sampled and transferred to the Effluent Treatment Facility. The RC analysis is performed on the WFE concentrate to confirm compliance with Class A concentration limits prior to mixing with solidification agent. The mixture is gravity transferred to soft sided containers and packaged for transportation to a licensed commercial disposal site. The dry solidification agent is pneumatically transferred from the storage silo into a feed hopper located above the mixer. The dry solidification agent is added to the mixer by a rotary airlock in batch quantities sufficient to fill a soft sided container to $80 \%$ capacity.

The solidification agent is intended to convert the concentrated waste from a liquid state to a solid state containing no free liquid during trans portation. The non-complying WFE concentrate is recycled to the feed tank for blending and reprocessing.

In Figure 1, the process blocks shown in green illustrate treatment steps of the Alternative-2 Configuration. The process blocks shown in red represent extra operations included in the overall Alternative- 3 system. The Alternative- 3 system sizing calculation described in this document and in Figure 1 represent all major pieces of equipment involved in feed receipt and storage, concentration, and solidification treatment operations. Therefore, the calculation shown in AEM-WRPS-2012-CN-013 are related to provide a stand alone document for Alternative-3.

File: AEM-WRPS-2012-CN-014 Rev 0.xmcd 


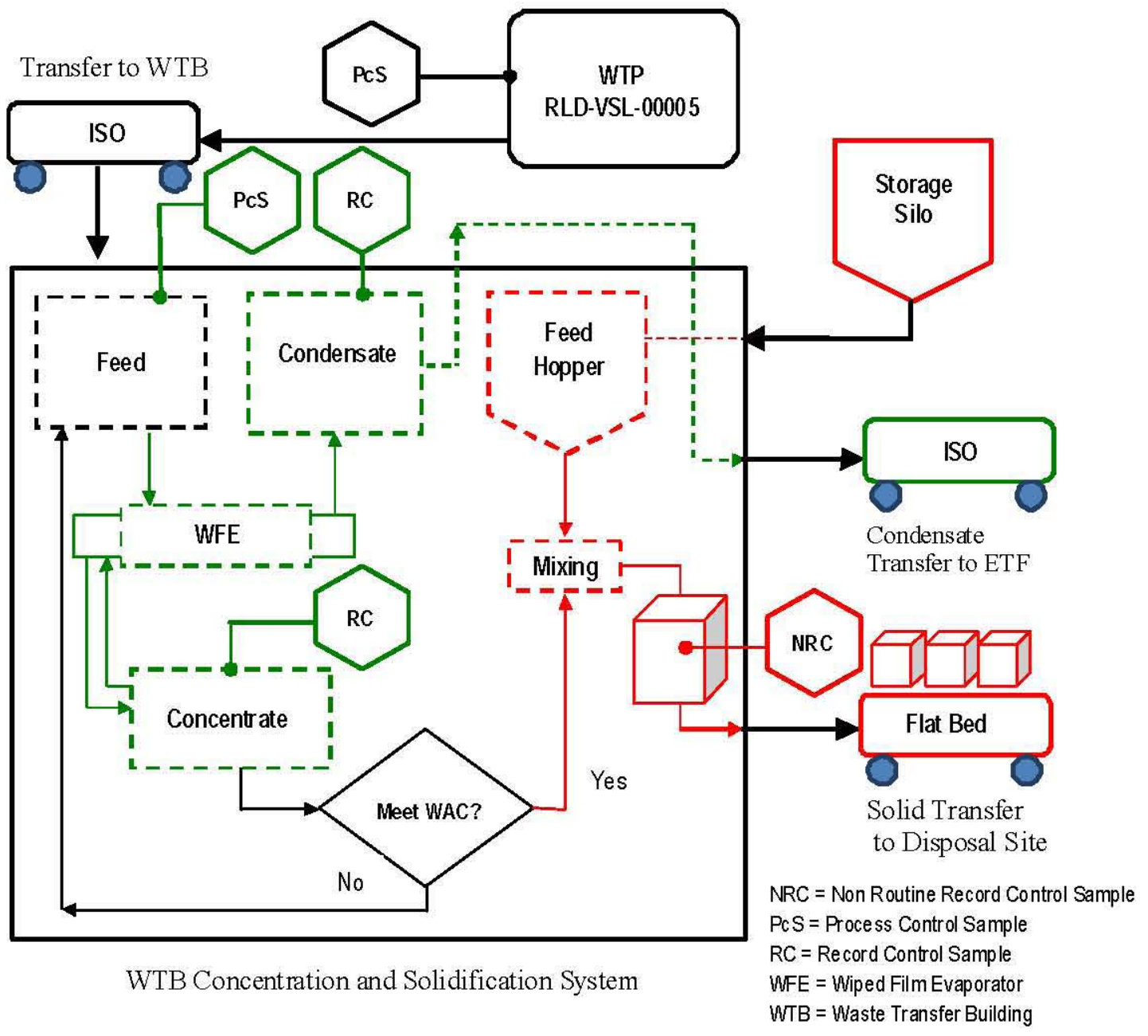

Figure 1 Alternative-3 Configuration and Sampling

\subsection{Input Data}

The input data for the Alternative-3 is organized as inputs a) distinct to Alternative-3 configuration, b) general inputs common to equipment sizing calculation in AEM-WRPS-2012-CN-013 for Alternative-2.

Inputs Specific to Alternative-3:

- The throughput rate documented in SVF-2440, SBS Disposal PreConcept Alts. (worksheet Eqpt DesignAlt-2) is used as the basis for sizing. The equipment is sized to receive 7500 gallons per operating day of the SBS condensate at peak generation. The rate is defined as "DesignRateStream2" in the calculation described in Section 4.0, and referred as "Stream2, WFE Feed" in the Eqpt DesignAlt-2 worksheet. NOTE: The material balance work sheet (of the SVF-2440) for Alternative-3, Eqpt DesignAlt-3 is an addendum to the Eqpt DesignAlt-2 material balance worksheet, and extend mass balance calculations to the solidification process specific to the Alternative- 3 configuration. The input rates for the feed, WFE condensate and WFE concentrate referred in this document are taken from the Eqpt DesignAlt-2 material balance worksheet. 
- The WFE concentrate and dry solidification agent mixture flow rate at $1.56 \mathrm{gpm}$, and density of $11.73 \mathrm{lb} / \mathrm{gal}$ are defined in "Stream 17 Solidified Concentrate" of the SVF-2440 (Eqpt DesignAlt-3 worksheet). The inputs are used to calculate daily numbers of containers produced.

- The dry solidification agent flow rate at $1.10 \mathrm{gpm}$, and density of $7.35 \mathrm{lb} / \mathrm{gal}$ are defined in "Stream 16 Solidification Agent Supply" of the SVF-2440 (worksheet Eqpt DesignAlt-3). The inputs are used to cal culate the daily volumetric and mass flow rate of dry Petroset-H solidification agent.

- The SVF-2440 (w orksheet Eqpt DesignAlt-3, Inputs1) uses Petroset-H by Fluidtech Inc. as the dry solidification agent for the solidification process.

- The hopper chart design of Figure 10, reported in Solve Solids Handling Problems by Retrofitting, and illustrated as Figure 2 is used to estimate a conical hopper angle (measured from vertical) for both silo/ hopper dimension estimates.

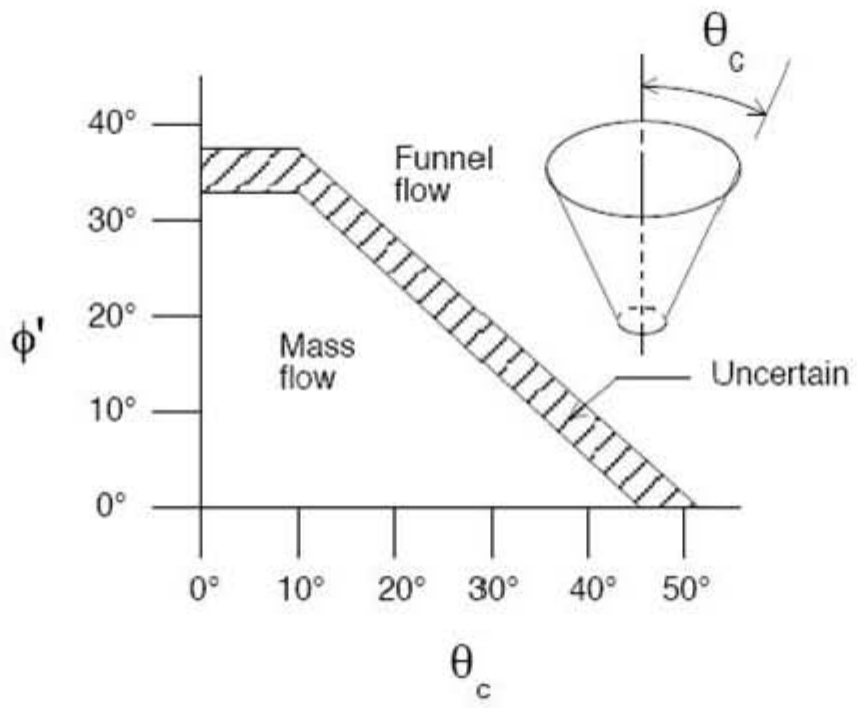

Figure 2 Design Chart For Setting Conical Hopper Angles for Mass Flow (Figure 10-Solve Solids Handling Problems by Retrofitting)

- The pneumatic conveying system uses ambient air as the carrier gas phase at $70^{\circ} \mathrm{F}$ at bulk density of 0.075 $\mathrm{lbm} / \mathrm{ft}^{3}$ and dynamic v iscosity of $0.000012 \mathrm{lbm} / \mathrm{ft}-\mathrm{s}$ at atmospheric pressure, $\mathrm{P}_{\mathrm{atm}}=14.7 \mathrm{psi}$. These values were determined by interpolating v alues at $60^{\circ} \mathrm{F}$ and $80^{\circ} \mathrm{F}$ in Appen dix I, Physical Properties of Gases and Liguids; Fundamentals of Momentum, Heat and Mass Transfer Book.

- The gas friction factor $\left(\mathrm{f}_{\mathrm{g}}\right)$ used in estimating the pressure drop due to frictional losses between the conveying gas and the pipe wall in the pneumatic conveying system is determined from the Moody diagram (Fiudidechanics, page 313)

- A fifteen minutes mixing time is reported in vendor literature about a Horizontal Ribbon Blender. Inputs Common to Alternatives 2 and 3 :

- The WTP vessels RLD-VSL-00005 SBS condensate output is used as the input feed stream to the Alternative-3 evaluation. 
- Equipment sizing is based on a peak processing rate such that operating efficiency adjustments are not required (overall Total Operating Efficiency (TOE) of $100 \%$ ).

- The Wiped Film Evaporator size is based on experimental WFE condensate generation rates using an Artisan Rototherm $\otimes$ horizontal thin film evaporator contain ing 50 square feet of heat transfer area. The WFE testing was conducted using AN-105 liquid simulant and documented in RPP-RPT-47443, Wiped Film Evaporator Full-Scale Demonstration System Test Report. The WFE condensate rates are shown in Table 1 and reported in Table 6-1 of RPP-RPT-47443.

- An ISO tank is used to transfer SBS condensate from the WTP to the Waste Transfer/Building (WTB). The ISO tanks provide additional storage capacity at the WTB, and are used for transportation of SBS condensate to the Effluent Treatment Facility (ETF) (see Figure 1).

- The "Stream 8 WFE Condensate" of the SVF-2440 Eqpt DesignAlt-2 worksheet at $4.05 \mathrm{gpm}$ is used to size WFE condensate storage vessels. The WFE conden sate rate is defined as "QStream 8 " in Section 4.0.

- The "Stream 3 WFE Concentrate" of the SVF-2440 Eqpt DesignAlt-2 worksheet at $1.16 \mathrm{gpm}$ is the basis for the WFE concentrate storage vessels sizing, and is defined as "QStream3" in Section 4.0.

- The SVF-2440 Eqpt DesignAlt-2 worksheet "Stream 10 Cooling Water Supply" heat transfer rate across the heat exchanger $/ \mathrm{s}$ is $2,157,269.1 \mathrm{BTU} / \mathrm{hr}$. It condenses the overhead WFE water vapor at $125^{\circ} \mathrm{F}$ to liquid water at $82{ }^{\circ} \mathrm{F}$ and is used to determine heat exchanger/s heat transfer area.

Table 1-1 Experimental Average Condensate Production Rate (RPP-RPT-47443, Rev 0, Table 6-1)

\begin{tabular}{|c|c|c|c|c|c|c|c|c|}
\hline $\begin{array}{l}\text { Test } \\
\text { Run }\end{array}$ & $\begin{array}{l}\text { Average } \\
\text { Feed } \\
\text { Rate } \\
\text { [UT-001] } \\
\text { (gpm) }\end{array}$ & $\begin{array}{c}\text { Average } \\
\text { WFE } \\
\text { Operating } \\
\text { Pressure } \\
\text { [DPT-305] } \\
\text { torr } \\
\text { absolute }\end{array}$ & $\begin{array}{l}\text { Average } \\
\text { Steam } \\
\text { Pressure } \\
\text { [PT502] } \\
\text { (psig) }\end{array}$ & $\begin{array}{l}\text { Feed Starting } \\
\text { SpG [UT-001] }\end{array}$ & $\begin{array}{c}\text { Feed Starting } \\
\text { Temp [UT-001] } \\
\left({ }^{\circ} \mathrm{F}\right)\end{array}$ & $\begin{array}{c}\text { Feed Ending SpG } \\
\text { [UT-001] }\end{array}$ & $\begin{array}{c}\text { Feed } \\
\text { Ending } \\
\text { Temp } \\
\text { [UT-001] } \\
\left({ }^{\circ} \mathrm{F}\right)\end{array}$ & $\begin{array}{c}\text { Average } \\
\text { Condensate } \\
\text { FT-401 } \\
\text { Flow Rate } \\
\text { (gal/min) } \\
{[\mathrm{lb} / \mathrm{hr}]}\end{array}$ \\
\hline 1 & 8.6 & 110 & 24 & 1.17 & 77 & 1.23 & 116.4 & $\begin{array}{l}2.071 \\
{[1037]}\end{array}$ \\
\hline 2 & 10 & 110 & 24 & 1.17 & 100 & 1.25 & 126.1 & $\begin{array}{l}2.185 \\
{[1094]}\end{array}$ \\
\hline 3 & 10 & 90 & 24 & 1.17 & 102.3 & 1.27 & 121.8 & $\begin{array}{c}2.363 \\
{[1183]}\end{array}$ \\
\hline 4 & 8 & 90 & 24 & 1.17 & 100.9 & 1.28 & 118.0 & $\begin{array}{c}2.312 \\
{[1157]}\end{array}$ \\
\hline 5 & 8 & 110 & 37 & 1.17 & 96.9 & 1.28 & 124.1 & $\begin{array}{c}2.514 \\
{[1258]}\end{array}$ \\
\hline 6 & 10 & 110 & 33 & 1.17 & 100.2 & 1.28 & 126.0 & $\begin{array}{c}2.479 \\
{[1241]}\end{array}$ \\
\hline 7 & 10 & 90 & 31 & 1.17 & 102.4 & 1.31 & 120.7 & $\begin{array}{c}2.599 \\
{[1301]}\end{array}$ \\
\hline 8 & 8 & 90 & 29 & 1.17 & 97.1 & 1.27 & 118.3 & $\begin{array}{c}2.473 \\
{[1238]}\end{array}$ \\
\hline
\end{tabular}

File: AEM-WRPS-2012-CN-014 Rev 0.xmcd 
- The overall heat transfer coefficient for a Service value Stainless Steel $316 \mathrm{~L}$ shell and tube heat exchanger at 105.56 BTU/(hr. $\left.\mathrm{ft}^{2}{ }^{\circ} \mathrm{F}\right)$ documented in Appendix 10 of RPP-RPT-47433, Rev0 page A10-51 is applied in the heat exchanger area calculation.

- The SVF-2440 Eqpt DesignAlt-2 worksheet fluid temperatures for: "Stream 4 WFE vapor" at $125^{\circ} \mathrm{F}$, "Stream 8 WFE Condensate" at $82^{\circ} \mathrm{F}$, "Stream 10 Cooling Water Supply" at $77^{\circ} \mathrm{F}$, and "Stream 11 Cooling Water Return" at $87^{\circ} \mathrm{F}$ are inputs to calculate the log mean temperature difference (LMTD), $\Delta \mathrm{T}$ lm. $\mathrm{A}$ countercurrent flow heat exchanger is selected for applying LMTD as the mean temperature difference in heat exchanger design equation.

Input Calculation Constants:

$\begin{array}{lll}\text { Facility Design Basis : } & \text { DesignRate }_{\text {Stream } 2}:=7500 \quad \text { gal condensate/Operating day } \\ \text { Overall Operating Efficiency: } & \text { TOE }:=1 & \text { Operating days/Calendar day } \\ \text { Days per year: } & \text { Days }:=365 & \text { Calendar days/Calendar yr }\end{array}$

Daily Input Feed Volumetric Flow Rate:

$$
\begin{array}{ll}
\mathrm{Q}_{\text {Feedin }}:=\text { DesignRate }_{\text {Stream2 }} \cdot \mathrm{TOE} & \mathrm{Q}_{\text {Feedin }}=7500 \quad \text { gal } / \text { Calendar day } \\
\mathrm{Q}_{\text {FeedinGPM }}:=\frac{\mathrm{Q}_{\text {Feedin }}}{24 \cdot 60} & \mathrm{Q}_{\text {FeedinGPM }}=5.208 \quad \mathrm{gpm}
\end{array}
$$

Overall Heat Transfer Rate Across the Heat Exchanger: $\quad Q_{\text {Heat.Stream10 }}:=2157269.1$ BTU/hr

Overall Heat Transfer Coefficient Using a Service value Stainless Steel 316 L Shell and Tube Heat Exchanger:

$$
\mathrm{U}_{\text {Service }}:=105.56 \quad \mathrm{BTU} / \mathrm{hr} . \mathrm{ft}^{2}{ }^{\circ} \mathrm{F}
$$

$\begin{array}{lcc}\text { Input WFE Vapor Temperature: } & \mathrm{t}_{1}:=125 & { }^{\circ} \mathrm{F} \\ \text { Output WFE Condensate Temperature: } & \mathrm{t}_{2}:=82 & { }^{\circ} \mathrm{F} \\ \text { Input Cooling Water Temperature: } & \mathrm{t}_{1}:=77 & { }^{\circ} \mathrm{F} \\ \text { Input Cooling Water Temperature: } & \mathrm{t}_{2}^{\prime \prime}:=87 & { }^{\circ} \mathrm{F}\end{array}$

\subsection{Assumptions}

For Alternative-3 the following assumptions apply:

1. ISO tanks of 5000 gallon volumetric capacity are assumed for the SBS condensate transportation and storage in the WTB lag storage system as an enabling assumption. A minimum twelve ISO tanks and ISO tank positions are available to support lag storage.

2. A two-tank storage configuration is selected for storage and processing of the SBS Feed condensate, WFE condensate, and WFE concentrate that support sampling.

3. The two-tank storage configuration is arranged such that one tank is always available to receive liquid from the ISO tanks or the upstream process without stopping the processing demand.

4. An additional third Feed tank is included for blending of off-normal downstream WFE concentrate with the

File: AEM-WRPS-2012-CN-014 Rev 0.xmcd 
RPP-RPT-52796, Rev. 0

A E M Consulting, LLC. Calculation Set No.AEM-WRPS-2012-CN-014 Rev No. 0

Sheet 8 of 34

feed batches.

5. A two day Record Control (RC) sample analysis turnaround time is assumed to verify compliance with the transportation and disposal site waste acceptance criteria (WAC). This assumes analysis and data package preparation activities similar to that described for sample point PT-27 in 24590-WTP-PL-PR-04-0001, Integrated Sampling and Analysis Requirements Document (ISARD), which characterized waste transfers from RLD-TK-0006A/B for comparison with the Liquid Effluent Retention Facility/Effluent Treatment Facility $\mathrm{WAC}$, and is assumed similar to sample requirement for this application. The $\mathrm{RC}$ sampling is performed on the WFE condensate, and on the WFE concentrate stored in the lag storage tanks prior to off site shipment (see Figure 1).

6. A 0.4 day Process Control $(\mathrm{PcS})$ sample turnaround time to monitor processing is assumed. Unlike the RC sampling, the PcS is assumed as a monitoring verification step and thereby no alternating between the feed vessels is required. This assumes analysis and data package preparation activities similar to that described for sample point PT-35 in 24590-WTP-PL-PR-04-0001, and is assumed similar to the sample requirement for this application. The PcS sampling is performed on the SBS condensate vessel batches transferred from the WTP and stored in ISO tanks at the WTB facility, and the SBS condensate feed at the WTB as illustrated on Figure 1.

7. Process knowledge and/or process control sampling is assumed sufficient for loading the content of the RLV-VSL-00005 vessel into ISO tanks, and transfer to the WTB facility as an enabling assumption.

8. The WFE condensate and WFE concentrate storage tanks in combination with ISO tanks are sized to hold liquid for seven days of storage before transferring to offsite. The assumption is allocated for poor weather condition along transport routes. This logic implicitly includes the two-day hold point for tank sampling analysis turnaround prior to loading condensate on a transport.

9. The SBS Feed condensate tanks are assumed to function as staging vessels prior to the concentration process. The sizing of these vessels are assumed unconstrained by seven days of storage as assumed for WFE condensate and WFE concentrate storage tanks. The PcS monitoring residence time of the feed tanks is assumed as sizing criteria for these vessels in a preliminary analysis.

10. The storage tanks are assumed to be cylindrical, above ground vessels.

11. A 1:1 aspect ratio for each tank diameter and height is used as an enabling assumption.

12. The heat exchangers are considered to be Stainless Steel $316 \mathrm{~L}$ shell and tube heat exchanger operating in a countercurrent flow as an enabling assumption.

13. A "Five Yard Soft Sided Container System" of 5 cubic yard and 10,000 lbs loading weight supplied by MHF services" is used for packaging the mixture of WFE concentrate and solidification agent. In the remainder of this document the Five Yard Soft Sided Container System is referred as a container.

14. A Ribbon Blender is assumed to adequately mix the dry Petroset-H solidification agent with the WFE concentrate.

15. A design margin of $80 \%$ volumetric fill capacity is defined in tank volumes, solidification mixer, and packaging container estimates.

16. The solidification agent, dry Petroset- $\mathrm{H}$ is considered to be delivered in bulk truck loads of approximately 42,000 pounds at the WTB facility.

17. The feed hopper is assumed to be filled daily.

18. The conveying system is assumed to be sized that the transfer of Petroset- $\mathrm{H}$ from the storage silo to the feed hopper can be completed within 1 to 2 hours daily.

19. The storage silo is placed in a separate room.

20. The dry solidification agent, Petroset-H, is transported from the storage silo to the feed hopper by a positive pressure conveying system using ambient air.

21. A conical shaped hopper design is used to determine the storage silo and feed hopper dimensions.

22. To estimate the hopper angle (from vertical) for the storage silo and feed hopper in a mass flow mode, the flow of dry Petroset-H along a selected hopper wall needs to be measured to obtain the wall angle of friction parameter used in hopper design charts. In the absence of data, the wall angle of friction, $\phi^{\prime}$, at approximately $28^{\circ}$ reported for clay in Flow Property Measurement Using The Jenike Shear Cell for 7 different bulk solids is assumed for the pre-conceptual dimension estimates.

23. A conservative solids loading ratio of 7 , or phase density defined as the ratio of flow rate of particles divided by the flow rate of the air is used in pneumatic conveying system. For dilute phase conveying, maximum values of achievable solids loading ratio are typically of the order of 15 (Pneumatic Conveying Design

File: AEM-WRPS-2012-CN-014 Rev 0.xmcd 
guide). Assume future pilot scale testing of Petroset-H addresses the input data to specify the appropriate values of solids loading ratio.

24. A layout between the storage silo to the feed hopper assume a 50 feet of horizontal length from the storage silo solids feed-in if confirmed to be above 30D pipeline length criteria, followed by a 30 -feet vertical elevation, and then a 50 -feet horizontal pipeline. These length are overestimated that produce a conservative pressure drop estimation for the frictional losses between the conveying gas and the pipe wall.

25. A total of five 90-deg bends in the pipeline layout is assumed to provide a conservative equivalent length pressure drop. Also a distance of 20 pipe diameters (20D) in the pipeline is allowed between the bends to facilitate re-acceleration of the solids, and plugging vulnerability by loss of solids velocity.

26. A slip ratio of 0.8 (velocity of solids/velocity of gas) is used. The slip ratio ranges from 0.5 to 0.9 . Heavier coarse particles (e.g., gravel or plastic pellets) have a slip ratio closer to 0.5 , while lighter, finer powder (e.g. talc) have a value closer to 0.9 .

27. A positive pressure conveying system using ambient air is considered. The mode of transporting the powder is assumed to be a dilute-phase conveying mode by maintaining sufficient air stream velocity at low powder to air ratio at a velocity greater than the saltation gas velocities, where suspended particles begin to drop out and settle in a layer on the bottom of the pipeline.

28. A minimum velocity $\left(\mathrm{V}_{\text {min }}\right.$ ) or pickup velocity of $70 \mathrm{ft} / \mathrm{s}$ (in high range of velocity limit), for the air to convey the dry Petroset- $\mathrm{H}$ powder in suspension flow without saltation in a dilute-phase conveying is assumed for pre-conceptual estimates. A typical fine powder may need a gas velocity of 40-60 ft/s (Troubleshoot and Solve Pneumatic Conveying Problems). Assume future pilot testing of Petroset-H addresses the input data to specify the appropriate minimum velocity.

29. The solids friction factor of $\lambda_{\mathrm{s}}=0.02$ for the dry Petroset- $\mathrm{H}$, which is typical for fine solids, and the pneumatic conveying pipeline absolute roughness $\varepsilon_{\mathrm{abs}}=0.0005 \mathrm{ft}$, which is typical for a smooth-bore steel pipeline is assumed.

30. The pneumatic conveying pipeline layout from the storage silo to the feed hopper assumes only horizontal and vertical runs connected with bends. The layout avoids inclined lines.

31. All the pipeline components (e.g. bends/elbows) have the same internal diameters as the conveying line to avoid formation of lips and ledges.

\section{Assumption Calculation Constants:}

Residence Time For SBS Condensate Feed before Downstream WFE Concentration

Residence Time for Feed Process Control Sample Analysis: $\quad t_{\mathrm{PcS}}:=0.4 \quad$ Day

Storage Hold Time before Transfer for the WFE Concentrate Or WFE Condensate Storage Tanks:

Hold time before Transfer:

Design Margin of Tank Volume Filled by Feed:

$$
\begin{aligned}
& \mathrm{t}_{\text {HoldMax }}:=7 \text { day } \\
& { }_{\text {Fill }}:=0.8 \\
& \mathrm{AR}:=1 \quad \text { Dimensionless }
\end{aligned}
$$

\subsection{Method of Analysis}

The Alternative-2 configuration and sampling schematic is shown in Figure 1. A preliminary vessel sizing is performed to estimate the volume constraint (minimum volume for feed tank, and maximum volume for downstream storage tanks) when $80 \%$ full. The calculation uses a residence time of 0.4 days for PcS monitoring and the input rate of 7500 gallons per operating day at peak generation to estimate a minimum feed tank size, since the feed vessel functions as an interim vessel before concentration. The volumetric flow rate for the WFE condensate and WFE concentrate, documented in SVF-2440, and seven days of storage are used to calculate the maximum storage required in this case.

File: AEM-WRPS-2012-CN-014 Rev 0.xmcd 
RPP-RPT-52796, Rev. 0

In the second phase of vessel sizing, the calculated maximum storage capacity for the WFE condensate and concentrate storage tanks are applied as the basis to estimate a reduced storage tank volume, when it is assumed a combination of the ISO tanks and reduced storage tanks satisfy the seven days storage criteria. An additional third Feed tank is included to be used in the blending of off-normal downstream WFE concentrate with the feed batches. The vessel sizing and facility layout was further simplified by assuming an identical vessel size for all seven tanks used in the Alternative-2 configuration. Furthermore, the complexity associated with sorting ISO tanks allocated for liquid storage by WFE condensate or WFE concentrate streams is decreased, when the selected tank size is conservatively based on the initial WFE concentrate storage capacity that is equivalent to the capacity in units of ISO tanks. The reduced tank sizing is not constrained by the feed tank volume since the residence time for the feed tanks is less than one day as compared to seven day of storage for WFE condensate and WFE concentrate.

The Wiped Film evaporator is sized to meet the design WFE condensate rate at $4.05 \mathrm{gpm}$. The calculation described below uses the experimental WFE condensate production flux provided by a 50 square feet heat transfer area (RPP-RPT-47433). The WFE scale up is simplified by assuming the overall heat transfer coefficient for the Alternative-2 WFE to be the same as the tested system without postulating a scaling factor for the overall heat transfer. The calculation assume WFE units of 50 square feet heat transfer area that are identical to the tested WFE to operate in parallel configuration in meeting the design condensate production rate.

The system heat exchanger area size is based on the calculated heat removal rate to generate WFE water condensate from the WFE overhead vapor. The heat exchanger area is calculated using an overall heat transfer coefficient based on the service value of stainless for a steel shell and tube heat exchanger. A countercurrent flow heat exchanger is assumed when applying LMTD as the mean temperature difference in heat exchanger design equation.

The mixer is sized to hold sufficient material to produce a single container in one pour. The number of mixers required is based on an estimate of the mixer cycle time.

A total pressure drop for the pneumatic conveying system must be estimated in order to properly select a gas motive force. The major forces involved in the pneumatic conveying of bulk solids in a gas stream are: friction between flowing solids or gas and the pipeline wall; the force required to move gas through vertical pipeline sections; and the force required to lift solids through vertical pipeline sections or to accelerate solids from the feed-point velocity to the conveying velocity.

Petroset- $\mathrm{H}$ is used as the dry powder solidification agent. The storage silo is sized to store a truck load of Petroset- $\mathrm{H}$. The feed hopper is sized to hold the capacity of the Petroset-H daily mixing use. Both silo and hopper are shaped as a cylindrical top and a lower conical geometry operating in a mass flow pattern. Each silo/hopper volume equation is based on a cylindrical section and a conical section. The volume equation is simplified in terms of the each silo/hopper cylindrical section diameter and height, and a half-angle of the conical section (form vertical).

\section{Alternative-3 Tank Storage Sizing (duplicated from AEM-WRPS-2012-CN-013):}

For all three staging operations a two tank storage configuration is used. The two storage tank system is arranged such that one tank is always available to receive a liquid stream without stopping the upstream production flow. Each tank volume is sized using a design margin of $80 \%$ fill capacity. A preliminary sizing calculation for: a) Feed, b) WFE condensate, and c) WFE concentrate storage (see Figure 1) is based on the assumed throughput and the storage time to establish the design based storage capacities requirement. The PcS sampling is assumed to not be a holding point to alternate between the tanks for the feed tanks.

The tank storage capacities are then modified to reach a storage volume applicable for all three staging operations by incorporating the use of the ISO containers at each stage with the storage vessels in a two tank storage system

File: AEM-WRPS-2012-CN-014 Rev 0.xmcd 
that meet the initially calculated capacities. An additional third Feed tank is included to be used in blending of off-normal downstream WFE concentrate with the feed batches.

Alternative -3 Preliminary Feed Tank Sizing

The output flow rate from the Feed vessel,"Stream 2 WFE Feed" in the Eqpt DesignAlt-2 worksheet, which is the WTP vessel RLD-VSL-00005 condensate and the PcS sampling residence time for the Feed process control is used. The Feed process control sampling assume a 0.4 day turn around.

Feed Output Volumetric Flow Rate to the WFE:

$$
\begin{aligned}
& Q_{\text {FeedoutGPM }}:=Q_{\text {FeedinGPM }} \\
& Q_{\text {FeedoutGPM }}=5.208 \quad \text { gpm } \\
& Q_{\text {FeedGPH }}:=Q_{\text {FeedoutGPM }} \cdot 60 \\
& Q_{\text {FeedGPH }}=312.5 \quad \text { GPH }
\end{aligned}
$$

Residence Time for Feed Process Control Sample Analysis: $\quad t_{\mathrm{PcS}}=0.4 \quad$ Day

$$
\mathrm{t}_{\mathrm{PcSHR}}:=\mathrm{t}_{\mathrm{PcS}} \cdot 24 \quad{ }^{\mathrm{PcSHR}}=9.6 \quad \mathrm{hr}
$$

The minimum capacity for the Feed tank is to hold 9.6 hours of material.

Minimum Feed Volume per Storage Tank:

Design Margin of Tank Volume Filled by Liquid:

Minimum Tank Volume at $80 \%$ Storage Capacity for Feed Storage: $\quad \mathrm{V}_{\text {FeedSize }}:=\frac{\mathrm{V}_{\text {Feed }}}{\text { Fill }}$

$$
\begin{aligned}
& \mathrm{V}_{\text {Feed }}:=\mathrm{Q}_{\text {FeedGPH }}{ }^{-\mathrm{t}_{\mathrm{PcSHR}}} \\
& \mathrm{V}_{\text {Feed }}=3000 \quad \text { gal Feed } / \text { Storage Tank }
\end{aligned}
$$$$
\text { Fill }_{\mathrm{DM}}=0.8
$$

$$
\mathrm{V}_{\text {FeedSize }}:=\frac{\mathrm{V}_{\text {Feed }}}{\text { Fill }}
$$

gallon Size Capacity/ Storage Tank

or

$$
\mathrm{V}_{\text {FeedSizeft3 }}:=\frac{\mathrm{V}_{\text {FeedSize }}}{7.4805} \quad \mathrm{~V}_{\text {FeedSizeft3 }}=501 \quad \mathrm{ft}^{3} \text { Size Capacity/ Storage Tank }
$$

Alternative -3 Preliminary WFE Condensate Storage Tank Sizing

The vapor stream leaving the WFE flows into a condenser and the WFE condensate is collected in a WFE condensate storage vessel. The WFE condensate storage vessels are sized to meet: a) WFE condensate production rate of $4.05 \mathrm{gpm}$ described in Section 2.0 for the "Stream 8 WFE Condensate", and b) hold seven days of condensate storage. The assumed two days holding point analysis turnaround for the RC sampling is implicitly accounted in allow holding time.

Stream 8 WFE Condensate Volumetric Rate All WFE modules:

$$
\mathrm{Q}_{\text {Stream8 }}:=4.05 \quad \text { gpm }
$$




$$
\begin{aligned}
& Q_{\text {Stream8.Day }}:=Q_{\text {Stream8 }} \cdot 60 \cdot 24 \\
& Q_{\text {Stream8.Day }}=5.832 \times 10^{3} \quad \mathrm{gal} / \text { day }
\end{aligned}
$$

In a Two Tank WFE Condensate storage, a WFE condensate tank is always available to receive WFE condensate stream from the WFE vapor condensation without stopping the upstream WFE condensate production flow.

Number of WFE Condensate Storage Tanks:

Hold Time before Transfer from Two Tank WFE Condensate Storage System:

$$
\mathrm{N}_{2 \mathrm{~T} . \text { Cond }}:=2 \quad \text { Tanks Configuration }
$$$$
\mathrm{t}_{\text {Hold2T }}:=\mathrm{t}_{\text {HoldMax }} \quad(7 \text { days })
$$

WFE Condensate Volume per Storage Tank:

$$
\begin{gathered}
\mathrm{V}_{2 \mathrm{~T} . \text { Cond }}:=\mathrm{Q}_{\text {Stream8.Day }}{ }^{\mathrm{t}}{ }_{\mathrm{Hold} 2 \mathrm{~T}} \\
\mathrm{~V}_{2 \mathrm{~T} \text {.Cond }}=40824 \quad \text { gal WFE Condensate/ Storage Tank }
\end{gathered}
$$

Design Margin of Tank Volume Filled by Liquid: $\quad$ Fill $_{\mathrm{DM}}=0.8$

Tank Volume to Meet the Design Criteria and $80 \%$ Storage Capacity: $\quad \mathrm{V}_{2 \mathrm{~T} . \text { Cond.Size }}:=\frac{\mathrm{V}_{2 \mathrm{~T}} \text {.Cond }}{\text { Fill }_{\mathrm{DM}}}$

$$
\mathrm{V}_{2 \mathrm{~T} . \text { Cond.Size }}=51030 \quad \text { gallon Size Capacity } / \text { WFE Condensate Storage Tank }
$$

or

$$
\mathrm{V}_{2 \mathrm{~T} . \text { Cond.ft3 }}:=\frac{\mathrm{V}_{2 \mathrm{~T} \text {.Cond.Size }}}{7.4805} \quad \mathrm{~V}_{2 \mathrm{~T} . \text { Cond. } \mathrm{ft} 3}=6822 \quad \mathrm{ft}^{3} \text { Size Capacity/ Storage Tank }
$$

\section{Alternative -3 Preliminary WFE Concentrate Storage Tank Sizing}

The WFE concentrate storage vessel system is sized to meet: a) WFF concentrate production rate of $1.16 \mathrm{gpm}$ described in Section 2.0 for the "Stream 3 WFE Concentrate", and b) the seven days of storage time.

Stream 3 WFE Concentrate Volumetric Rate from All WFE modules:

Stream 3 WFE Concentrate Volumetric Rate:

$$
\begin{aligned}
& Q_{\text {Stream3 }}:=1.16 \quad \mathrm{gpm} \\
& \mathrm{Q}_{\text {Stream3.Day }}:=\mathrm{Q}_{\text {Stream3 }} \cdot 60 \cdot 24 \\
& \mathrm{Q}_{\text {Stream3.Day }}=1.67 \times 10^{3} \quad \mathrm{ga} / \text { day }
\end{aligned}
$$

Number of WFE Concentrate Storage Tanks:

$$
\mathrm{N}_{2 \mathrm{~T} . \text { Conc }}:=2 \quad \text { Tanks Configuration }
$$

File: AEM-WRPS-2012-CN-014 Rev 0.xmcd 
Hold Time before Transfer from Two Tank WFE

Concentrate Storage System:

WFE Concentrate Volume per Storage Tank:

$$
\begin{gathered}
\mathrm{t}_{\text {Hold2T }}=7 \quad \text { days } \\
\mathrm{V}_{2 \mathrm{~T} \text {.Conc }}:=\mathrm{Q}_{\text {Stream3.Day }} \cdot \mathrm{t}_{\text {Hold2T }} \\
\mathrm{V}_{2 \mathrm{~T} \text {.Conc }}=11693 \quad \text { gal WFE Concentrate/ Storage Tank }
\end{gathered}
$$

Design Margin of Tank Volume Filled by Liquid:

$$
\text { Fill }_{\mathrm{DM}}=0.8
$$

$$
\mathrm{V}_{2 \mathrm{~T} . \text { Conc.Size }}:=\frac{\mathrm{V}_{2 \mathrm{~T} . \text { Conc }}}{\text { Fill } \mathrm{DM}}
$$

Capacity:

$$
\mathrm{V}_{2 \mathrm{~T} . \text { Conc.Size }}=14616
$$

gallon Size Capacity/ WFE Concentrate Storage Tank

or

$$
\mathrm{V}_{2 \mathrm{~T} . \text { Conc. } \mathrm{ft} 3}:=\frac{\mathrm{V}_{2 \mathrm{~T} \text {.Conc.Size }}}{7.4805} \quad \mathrm{~V}_{2 \mathrm{~T} . \text { Conc. } \mathrm{ft} 3}=1954 \mathrm{ft}^{3} \text { Size Capacity/ Storage Tank }
$$

\section{$\underline{\text { Reduced Size Based on Allocating Storage to ISO Tanks: }}$}

The WFE concentrate tanks are sized for seven days of holding are used as common tank size that can be supplemented by ISO tanks in different application. The tank storage capacity and volume calculations can be modified for all three staging operations when it is assumed a combination of the ISO tanks and storage tanks are available to satisfy the seven days storage criteria. An additional Feed tank is included for blending off-normal downstream WFE concentrate feed batches if needed. The vessel sizing and facility layout was further simplified by assuming an identical vessel size for all seven tanks used in the Alternative- 2 configuration. Furthermore, the complexity associated with sorting ISO tanks allocated for liquid storage by WFE condensate or WFE concentrate streams is decreased, when the tank size selection is conservatively based on the initial WFE concentrate storage capacity that is equivalent to the capacity in units of ISO tanks. The reduced tank sizing is not constrained by the feed tank volume since the residence time for the feed tanks is less than one day as compared to seven day of storage for WFE condensate and WFE concentrate.

The remaining volume of WFE condensate is allocated to ISO tanks. It is assumed that a modified WFE condensate tank is filled to capacity and an RC sample is taken. Then the tank content is transferred to ISO tanks for storage while analysis is performed.

The tank capacity is assumed to be used for the three feed and blending tanks that satisfy the tanks capacity above needed residence time. If needed, the full content of an off-normal WFE concentrate can be rerouted and blended with fresh SBS feed condensate.

Assume Using the Preliminary Storage Volume for WFE Concentrate as Basis in Reduced Storage Tank Volumes per Seven Days of Storage:

WFE Concentrate Volume per Storage Tank:

Volume of an ISO Tank:

$$
\begin{array}{cc}
\mathrm{V}_{2 \mathrm{~T} . \text { Conc }}=11693 & \text { gal WFE Concentrate/ Storage Tank } \\
\mathrm{V}_{\text {ISO.Tank }}:=5000 & \text { gallon/ ISO Tank }
\end{array}
$$


Equivalent Number of ISO Tanks for WFE Concentrate Volume:

$$
\begin{aligned}
\text { Num }_{\text {ISOTankEQ }}:=\frac{V_{2 T} \text {.Conc }}{V_{\text {ISO.Tank }}} \\
\text { Num }_{\text {ISOTankEQ }}=2.34 \text { Number of ISO Tanks for balance SBS condensate }
\end{aligned}
$$

Rounding Up to Next Integer for Number of ISO Tanks

$$
\begin{aligned}
& \text { RoundNum }_{\text {ISOTankEQ }}:=\left(\operatorname{round}\left(\text { Num }_{\text {ISOTankEQ }}\right)\right)+1 \\
& \text { RoundNum }_{\text {ISOTankEQ }}=3
\end{aligned}
$$

The Rounded Up Number of ISO tanks is Used For Each Modified Storage Capacity In a Two Tank Storage Configuration for All Processing Stages:

Using the Preliminary WFE Concentrate Storage:

Modified Volume per Storage Tank:

Design Margin of Tank Volume Filled by Liquid:

Modified Tank Volume at 80\% Storage Capacity:

$$
\begin{gathered}
\mathrm{V}_{2 \text { TModified }}:=\mathrm{V}_{\text {ISO.Tank }} \cdot \text { RoundNum }_{\text {ISOTankEQ }} \\
\mathrm{V}_{2 \text { TModified }}=15000 \quad \text { gal Capacity } / \text { Storage Tank } \\
\text { Fill }_{\mathrm{DM}}=0.8
\end{gathered}
$$$$
\mathrm{V}_{\text {2TModifiedSize }}:=\frac{\mathrm{V}_{\text {2TModified }}}{\text { Fill }_{\mathrm{DM}}}
$$$$
\mathrm{V}_{\text {2TModifiedSize }}=18750 \text { gallon Size Capacity/ Storage Tank }
$$

or

$$
\begin{aligned}
& \mathrm{V}_{2 \text { TModifiedft } 3}:=\frac{\mathrm{V}_{2 \text { TModifiedSize }}}{7.4805} \\
& \mathrm{~V}_{2 \text { TModifiedft } 3}=2507 \quad \mathrm{ft}^{3} \text { Size Capacity/ Storage Tank }
\end{aligned}
$$

Using a 1:1 aspect ratio for tank diameter and height, each storage tank dimensions become:

Tank Height to Diameter Aspect Ratio:

$$
\mathrm{AR}=1
$$

Storage Tank Reduced Diameter: $\quad \mathrm{D}_{\text {2TModified }}:=\left[\frac{\mathrm{V}_{\text {2TModifiedft3 }}}{\left(\frac{\pi}{4}\right) \mathrm{AR}}\right]^{\frac{1}{3}}$
$\mathrm{D}_{\text {2TModified }}=14.7 \mathrm{ft}$

File: AEM-WRPS-2012-CN-014 Rev 0.xmcd 
Storage Tank Reduced Height:

$$
\begin{aligned}
& \mathrm{H}_{2 \text { TModified }}:=\mathrm{D}_{2} \text { TModified } \\
& \mathrm{H}_{2} \text { TRodified } \\
& =14.7
\end{aligned}
$$

Remaining Volume of WFE condensate allocated to ISO Tanks:

$$
\begin{aligned}
& \mathrm{V}_{2 \mathrm{~T} . \text { CondNeed }}:=\mathrm{V}_{2 \mathrm{~T} \text {.Cond }}-\mathrm{V}_{2 \mathrm{TModified}} \\
& \mathrm{V}_{2 \mathrm{~T} \text {.CondNeed }}=25824 \quad \text { gal WFE Condensate/ Storage Tank }
\end{aligned}
$$

Number of ISO Tanks Needed to Add to the Modified Tank Storage for WFE Condensate Storage:

$$
\begin{aligned}
& \mathrm{N}_{\text {ISOTankNeed }}:=\frac{\mathrm{V}_{\text {2T.CondNeed }}}{\mathrm{V}_{\text {ISO.Tank }}} \\
& \mathrm{N}_{\text {ISOTankNeed }}=5.2 \quad \begin{array}{l}
\text { Number of ISO Tanks for balance volume of WFE } \\
\text { condensate/Storage Tank }
\end{array}
\end{aligned}
$$

Rounding Up to Next Integer for Number of ISO Tanks Used for 7 Days of SBS Condensate Storage per Reduced Storage Tank.

$$
\begin{aligned}
& \text { RoundN } \mathrm{N}_{\text {ISOTankNeed }}:=\left(\text { round }\left(\mathrm{N}_{\text {ISOTankNeed }}\right)\right)+1 \\
& \text { RoundN } \mathrm{N}_{\text {ISOTankNeed }}=6 \quad \text { ISO tanks } / \text { Reduced Storage Tank }
\end{aligned}
$$

An additional 6- ISO tanks (rounded up) per each WFE condensate storage tank, or a total of 11- ISO tanks are needed to meet the storage required for the WFE Condensate.

Number of ISO Tanks (Rounded) Used for 7 Days of SBS Condensate Storage per Reduced Two Storage Tank approximately for ETF Transportation.

$$
\begin{aligned}
& \mathrm{N}_{\text {ISOTankFull }}:=\mathrm{N}_{\text {ISOTankNeed }} \mathrm{N}_{2 \text { T.Cond }} \text { ISO tanks/ Reduced Two Storage Tank Configuration } \\
& \text { RoundN }_{\text {ISOTankFull }}:=\left(\operatorname{round}\left(\mathrm{N}_{\text {ISOTankFull }}\right)\right)+1 \\
& \text { RoundN }_{\text {ISOTankFull }}=11 \quad \text { ISO tanks (Rounded up)/ Reduced Two Storage Tank Configuration }
\end{aligned}
$$

\section{Alternative-3 Wiped Film Evaporator Sizing (duplicated from AEM-WRPS-2012-CN-013):}

The Wiped Film evaporator (WFE) is sized to meet the WFE condensate rate of $4.05 \mathrm{gpm}$ described in Section 2.0 for the "Stream 8 WFE Condensate". The sizing calculation is based on the WFE testing conducted using AN-105 liquid simulant documented in RPP-RPT-47443, Wiped Film Evaporator Full-Scale Demonstration System Test Report. Rev 0. The results for the WFE averaged condensate production rate listed in Table 6-1 of RPP-RPT-47443, and shown in Table 1 are used to determine the experimental condensate flux. The testing used an Artisan Rototherm horizontal thin film evaporator providing 50 square feet heat transfer area. To simplify WFE scale up, modules of Artisan Rototherm horizontal thin film evaporator containing 50 square feet heat transfer area are assumed to be used in parallel configuration for sizing the Alternative- 2 WFE. In this approach the WFE overall heat transfer coefficient, $U$, is maintained constant and the resistances to the flow of heat from

File: AEM-WRPS-2012-CN-014 Rev 0.xmcd 
the heating medium to the product affecting the $U$ determination (resistance of the inner product film, inner fouling factor, the metal wall of the evaporator vessel, the outer fouling factor and the outer heating medium film) are not changed and thereby no additional scaling factor to determined a scaled $U$ is required in sizing the WFE.

The averaged condensate rate shown in Table 1 are ranges between $2.071 \mathrm{gal} / \mathrm{min}$ to $2.599 \mathrm{gal} / \mathrm{min}$. By using the minimum condensate production rate of $2.071 \mathrm{gal} / \mathrm{min}$ shown as the test run number 1 in Table 1 , the largest heat exchange surface area to meet the WFE design throughput is calculated.

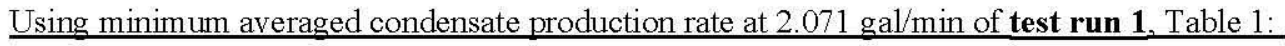

Heat Transfer Surface Area of Artisan Rototherm Horizontal Thin Film Evaporator used in Testing :

$$
\mathrm{A}_{\text {Rototherm }}:=50 \quad \mathrm{ft}^{2} \text { Heat exchange area }
$$

Minimum Averaged WFE Condensate Volumetric Rate:

Minimum WFE Condensate Volumetric Flux:

$$
\begin{aligned}
& \text { qWFE.cond.min }_{\text {W }}:=2.071 \mathrm{gpm} \\
& \text { Flux }_{\text {WFE.cond.min }}:=\frac{\text { qWFE.cond.min }_{\text {Rototherm }}}{\mathrm{A}_{\text {Wot }}} \\
& \text { Flux }_{\text {WFE.cond.min }}=4.142 \times 10^{-2} \mathrm{gpm} / \mathrm{ft}^{2}
\end{aligned}
$$

Stream 8 WFE Condensate Volumetric Rate (see Section 2.0):

$$
\mathrm{Q}_{\text {Stream8 }}=4.05 \mathrm{gpm}
$$

Required WFE Heating Surface Area for Minimum Condensate Rate:

$$
\begin{aligned}
& \mathrm{A}_{\text {req1.WFE }}:=\frac{\mathrm{Q}_{\text {Stream8 }}}{\text { Flux }_{\text {WFE.cond.min }}} \\
& \mathrm{A}_{\text {req1.WFE }}=97.8 \quad \mathrm{ft}^{2}
\end{aligned}
$$

Required Number of Artisan Rototherm Evaporators;

$$
\begin{gathered}
\mathrm{N}_{\text {WFE }}:=\frac{A_{\text {req1.WFE }}}{A_{\text {Rototherm }}} \\
\mathrm{N}_{\text {WFE }}=1.96 \text { WFE Units } \\
\text { RoundN }_{\text {WFE }}:=\operatorname{round}\left(\mathrm{N}_{\mathrm{WFE}}\right) \\
\text { RoundN }_{\text {WFE }}=2 \quad \text { WFE Units (Rounded) }
\end{gathered}
$$

The calculated WFE heat transfer surface area indicate 97.8 square feet of evaporation is required to produce 4.05 gpm of WFE condensate. Therefore two-50 square feet of Artisan Rototherm evaporator units operating in parallel are needed to meet the design WFE condensate throughput.

\section{Alternative 3 - Heat Exchanger Sizing (duplicated from AEM-WRPS-2012-CN-013):}

The heat exchanger design equation is used to calculate the heat transfer surface area to condense the overhead WFE water vapor at $125^{\circ} \mathrm{F}$ to liquid water at $82^{\circ} \mathrm{F}$ at an overall heat transfer rate of $2,157,269.1 \mathrm{BTU} / \mathrm{hr}$ across the heat exchanger operating in countercurrent flow. As described in section 2.0 the overall heat transfer rate is calculated for "Stream 10 Cooling Water Supply" of SVF-2440 Eqpt Design Alt-2 worksheet. A countercurrent flow heat exchanger is selected for applying LMTD as the mean temperature difference in heat exchanger design equation. The heat exchanger is assumed to be a shell and tube exchanger. Initially an overall heat exchanger area

File: AEM-WRPS-2012-CN-014 Rev 0.xmcd 
is calculated. Then, since each WFE unit is configured to operate with a heat exchanger in series, the combination of each of the two -WFE unit and heat exchanger- modules operating in parallel produce the design WFE condensate rate and the heat transfer rate (of 2,157,269.1 BTU/hr).

An estimate of the number of heat exchanger tubes, etc. outlining a detailed heat exchanger design layout is differed to ore detailed studies.

Overall Heat Transfer Rate Across the Heat Exchanger: $\quad Q_{\text {Heat.Stream10 }}=2157269.1 \quad$ BTU $/ \mathrm{hr}$

Overall Heat Transfer Coefficient Using a Service value for Stainless Steel 316 L Shell and Tube Heat Exchanger

$\begin{array}{lccc} & & & \\ \text { Input WFE Vapor Temperature: } & \mathrm{t}_{1}{ }_{1}=125 & { }^{\circ} \mathrm{F} \\ \text { Output WFE Condensate Temperature: } & \mathrm{t}_{2}=82 & { }^{\circ} \mathrm{F} \\ \text { Input Cooling Water Temperature: } & \mathrm{t}^{\prime \prime}{ }_{1}=77 & { }^{\circ} \mathrm{F} \\ \text { Input Cooling Water Temperature: } & \mathrm{t}^{\prime \prime}{ }_{2}=87 & { }^{\circ} \mathrm{F}\end{array}$

Countercurrent flow, Perry Eqn10-118a, 6th edition:

$$
\begin{aligned}
& \Delta \mathrm{T}_{1 \mathrm{~m}}:=\frac{\left(\mathrm{t}_{1}-\mathrm{t}_{2}{ }_{2}\right)-\left(\mathrm{t}_{2}-\mathrm{t}_{1}\right)}{\ln \left(\frac{\mathrm{t}_{1}-\mathrm{t}_{2}}{\mathrm{t}_{2}-\mathrm{t}_{1}}\right)} \\
& \Delta \mathrm{T}_{1 \mathrm{~m}}=16.27 \quad{ }^{\circ} \mathrm{F} \\
& \mathrm{A}_{\text {Heat.Transfer }}:=\frac{\mathrm{Q}_{\text {Heat.Stream10 }}}{\mathrm{U}_{\text {Service }} \cdot \Delta \mathrm{T}_{1 \mathrm{~m}}} \\
& \mathrm{~A}_{\text {Heat.Transfer }}=1256 \quad \mathrm{ft}^{2}
\end{aligned}
$$

Total Heat Transfer Area:

Heat Transfer Area per WFE and Heat Exchanger Module: $\quad A_{\text {per.Module }}:=\frac{A_{\text {Heat.Transfer }}}{\text { RoundN }_{W F E}}$

$$
\mathrm{A}_{\text {per.Module }}=628 \mathrm{ft}^{2} / \text { Module of WFE and Heat Exchanger }
$$

\section{Alternative 3- Concentrate Solidification System:}

A closer view of the Alternative-3 solidification system consisting of a pneumatic conveying system, storage silo, feed hopper, mixer (a Ribbon Blender) is shown in Figure 3. The storage silo is located in a separate room. The dry Petroset-H is pneumatically transferred to the feed hopper located above the mixer. The Petroset-H is added to the mixer in batches and the WFE concentrate is then sprayed on and mixed. The mixture is gravity poured into soft sided containers (supersacks) and shipped for offsite disposal. 


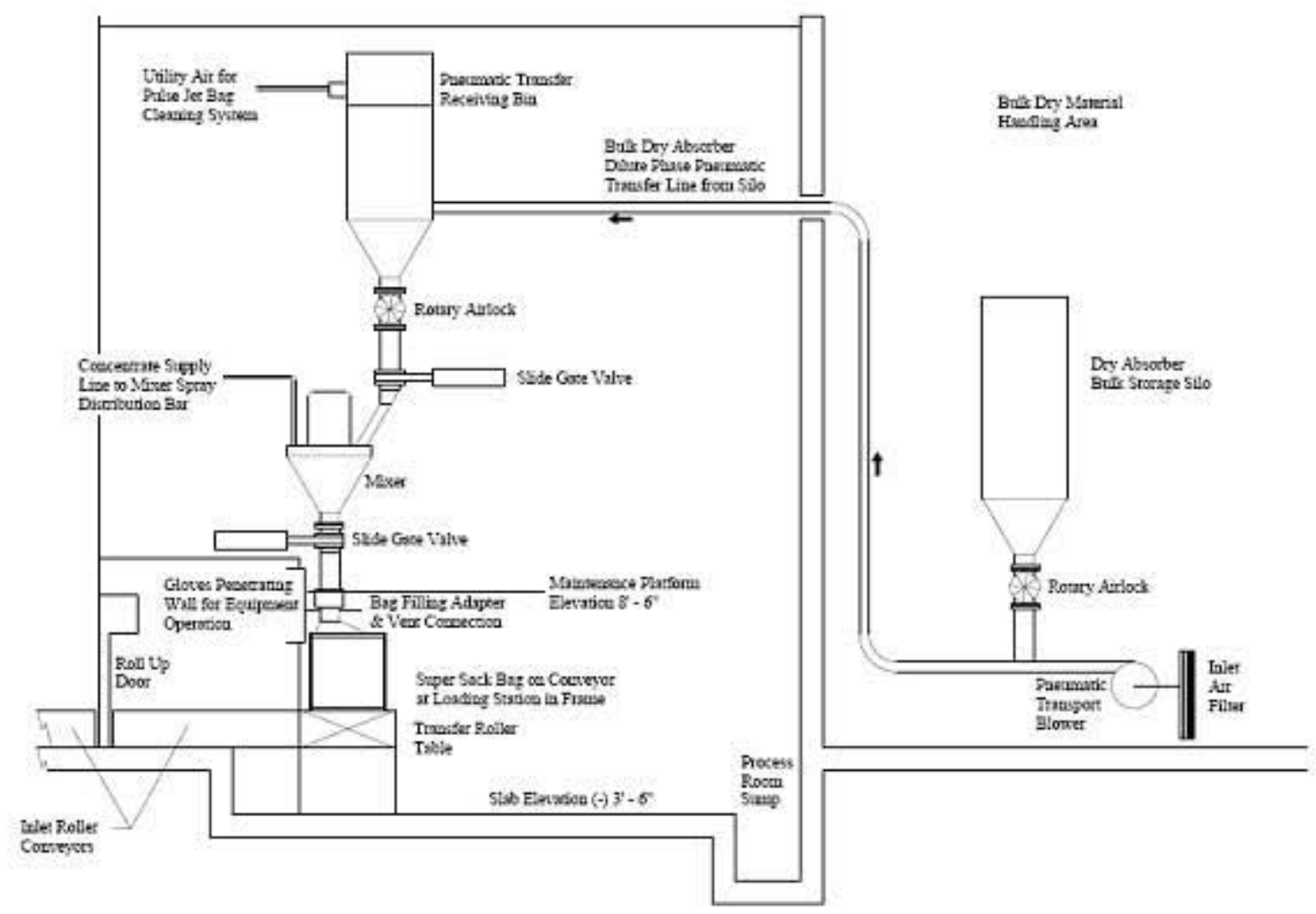

Figure 3 C oncentrate Solidification System Layout

\section{Alternative 3- Mixer Sining:}

A Ribbon Blender is assumed to adequately mix the dry Petroset-H solidification agent with the WFE concentrate. The mix ture of the WFE concentrate and dry solidification agent at $1.56 \mathrm{gpm}$, and density of $11.73 \mathrm{lb} / \mathrm{gal}$ are defined in "Stream 17 Solidified Concentrate" is used to calculate daily numbers of Soft Sided containers produced. Then based on the fill volume of each Soft Sided container, the mixer size and intervals of mixing to meet the daily rate of $1.56 \mathrm{gpm}$ is determined. The mixing and solidification process is conducted as a batch operation

Mass Balance "Stream 17 Solidified C oncentr ate" Inqut :

$$
\begin{aligned}
& Q_{\text {Stream17.GPM }}:=1.56 \mathrm{gpm} \\
& Q_{\text {Stream3.Day }}=1.67 \times 10^{3} \quad \mathrm{gal} / \mathrm{day}
\end{aligned}
$$

A rectangul ar super sack supplied by MHF Services called Five Yard Soft Sided Container System with a capacity of 5 cubic yard volume and $10,0001 \mathrm{~b}$ capacity (and loaded size of $8 \mathrm{ft} \mathrm{L} \times 4 \mathrm{ft} \times 4 \mathrm{ft} \mathrm{H}$ ) is used.

The V olume of Each Container:

$$
\begin{aligned}
& \text { Vol } 1_{\text {sack.yd }}:=5 \mathrm{yd}^{3} \\
& V o 1_{\text {sack }}:=\mathrm{Vol}_{\text {sack.yd }} \cdot 27 \quad \mathrm{ft}^{3} \\
& V o 1_{\text {sack }}=135 \quad \mathrm{ft}^{3}
\end{aligned}
$$

File: AEM-WRPS-2012-CN-014 Rev0.xmcd 
Assuming the Container Fill Volume of $80 \%$ :

$$
\begin{aligned}
& \mathrm{Vol}_{\text {sack. } 80 \%}:=\mathrm{Vol}_{\text {sack }} \cdot \frac{80}{100} \\
& \mathrm{Vol}_{\text {sack. } 80 \%}=108 \quad \mathrm{ft}^{3} \\
& \mathrm{Vol}_{\text {sack.gal. } 80 \%}:=\mathrm{Vol}_{\text {sack. } 80 \%} \cdot 7.4805 \\
& \mathrm{Vol}_{\text {sack.gal. } 80 \%}=808 \quad \text { gallon }
\end{aligned}
$$

Mass Balance "Stream 17 Solidified Concentrate" Input :

$$
\rho_{\text {Stream17 }}:=11.73 \quad \mathrm{lb} / \mathrm{gal}
$$

Check if the Solidified Concentrate Weight at $80 \%$ Fill volume is below the Container Weight Limit:

$$
\begin{aligned}
& \mathrm{M}_{\text {sack. } 80 \%}:=\rho_{\text {Stream } 17} \cdot \mathrm{Vol}_{\text {sack.gal.80\% }} \\
& \mathrm{M}_{\text {sack. } 80 \%}=9477 \quad \mathrm{lbs}
\end{aligned}
$$

Each container filled up to $80 \%$ volume is within the weight limit.

Therefore 808 gallons of the solidified concentrate is prepared and gravity poured into a container.

$$
\begin{aligned}
& \begin{array}{l}
\text { Ribbon Blender Size at } 80 \% \text { Fill Capacity: } \quad \text { RBlender }_{\text {Size }}:=\frac{V_{\text {solk.gal. }} .80 \%}{\text { Fill }_{\mathrm{DM}^{7}} \cdot .4805} \\
\text { Fill }_{\mathrm{DM}}=0.8
\end{array} \\
& \text { or } \\
& \text { RBlender }_{\text {Size }}=135 \quad \mathrm{ft}^{3} \text { Full Capacity (equal to } 5 \mathrm{yd}^{3} \text { ) } \\
& \text { RBlender }_{\text {Size.gal }}:=\text { RBlender }_{\text {Size }} \cdot 7.4805 \\
& \text { RBlender }_{\text {Size.gal }}=1010 \quad \text { gallon Full capacity }
\end{aligned}
$$

The result indicate a Horizontal Ribbon Blender with calculated full capacity of $135 \mathrm{ft}^{3}$ or 1010 gallon that is commercially available in the estimated size will meet the mixing operation requirement.

$$
\begin{aligned}
& \text { Solidified Concentrate Volumetric Flow Rate: } \quad Q_{\text {Stream17.Day }}:=Q_{\text {Stream17.GPM }} \cdot 60 \cdot 24
\end{aligned}
$$

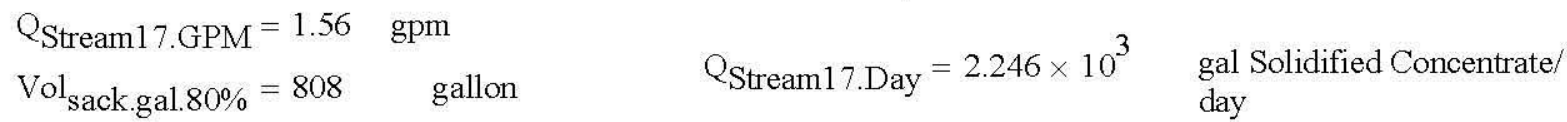

Number of Containers Filled to Satisfy Daily Solidification Rate

$$
\begin{aligned}
& \mathrm{N}_{\text {sack.Stream17.Day }}:=\frac{\mathrm{Q}_{\text {Stream17.Day }}}{\mathrm{Vol}_{\text {sack.gal.80\% }}} \\
& \mathrm{N}_{\text {sack.Stream17.Day }}=2.8 \quad \text { Container of Solidified Concentrate/Day }
\end{aligned}
$$

The result indicates approximately three container of solidified concentrate are generated per day using one horizontal ribbon blender. 


\section{Alternative 3- Storage Silo and Feed Hopper Sizing:}

Petroset- $\mathrm{H}$ is used as the dry powder solidification agent for mixing and solidification. It is assumed to be delivered in bulk truck loads of approximately 42,000 pounds at the WTB facility. The storage silo is sized to store a truck load of Petroset-H. The feed hopper is sized to hold the capacity of the Petroset-H daily mixing use. As calculated approximately 3 sacks of solidified WFE concentrate is produced per day in a batch mixing operation. Based on the SVF-2440 Eqpt DesignAlt-3 mass balance worksheet the dry Petroset-H, "Stream 16 Solidification Agent Supply" at a volumetric flow rate of $1.10 \mathrm{gpm}$ is mixed with the WFE concentrate, "Stream 3 WFE Concentrate" at a volumetric flow rate of $1.16 \mathrm{gpm}$.

Mass Balance " Stream 16 Solidification Agent Supply" Input for Petroset-H dry powder:

$\mathrm{Q}_{\text {Stream16 }}:=1.10 \quad$ gpm

$\rho_{\text {Stream16 }}:=7.35 \quad \quad \mathrm{lb} /$ gal Petroset-H bulk density

Calculated Volume of Petroset-H per Day Stored in Feed Hopper:

$$
\begin{aligned}
& \mathrm{Q}_{\text {Stream16.Day }}:=\mathrm{Q}_{\text {Stream16 }} \cdot 60 \cdot 24 \\
& \text { or } \quad \mathrm{Q}_{\text {Stream16.Day }}=1.584 \times 10^{3} \mathrm{gal} / \text { day } \\
& \mathrm{M}_{\text {Stream16.Day }}:=\mathrm{Q}_{\text {Stream16.Day }} \cdot \mathrm{P}_{\text {Stream } 16} \\
& \mathrm{M}_{\text {Stream16.Day }}=1.164 \times 10^{4} \quad \mathrm{lb} / \text { day }
\end{aligned}
$$

Feed Hopper Volume at 80\% Fill Capacity for Daily Petroset-H Powder Storage:

$$
\begin{aligned}
& \text { Fill }_{\mathrm{DM}}=0.8 \quad \text { FeedHopper } \\
& \text { Vol }
\end{aligned}
$$

Petroset-H Powder Bulk Volume per Truck Load Delivery:

$\rho_{\text {Stream16 }}=7.35 \quad 1 \mathrm{~b} /$ gal bulk density

$$
\begin{aligned}
& \text { PetH }_{\text {TruckLoad }}:=42000 \quad \text { lbs } \\
& \text { PetH } \mathrm{TruckVol}:=\frac{\text { PetH }_{\text {TruckLoad }}}{\rho_{\text {Stream16 }}} \\
& \mathrm{PetH}_{\mathrm{TruckVol}}=5.714 \times 10^{3} \quad \begin{array}{l}
\text { gallon Petroset- } \mathrm{H} / \text { Truck } \\
\text { Load }
\end{array}
\end{aligned}
$$

Petroset-H Truck Load Supply Rate:

$$
\text { PetH }_{\text {TruckUse }}:=\frac{\text { PetH }_{\text {TruckVol }}}{Q_{\text {Stream16.Day }}}
$$

File: AEM-WRPS-2012-CN-014 Rev 0.xmcd 


$$
\text { PetH }_{\text {TruckUse }}=3.61 \quad \begin{aligned}
& \text { Days Petroset-H Supply } / \text { Truck } \\
& \text { load }
\end{aligned}
$$

Storage Silo Volume at 80\% Fill Capacity for Petroset-H Powder Storage per Truck Load Delivery:

$$
\begin{aligned}
\text { Fill }_{\mathrm{DM}}=0.8 & \text { StorageSilo }_{\mathrm{Vol}}:=\frac{\mathrm{PetH}_{\mathrm{TruckVol}}}{\mathrm{Fill}_{\mathrm{DM}^{-7.4805}}} \\
\text { StorageSilo }_{\mathrm{Vol}} & =955 \quad \mathrm{ft}^{3} \text { Storage Silo Volume at } \sim 3.6 \text { days of Storage }
\end{aligned}
$$

Feed Hopper and Storage Silo Dimensions:

Both silo and hopper are shaped as a cylindrical top and a lower conical geometry operating in a mass flow pattern. In a mass flow mode all of the material in the hopper/silo is in motion during discharge, with particles sliding along the hopper wall. Mass flow occurs when sloping hopper walls are smooth (low enough friction) and steep enough for particles to slide along them.

To estimate a silo/hopper cross section and height dimension, each silo/hopper stored volume is illustrated in Figure 4 .

$$
\begin{aligned}
\mathrm{V}_{\text {Total }} & :=\mathrm{V}_{\text {cylinder }}+\mathrm{V}_{\text {conical.section }} \\
\mathrm{V}_{\text {Total }}:= & \frac{\pi \cdot \mathrm{D}_{\text {Cylinder }}{ }^{2} \cdot \mathrm{H}_{\text {Cylinder }}}{4}+\frac{\pi \cdot \mathrm{D}_{\text {Cylinder }}{ }^{2} \cdot \mathrm{h}_{\text {cone }}}{12}-\frac{\pi \cdot \mathrm{D}_{\text {outlet }}{ }^{2} \cdot \mathrm{h}_{\text {outlet }}}{12} \text { (Equation 1) }
\end{aligned}
$$

The estimates assume, the volume of space between the hopper bottom opening outlet and the vertex of the conical section is negligible. Then the Equation 1 is simplified to:

$$
\mathrm{V}_{\text {Total }}:=\frac{\pi \cdot \mathrm{D}_{\text {Cylinder }}{ }^{2} \cdot \mathrm{H}_{\text {Cylinder }}}{4}+\frac{\pi \cdot \mathrm{D}_{\text {Cylinder }}{ }^{2} \cdot \mathrm{h}_{\text {cone }}}{12} \text { (Equation 2) }
$$

From Figure 5, the cone height, $\mathrm{h}$, is defined in terms of cylinder diameter, and the half-angle of the conical section, defined as hopper angle, $\theta_{c}$ :

$$
\left.\mathrm{h}_{\text {cone }}:=\frac{\mathrm{D}_{\text {Cylinder }}}{2 \cdot \tan \left(\theta_{\mathrm{c}}\right)} \quad \text { (Equation } 3\right)
$$

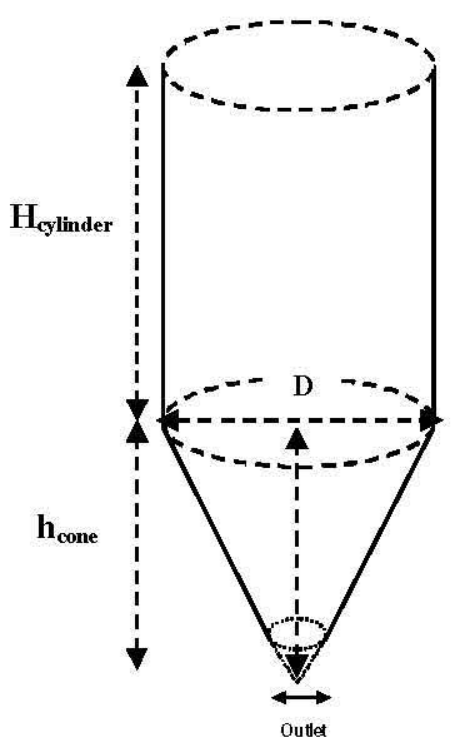

The Equation 3 is substituted in Equation 2. The storage volume equation is then solved for the diameter and height of cylindrical section, the hopper angle, $\theta_{c}$, and the total volume of the hopper

Figure 4 Hopper Storage Volume

File: AEM-WRPS-2012-CN-014 Rev 0.xmcd 
shown in Equation 4.

$$
\mathrm{H}_{\text {Cylinder }}:=\frac{4}{\pi \cdot \mathrm{D}_{\text {Cylinder }}{ }^{2}} \cdot V_{\text {Total }}-\frac{D_{\text {Cylinder }}}{6 \cdot \tan \left(\theta_{c}\right)} \quad \text { (Equation 4) }
$$

The mass-flow silothoppers are designed with a height (cylindrical/parallel section) between one and 4 times the diameter, $\mathrm{D}_{\text {Cylinder }}<\mathrm{H}_{\mathrm{Cylinder}}<4 \mathrm{D}_{\text {cylinder }}$, as outlined in Bulk Solids Handling: An Introduction to Practice and Technology.

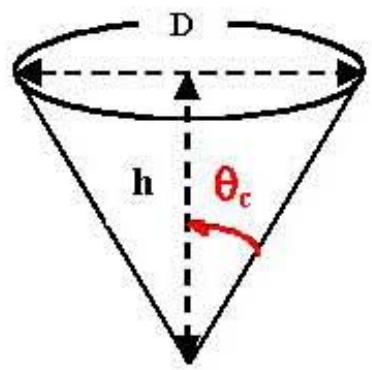

Figure 5 Conical Geometry

To determine the hopper angle, $\theta_{c}$, (measured from vertical) in a mass flow hopper, the friction term defined as the angle of wall friction, $\phi^{\prime}$, between the bulk Petroset-H powder and the hopper surface need to be measured. It represent the flow properties of a powder along the hopper wall as a result of friction between the bulk solid and the hopper wall surface The angle of wall friction, $\phi^{\prime}$ is obtained by method described in ASTM D-6128, Standard Test Method for Shear Testing of Bulk Solids using the Jenike Shear Cell. Using the measured $\phi^{\prime}$, then the hopper angle , $\theta_{c}$, that fall in the mass flow region is obtained from the design chart shown in Figure 1-2 for conical hoppers. In the absence of data about angle of wall friction for Petroset-H and a given hopper wall surface, a typical wall friction angle of approximately $28^{\circ}$ for clay reported in Flow Property Measurement Using the Jenike Shear Cell for 7 Different Bulk Solids is assumed for the pre-conceptual sizing. From the design chart (see Figure 6), the combination of $\phi^{\prime}$ at $28^{\circ}$, and $\theta_{c}$ at $20^{\circ}$ falls within the mass-flow region. Then, the hopper angle (from vertical), $\theta_{c}$ is used to estimate the cylinder height (Equation 4), the cone height (Equation 3), and the overall hopper height $\left(\right.$ Height $_{\text {cylinder }}+$ Height $\left._{\text {Cone }}\right)$

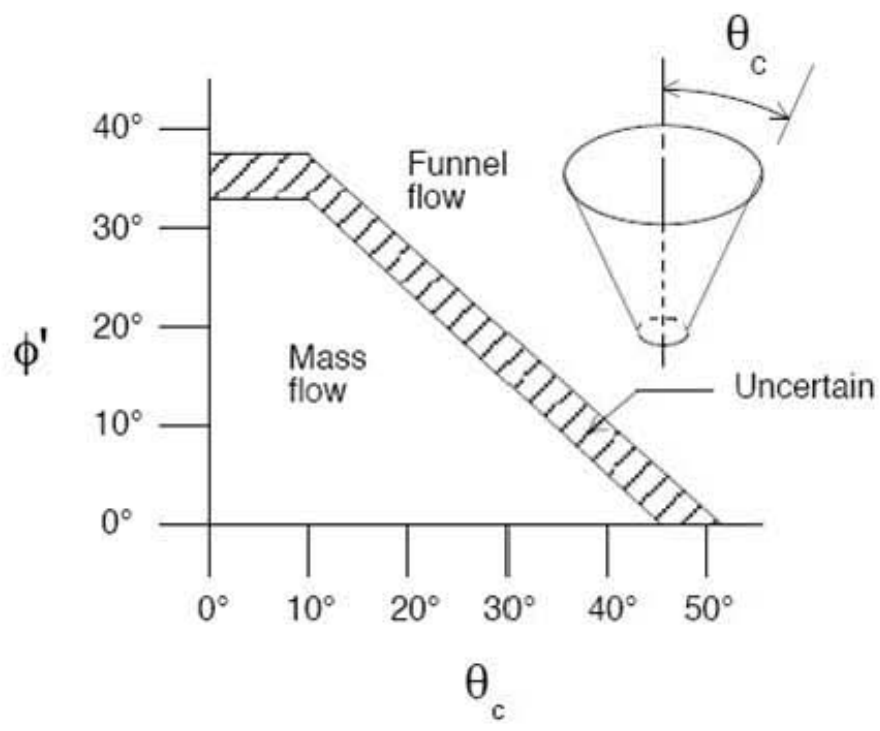

Figure 6 Design Chart For Setting Conical Hopper Angles for Mass Flow (Figure 10-Solve Solids Handling Problems by Retrofitting)

The WTB design as sumes the feed hopper and the storage silo are located inside the building and thereby considerations are made to maintain the overall hopper height reasonable.

File: AEM-WRPS-2012-CN-014 Rev 0.xmcd 
Using the Hopper Angle (from vertical), $\theta_{\mathrm{c}}$, at $20^{\circ}$ for both the Feed Hopper and the Storage Silo :

\section{Feed Hopper Dimensions:}

Feed Hopper Volume:

Hopper Angle (from vertical), $\theta_{c}$

Select a Cylinder Diameter for the Feed Hopper:

$$
\text { FeedHopper }_{\text {Vol }}=265 \quad \mathrm{ft}^{3}
$$$$
\theta_{\mathrm{c}}:=20
$$$$
\mathrm{D}_{\text {FHcylinder }}:=5.5 \quad \mathrm{ft}
$$

Solve for Height of cylindrical and conical sections:

Cylindrical Section:

$$
\begin{gathered}
\mathrm{H}_{\text {FHcylinder }}:=\frac{4}{\pi \cdot \mathrm{D}_{\text {FHcylinder }}{ }^{2}} \cdot \text { FeedHopper }_{\text {Vol }}-\frac{\mathrm{D}_{\text {FHcylinder }}}{6 \cdot \tan \left(\theta_{\mathrm{c}} \cdot \frac{\pi}{180}\right)} \\
\mathrm{H}_{\mathrm{FH} \text { cylinder }}=8.6 \quad \mathrm{ft}
\end{gathered}
$$

Conical Section:

$$
\begin{aligned}
& \mathrm{h}_{\text {FHcone }}:=\frac{D_{\text {FHcylinder }}}{2 \cdot \tan \left(\theta_{c} \cdot \frac{\pi}{180}\right)} \\
& \mathrm{h}_{\text {FHcone }}=7.56 \quad \mathrm{ft}
\end{aligned}
$$

Cylinder Section- height to diameter ratio:

If $\mathrm{D}_{\text {cylinder }}<\mathrm{H}_{\text {cylinder }}<4 \mathrm{D}_{\text {cylinder }}$ is not within, then re-enter a new cylinder diameter

$$
\text { Ratio }_{\mathrm{FH}}:=\frac{\mathrm{H}_{\mathrm{FHcylinder}}}{\mathrm{D}_{\mathrm{FHcylinder}}}
$$

$$
\text { Ratio }_{\mathrm{FH}}=1.6
$$

Overall Feed Hopper Height:

$$
\begin{aligned}
& \mathrm{H}_{\text {FHOverall }}:=\mathrm{H}_{\text {FHcylinder }}+\mathrm{h}_{\text {FHcone }} \\
& \mathrm{H}_{\text {FHOverall }}=16.2 \quad \mathrm{ft}
\end{aligned}
$$

Storage Silo Dimensions:

Storage Silo Volume:

$$
\begin{aligned}
& \text { StorageSilo }_{\mathrm{Vol}}=955 \quad \mathrm{ft}^{3} \\
& \theta_{\mathrm{c}}=20 \quad \text { degree } \\
& \mathrm{D}_{\text {SScylinder }}:=8.2 \quad \mathrm{ft}
\end{aligned}
$$

Select a Cylinder Diameter for the Storage Silo:

Solve for Height of cylindrical and conical sections:

Cylindrical Section:

$$
\begin{gathered}
\mathrm{H}_{\text {SScylinder }}:=\frac{4}{\pi \cdot \mathrm{D}_{\text {SScylinder }}{ }^{2}} \cdot \text { StorageSilo }_{\mathrm{Vol}}-\frac{\mathrm{D}_{\text {SScylinder }}}{6 \cdot \tan \left(\theta_{\mathrm{c}} \cdot \frac{\pi}{180}\right)} \\
\mathrm{H}_{\text {SScylinder }}=14.3 \quad \mathrm{ft}
\end{gathered}
$$

File: AEM-WRPS-2012-CN-014 Rev 0.xmcd 
Conical Section:

$$
\begin{aligned}
& \mathrm{h}_{\text {SScone }}:=\frac{\mathrm{D}_{\text {SScylinder }}}{2 \cdot \tan \left(\theta_{\mathrm{c}} \cdot \frac{\pi}{180}\right)} \\
& \mathrm{h}_{\text {SScone }}=11.26 \quad \mathrm{ft}
\end{aligned}
$$

Cylinder Section- height to diameter ratio:

If $\mathrm{D}_{\text {cylinder }}<\mathrm{H}_{\text {cylinder }}<4 \mathrm{D}_{\text {cylinder }}$ is not within, then Ratio $_{\mathrm{SS}}:=\frac{\mathrm{H}_{\text {SScylinder }}}{\mathrm{D}_{\text {SScylinder }}}$ re-enter a new cylinder diameter

$$
\text { Ratio }_{\mathrm{SS}}=1.7
$$

Overall Storage Silo Height:

$$
\begin{aligned}
& \mathrm{H}_{\text {SSOverall }}:=\mathrm{H}_{\text {SScylinder }}+\mathrm{h}_{\text {SScone }} \\
& \mathrm{H}_{\text {SSOverall }}=25.6 \quad \mathrm{ft}
\end{aligned}
$$

Mixer, Storage Silo and Feed Hopper Summary:

Horizontal Ribbon Blender:

$$
\text { RBlender }_{\text {Size }}=135 \quad \mathrm{ft}^{3} \text { Full Capacity (equal to } 5 \mathrm{yd}^{3} \text { ) }
$$

or

$$
\text { RBlender }_{\text {Size.gal }}=1010 \quad \text { gallon Full capacity }
$$

Approximately three container of solidified concentrate are generated per day.

$$
\begin{aligned}
& \text { Feed Hopper: } \quad \text { FeedHopper }{ }_{\text {Vol }}=265 \quad \mathrm{ft}^{3} \text { Feed Hopper Storage Volume per Day use } \\
& \text { Hopper Angle (from vertical), } \theta_{c} \quad \theta_{c}=20 \text { degree } \\
& \mathrm{D}_{\text {FHcylinder }}=5.5 \quad \mathrm{ft} \\
& \mathrm{H}_{\mathrm{FH} \text { cylinder }}=8.6 \quad \mathrm{ft} \\
& \mathrm{h}_{\mathrm{FHcone}}=7.56 \quad \mathrm{ft} \\
& \mathrm{H}_{\mathrm{FHOverall}}=16.2 \quad \mathrm{ft} \\
& \text { Storage Silo: } \quad \text { StorageSilo }_{\text {Vol }}=955 \quad \mathrm{ft}^{3} \text { Storage Silo Volume at } \sim 3.6 \text { days of Storage } \\
& \text { Hopper Angle (from vertical), } \theta_{\mathrm{c}} \quad \theta_{\mathrm{c}}=20 \quad \text { degree } \\
& \mathrm{D}_{\text {SScylinder }}=8.2 \quad \mathrm{ft} \\
& \mathrm{H}_{\text {SScylinder }}=14.3 \quad \mathrm{ft} \\
& \mathrm{h}_{\text {SScone }}=11.26 \quad \mathrm{ft} \\
& \mathrm{H}_{\mathrm{SSOverall}}=25.6 \quad \mathrm{ft}
\end{aligned}
$$

Daily mass of Petroset-H to be transferred from the storage silo to the feed hopper.

File: AEM-WRPS-2012-CN-014 Rev 0.xmcd 


$$
\mathrm{M}_{\text {Stream16.Day }}=11642 \quad \mathrm{lb} / \text { day }
$$

\section{Alternative 3- Pneumatic Conveying System Sizing:}

A pneumatic conveying system consists of four components-- the gas mover, the solids feeder, the pipeline and the separator for removing solids from the gas. The calculation below is focused on system pipeline layout and the selection of the gas mover to provide the required gas flow rate for transporting solids at the proper velocity and pressure. A total pressure drop of the pneumatic conveying system need to be estimated in order to properly select the gas mover. The major forces involved in the pneumatic conveying of bulk solids in a gas stream are: friction between flowing solids or gas and the pipeline wall; the force required to move gas through vertical pipeline sections; and the force required to lift solids through vertical pipeline sections or to accelerate solids from the feed-point velocity to the conveying velocity.

The dry Petroset- $\mathrm{H}$ is pneumatically transferred from the storage silo to the feed hopper located above the mixer. It is assumed the feed hopper is filled daily. A mass of 11,642 lbs of Petroset- $\mathrm{H}$, as calculated in the previous section is transferred to the feed hopper per day. The conveying system is assumed to be sized that the transfer of Petroset-H from the storage silo to the feed hopper can be completed within 1 to 2 hours daily to support producing the calculated 3 batches of mixing per day. Thus, it is assumed the conveying system to transport $10.000 \mathrm{lb} / \mathrm{hr}$ of Petroset-H from the storage silo to the feed hopper.

Mass Flow Rate of Solids Transported Pneumatically from the Storage Silo to the Feed Hopper:

$$
\mathrm{M}_{\mathrm{S}}:=10000 \quad \mathrm{lb} / \mathrm{hr}
$$

Transfer Duration:

$$
\begin{aligned}
& \mathrm{t}_{\text {Transfer }}:=\frac{\mathrm{M}_{\text {Stream16.Day }}}{\mathrm{M}_{\mathrm{s}}} \\
& { }^{{ }_{\text {Transfer }}}=1.16 \quad \text { hr daily } \\
& { }^{\mathrm{t}_{\text {Transfer.min }}}:=\mathrm{t}_{\text {Transfer }} \cdot 60 \\
& { }^{\mathrm{t}}{ }_{\text {Transfer.min }}=70 \quad \text { Minutes }
\end{aligned}
$$

It takes approximately 70 minutes to transfer the daily load of Petoset-H from the storage silo to the feed hopper, thereby the assumption of $10,000 \mathrm{lb} / \mathrm{hr}$ is considered reasonable.

As described in sections 2.0 and 3.0, the dry Petroset-H is assumed to be transported by a positive pressure conveying system using ambient air in a dilute-phase conveying arrangement. Under this condition sufficient air stream velocity at low powder to air ratio is maintained that is greater than the saltation and choking gas velocities. The pipeline layout from the storage silo to the feed hopper assumes only horizontal and vertical runs and avoiding inclined lines. In addition:

1) a pipeline length of at least $30 \mathrm{D}$ (30 pipe diameters) after the solids in-feed point of the storage silo is assumed to allow particles to accelerate to the gas conveying velocity,

2) A length of at least $20 \mathrm{D}$ ( 30 pipe diameters) between bends are allowed to facilitate re-acceleration of the solids, and

3) all the pipeline components (e.g. elbows) have the same internal diameter to avoid formation of lips and edges.

4) A total of five 90 -deg bends in the pipeline layout is assumed to provide a conservative equivalent length pressure drop

A layout between the storage silo to the feed hopper assumes a 50 feet of horizontal length from the storage silo solids feed-in if confirmed to be above 30D pipeline length criteria, followed by a 30 -feet vertical elevation, and then a 50 -feet horizontal pipeline.

File: AEM-WRPS-2012-CN-014 Rev 0.xmcd 
Mass Flow Rate of Petroset-H Transported Pneumatically: $\quad \mathrm{M}_{\mathrm{S}} \quad \mathrm{lb} / \mathrm{hr}$

The conveying requirements of system are assumed to be:

Minimum Conveying Velocity:

$$
\mathrm{V}_{\min }:=70 \quad \mathrm{ft} / \mathrm{s}
$$

or

$$
\begin{aligned}
& \mathrm{V}_{\text {minHr }}:=\mathrm{V}_{\text {min }} \cdot 3600 \\
& \mathrm{~V}_{\text {minHr }}=2.52 \times 10^{5} \mathrm{ft} / \mathrm{hr}
\end{aligned}
$$

Minimum conveying gas velocity of $70 \mathrm{ft} / \mathrm{s}$ is chosen for many powders and granular solids in a dilute-phase mode.

The Solids Friction Factor:

The Solids Loading Ratio:

The Absolute Roughness of the Pipeline:

$$
\begin{array}{ll}
\lambda_{\mathrm{s}}:=0.02 & \text { dimensionless } \\
\phi:=7 & \text { dimensionless }
\end{array}
$$

$\varepsilon_{\mathrm{abs}}:=0.0005 \quad \mathrm{ft}$ (for smooth-bore steel pipeline)

Assuming Conveying gas is at $70 \mathrm{~F}$ air and the bulk gas density is

Ambient Air Conveying Gas at $70 \mathrm{~F}$ and Bulk Air Density:

$$
\rho_{\mathrm{g}}:=0.075 \quad \mathrm{lb}_{\mathrm{m}} / \mathrm{ft}^{3}
$$

Atmospheric Pressure:

$$
\mathrm{P}_{\mathrm{atm}}:=14.7 \quad \text { psi }
$$

Dynamic Air Viscosity:

$$
\mu_{\mathrm{g}}:=0.000012 \quad 1 \mathrm{~b}_{\mathrm{m}} / \mathrm{ft}-\mathrm{s}
$$

Air Mass Flow Rate:

$$
\mathrm{M}_{\mathrm{g}}:=\frac{\mathrm{M}_{\mathrm{S}}}{\phi}
$$$$
\mathrm{M}_{\mathrm{g}}=1.429 \times 10^{3} \quad \mathrm{lb} / \mathrm{hr}
$$$$
\mathrm{M}_{\text {g.minutes }}:=\frac{\mathrm{M}_{\mathrm{g}}}{60}
$$$$
\mathrm{M}_{\mathrm{g} \cdot \text { minutes }}=2.381 \times 10^{1} \quad \mathrm{lb} / \mathrm{min}
$$

Pipe Diameter Using Minimum Conveying Velocity:

$$
\begin{aligned}
& \mathrm{D}:=\left(\frac{4 \cdot \mathrm{M}_{\mathrm{g}}}{\rho_{\mathrm{g}} \cdot \pi \cdot \mathrm{V}_{\operatorname{minHr}}}\right)^{\frac{1}{2}} \\
& \mathrm{D}=0.31 \quad \mathrm{ft} \text { I.D. } \\
& \text { Or } \quad \mathrm{D}_{\text {inch }}:=\mathrm{D} \cdot 12 \quad \\
& \mathrm{D}_{\text {inch }}=3.72 \quad \text { in. I.D. }
\end{aligned}
$$

Using a $3.5 \mathrm{in.}$ Sch.40 pipe with and ID-3.548 in. At this smaller ID, the velocity will be slightly higher based on the ratio of the diameters squared. Recalculate the gas velocity based on the square of the ratio of the diameters 


$$
\begin{aligned}
& \mathrm{D}_{\mathrm{Sch} 40}:=3.548 \quad \text { in } \\
& \mathrm{D}_{\mathrm{ID}}:=\frac{3.548}{12} \quad \mathrm{D}_{\mathrm{ID}}=2.957 \times 10^{-1} \mathrm{ft}
\end{aligned}
$$

Corrected Air Velocity

$$
\mathrm{V}_{\mathrm{g}}:=\mathrm{V}_{\min } \cdot\left(\frac{\mathrm{D}_{\text {inch }}}{\mathrm{D}_{\mathrm{Sch} 40}}\right)^{2}
$$

Reynolds Number:

$$
\begin{aligned}
& \mathrm{R}_{\mathrm{e}}:=\frac{\mathrm{V}_{\mathrm{g}} \cdot \rho_{\mathrm{g}} \cdot \mathrm{D}_{\mathrm{ID}}}{\mu_{\mathrm{g}}} \\
& \mathrm{R}_{\mathrm{e}}=1.424 \times 10^{5}
\end{aligned}
$$

The Friction Factor from the Moody Diagram (Fluid Mechanics, page 313) is: $\mathrm{f}_{\mathrm{g}}:=0.023$

Minimum Required Length from the Solids feed-in Storage Silo:

$$
\begin{aligned}
& \mathrm{L}_{\text {feedmin }}:=30 \cdot \mathrm{D} \\
& \mathrm{L}_{\text {feedmin }}=9.3 \quad \mathrm{ft}
\end{aligned}
$$

Therefore it is conservative to assume a length of $30 \mathrm{ft}$ from the storage silo to the first 90 -deg bend Assumed Length from the Solids feed-in Storage Silo:

$$
\begin{aligned}
& \mathrm{L}_{\text {Feed }}:=50 \quad \mathrm{ft} \\
& \mathrm{L}_{\text {Vertical }}:=30 \quad \mathrm{ft} \\
& \mathrm{L}_{\text {Receiver }}:=50 \quad \mathrm{ft}
\end{aligned}
$$$$
\text { Assumed Vertical Pipeline Length: }
$$

Assumed Horizontal Length to the Feed Hopper:

Number of 90 -deg bends

$$
\mathrm{N}_{\text {bend }}:=5
$$

Equivalent Length of Elbow

$$
\begin{aligned}
& \mathrm{L}_{\text {eq.elbow }}:=30 \cdot \mathrm{D} \cdot \mathrm{N}_{\text {bend }} \\
& \mathrm{L}_{\text {eq.elbow }}=46.5 \quad \mathrm{ft}
\end{aligned}
$$

Equivalent Length of the System Pipeline: $\quad \mathrm{L}_{\text {eq.system }}:=\mathrm{L}_{\text {eq.elbow }}+\mathrm{L}_{\mathrm{Feed}}+\mathrm{L}_{\text {Vertical }}+\mathrm{L}_{\text {Receiver }}$

$$
\mathrm{L}_{\text {eq.system }}=176.5 \mathrm{ft}
$$

Actual Length of Pipeline, Straight Runs Only: $\quad \mathrm{L}_{\text {act }}:=\mathrm{L}_{\text {Feed }}+\mathrm{L}_{\text {Vertical }}+\mathrm{L}_{\text {Receiver }}$

$$
\mathrm{L}_{\text {act }}=130 \quad \mathrm{ft}
$$

Pressure Drop by the friction losses between the conveying gas and the pipe wall

Gravitational Constant:

$$
\begin{gathered}
\mathrm{g}_{\mathrm{c}}:=32.2 \quad 1 \mathrm{~b}_{\mathrm{m}} \mathrm{ft} / \mathrm{b}_{\mathrm{f}^{-\mathrm{s}}} \\
\Delta \mathrm{P}_{\mathrm{gf}}:=\mathrm{f}_{\mathrm{g}} \cdot \frac{\rho_{\mathrm{g}}}{\mathrm{g}_{\mathrm{c}}} \cdot \mathrm{V}_{\mathrm{g}}{ }^{2} \cdot\left(\frac{\mathrm{L}_{\text {eq.system }}}{2 \cdot \mathrm{D}_{\mathrm{ID}}}\right)
\end{gathered}
$$

File: AEM-WRPS-2012-CN-014 Rev 0.xmcd 
A E M Consulting, LLC. Calculation Set No.AEM-WRPS-2012-CN-014 Rev No. 0

$$
\Delta \mathrm{P}_{\mathrm{gf}}=9.498 \times 10^{1} \quad \mathrm{lb}_{\mathrm{f}} / \mathrm{ft}^{2}
$$

or

$$
\Delta \mathrm{P}_{\text {gfPsig }}:=\Delta \mathrm{P}_{\mathrm{gf}} \cdot 0.006944 \quad \Delta \mathrm{P}_{\text {gfPsig }}=0.66 \quad \text { psig }
$$

Assuming a slip ratio of 0.8 for the fine powder: $\quad$ Slip $:=0.8$

Velocity of Solids:

$$
\begin{aligned}
& \mathrm{V}_{\mathrm{S}}:=\mathrm{V}_{\mathrm{g}} \cdot \operatorname{Slip} \\
& \mathrm{V}_{\mathrm{S}}=6.165 \times 10^{1} \quad \mathrm{ft} / \mathrm{s}
\end{aligned}
$$

Pressure Drop due to the acceleration of solids from the feed point to the conveying velocity

$$
\begin{aligned}
& \Delta \mathrm{P}_{\mathrm{sa}}:=\phi \cdot\left(\frac{\rho_{\mathrm{g}}}{\mathrm{g}_{\mathrm{c}}}\right) \cdot \mathrm{V}_{\mathrm{s}} \cdot \mathrm{V}_{\mathrm{g}} \quad \Delta \mathrm{P}_{\mathrm{sa}}=7.746 \times 10^{1} \quad \mathrm{lb}_{\mathrm{f}} / \mathrm{ft}^{2} \\
& \text { or } \quad \Delta \mathrm{P}_{\text {saPsig }}:=\Delta \mathrm{P}_{\text {sa }} \cdot 0.006944 \quad \Delta \mathrm{P}_{\text {saPsig }}=0.538 \quad \text { psig }
\end{aligned}
$$

Pressure Drop due to moving solids through pipeline:

$$
\Delta \mathrm{P}_{\mathrm{sf}}:=\lambda_{\mathrm{s}} \cdot \phi \cdot\left(\frac{\rho_{\mathrm{g}}}{\mathrm{g}_{\mathrm{c}}}\right) \cdot \mathrm{v}_{\mathrm{g}}^{2} \cdot\left(\frac{\mathrm{L}_{\mathrm{act}}}{2 \cdot \mathrm{D}_{\mathrm{ID}}}\right) \quad \Delta \mathrm{P}_{\mathrm{sf}}=4.257 \times 10^{2} \quad \mathrm{lb}_{\mathrm{f}} / \mathrm{ft}^{2}
$$

or

$$
\Delta \mathrm{P}_{\text {sfPsig }}:=\Delta \mathrm{P}_{\text {sf }} \cdot 0.006944 \quad \Delta \mathrm{P}_{\text {sfPsig }}=2.956 \quad \text { psig }
$$

Pressure Drop due to lifting solids trough vertical conduits:

Acceleration By Gravity: $\quad \mathrm{g}_{\text {Gravity }}:=32.2 \mathrm{ft} / \mathrm{s}^{2}$

or

$$
\Delta \mathrm{P}_{\mathrm{s} 1}:=\phi \cdot \mathrm{g}_{\text {Gravity }} \cdot \mathrm{L}_{\text {Vertical }} \cdot \frac{\frac{\rho_{\mathrm{g}}}{\mathrm{g}_{\mathrm{c}}}}{\frac{\mathrm{V}_{\mathrm{s}}}{\mathrm{V}_{\mathrm{g}}}} \quad \Delta \mathrm{P}_{\mathrm{s} 1}=19.7 \quad 1 \mathrm{~b}_{\mathrm{f}} / \mathrm{ft}^{2}
$$

$$
\Delta \mathrm{P}_{\mathrm{slPsig}}:=\Delta \mathrm{P}_{\mathrm{sl}} \cdot 0.006944 \quad \Delta \mathrm{P}_{\mathrm{slPsig}}=0.137 \quad \text { psig }
$$

Pressure Drop due to movement of solids through bends:

$$
\begin{array}{rr}
\Delta \mathrm{P}_{\text {sb }}:=\mathrm{L}_{\text {eq.elbow }} \cdot\left(\frac{\Delta \mathrm{P}_{\text {sf }}}{\mathrm{L}_{\text {act }}}\right) & \Delta \mathrm{P}_{\text {sb }}=1.524 \times 10^{2} \\
\Delta \mathrm{P}_{\text {sbPsig }}:=\Delta \mathrm{P}_{\text {sb }} \cdot 0.006944 & \Delta \mathrm{P}_{\text {sbPsig }}=1.058 \quad \text { psig }
\end{array}
$$

File: AEM-WRPS-2012-CN-014 Rev 0.xmcd 
The Total Pressure Drop Of the System:

$$
\begin{aligned}
& \Delta \mathrm{P}_{\mathrm{T}}:=\Delta \mathrm{P}_{\text {gfPsig }}+\Delta \mathrm{P}_{\text {saPsig }}+\Delta \mathrm{P}_{\text {sfPsig }}+\Delta \mathrm{P}_{\text {slPsig }}+\Delta \mathrm{P}_{\text {sbPsig }} \\
& \Delta \mathrm{P}_{\mathrm{T}}=5.35 \text { psig }
\end{aligned}
$$

After the total pressure drop is calculated, the air velocity at the solid's feed point needs to be recalculated due to the higher pressure

$$
\rho_{\mathrm{g} . \text { Corr }}:=\rho_{\mathrm{g}} \cdot \frac{\Delta \mathrm{P}_{\mathrm{T}}+\mathrm{P}_{\mathrm{atm}}}{\mathrm{P}_{\mathrm{atm}}} \quad \rho_{\mathrm{g} \text {.Corr }}=0.1023 \quad \mathrm{lb}_{\mathrm{m}} / \mathrm{ft}^{3}
$$

The higher air density is due to the pressure drop through the system. With the corrected air density, a new air velocity is calculated to confirm the new velocity is within the range of pick up velocity for typical solids particles at defined pipeline diameter at the feed-in point.

$$
\begin{gathered}
\mathrm{V}_{\text {g.new }}:=\mathrm{V}_{\mathrm{g}} \cdot\left(\frac{\rho_{\mathrm{g}}}{\rho_{\text {g.Corr }}}\right) \\
\mathrm{V}_{\text {g.new }}=56.5 \quad \mathrm{ft} / \mathrm{s}
\end{gathered}
$$

In the absence of data for Petroset- $\mathrm{H}$ at the feed-in point, the new air velocity at $56.5 \mathrm{ft} / \mathrm{s}$ is judged reasonable for the pre-conceptual estimation. For example the $V_{\min }$ of air for fine powders is reported between $40-60 \mathrm{ft} / \mathrm{s}$ (Troubleshoot and Solve Pneumatic Conveying Problems), 33-36 ft/s for cement, and 43-53 ft/s for granular material (Pickup Velocity for Pneumatic Conveying).

The new velocity of $56.5 \mathrm{ft} / \mathrm{s}$ confirms the initial assumed Vmin of $70 \mathrm{ft} / \mathrm{s}$ provided a conservative pressure drop for selection of a gas mover using the calculated pipeline diameter.

The Volumetric air flow rate:

$$
\begin{aligned}
\mathrm{Q}_{\mathrm{g}} & :=\frac{\mathrm{M}_{\mathrm{g} \cdot \text { minutes }}}{\rho_{\mathrm{g}}} \\
\mathrm{Q}_{\mathrm{g}} & =317.5 \quad \mathrm{ft}^{3} / \mathrm{min} \text { at } 5.35 \mathrm{psig}
\end{aligned}
$$

Thus a multistage centrifugal blower or a positive-displacement rotary lobe Blower is suitable and a pneumatic conveying pipeline diameter (ID) of 3.548 inches Schedule 40 is used.

\section{Sample Load Estimate (duplicated from AEM-WRPS-2012-CN-013):}

Based on the sampling scheme shown on of Figure 1, RC samples are taken at the WTB for the WFE condensate and WFE concentrate. 
Number of RC Samples per Year per Modified Two Storage Tank WFE Concentrate Sample:

$$
\begin{aligned}
& \text { RCSample }_{2 \mathrm{~T}}:=\frac{\mathrm{Q}_{\text {Stream3.Day }} \cdot \text { Days }}{\mathrm{V}_{2 \mathrm{TModified}}} \\
& \text { RoundRCSample }_{2 \mathrm{~T}}:=\operatorname{round}\left(\mathrm{RCSample}_{2 \mathrm{~T}}\right) \\
& \text { RoundRCSample }_{2 \mathrm{~T}}=41 \quad \text { Samples WFE Concentrate/ yr }
\end{aligned}
$$

Number of RC Samples per Year per Modified Two Storage Tank WFE Condensate Sample:

It is assumed that a modified WFE condensate tank is filled to capacity and an RC sample is taken. Then the tank content is transferred to ISO tanks for storage while sampling analysis is performed.

$$
\begin{aligned}
& \text { RCSample }_{\text {WFECondensate }}:=\frac{\text { Q }_{\text {Stream8.Day }} \text { Days }}{\mathrm{V}_{\text {2TModified }}} \\
& \text { RCSample }_{\text {WFECondensate }}=142 \quad \text { Samples for Each WFE Condensate Storage Tank } / \mathrm{yr}
\end{aligned}
$$

\subsection{Use of Computer Software}

This calculation was performed using Mathcad, version 13.0 (Mathsoft Engineering \& Education, Inc.)

\subsection{Results}

\section{Alternative-3 Tank Storage Sizing (duplicated from AEM-WRPS-2012-CN-013) :}

In a two tank storage configuration using the design criteria the calculation indicate :

Minimum Feed Tank Volume at 80\% Storage Capacity: $V_{\text {FeedSize }}=3750$ gallons Size Capacity/ Storage Tank

WFE Condensate Tank Volume at $80 \%$ Storage Capacity:

$$
\mathrm{V}_{2 \mathrm{~T} . \text { Cond.Size }}=51030 \quad \text { gallons Size Capacity/WFE Condensate Storage Tank }
$$

WFE Concentrate Tank Volume at $80 \%$ Storage Capacity:

$$
\mathrm{V}_{2 \mathrm{~T} . \text { Conc. Size }}=14616 \quad \text { gallon Size Capacity/ WFE Concentrate Storage Tank }
$$

The tanks storage capacity and volumes are modified for all three staging operations when a portion of (if needed) storage is supplied also by ISO tanks for the 7days holding period. In this case each storage tank in a two tank storage system is assumed to hold the volumetric capacity of three ISO containers and thereby identical vessels are used for all stages of the Alternative- 2 processing.

An additional third storage vessel of equal capacity is included in the Feed storage configuration for blending of the off-normal downstream WFE concentrate with the feed batches if necessary.

File: AEM-WRPS-2012-CN-014 Rev 0.xmcd 
Modified Tank Volume at 80\% Storage Capacity:

$$
\mathrm{V}_{2 \mathrm{TM} \text { odifiedSize }}=18750 \quad \text { gallon Size Capacity/ Storage Tank }
$$

\section{Alternative-3 Wiped Film Evaporator Sizing (duplicated from AEM-WRPS-2012-CN-013):}

The Wiped Film evaporator (WFE) is sized to meet the WFE condensate rate of 4.05 gpm by using 2 units of Artisan Rototherm ${ }^{\circledR}$ horizontal thin film evaporator containing 50 square feet of heat transfer area operating in parallel configuration.

\section{Alternative 3- Heat Exchanger Sizing (duplicated from AEM-WRPS-2012-CN-013) :}

The heat exchanger design equation is used to calculate the required heat transfer surface area to condense the overhead WFE water vapor at $125^{\circ} \mathrm{F}$ to liquid water at $82^{\circ} \mathrm{F}$ at the overall heat transfer rate of $2,157,269.1 \mathrm{BTU} / \mathrm{hr}$. A countercurrent flow heat exchanger was selected for applying LMTD as the mean temperature difference in a basic heat exchanger design equation. The heat exchanger is assumed to be a shell and tube exchanger. It is configured that each WFE unit operates in series with a heat exchanger to produce a WFE condensate outflow. The combination of each of the two -WFE unit and heat exchanger- modules operating in parallel produce the design WFE condensate rate and the overall heat transfer rate.

$$
\text { Total Condenser Heat Transfer Area: } \quad \mathrm{A}_{\text {Heat.Transfer }}=1256 \quad \mathrm{ft}^{2}
$$

Heat Transfer Area per WFE and Heat Exchanger Module:

$$
\mathrm{A}_{\text {per.Module }}=628 \quad \mathrm{ft}^{2} / \text { Module of WFE and Heat Exchanger }
$$

\section{Alternative 3- Mixer Sizing:}

The mixer for mixing the dry Petroset-H with the WFE concentrate is sized based on the capacity of the Soft Sided container the mixture is gravity poured in to. A horizontal Ribbon Blenders with calculated full capacity of $135 \mathrm{ft}^{3}$ or 1010 gallon that is commercially available is estimated. The mixing is done in batch operation, and on a daily basis three Soft Sided containers are filled with $9480 \mathrm{lbs}$ or 808 gallons of the mixture to meet the daily generation of 1670 gallon of dry Petroset-H with the WFE concentrate .

Ribbon Blender Size at 80\% Fill Capacity:

$$
\begin{array}{llc}
\text { or } & \begin{array}{l}
\text { RBlender } \\
\text { Size }
\end{array}=135 \quad \mathrm{ft}^{3} \text { Full Capacity (equal to } 5 \mathrm{yd}^{3} \text { ) } \\
& \text { RBlender } \\
\text { Size.gal } & =1010 \quad \text { gallon Full capacity }
\end{array}
$$

A single mixer is required to produce approximately 3 batches of mixed Petroset-H with WFE concentrate per day at the equipment design processing rate. this allows approximately 8 hours to produce each mixer batch (fill with dry Perroset- $\mathrm{H}$, spray addition of WFE concentrate, mix for fifteen minutes, empty mixer to container, prepare mixer for next batch). An eight hour cycle was judged to be sufficient such that one mixer would be adequate to support the Alternative-3 operation.

\section{Alternative 3- Storage Silo, and Feed Hopper Sizing: \\ Both silo and hopper are shaped as a cylindrical top and a lower conical geometry operating in a mass flow pattern. Mass flow occurs when sloping hopper walls are smooth (low enough friction) and steep enough for particles to slide along them. To determine the hopper angle, $\theta_{\mathfrak{c}}$ (measured from vertical) in a mass flow hopper, an}

File: AEM-WRPS-2012-CN-014 Rev 0.xmcd 
angle of wall friction, $\phi^{\prime}$, between the bulk Petroset-H powder and the hopper surface is assumed by applying measurement conducted on clay powder using ASTM D-6128. Using a design chart for conical hoppers, the combination of $\phi^{\prime}$ at $28^{\circ}$, and $\theta_{c}$ at $20^{\circ}$ fell within the mass-flow region.

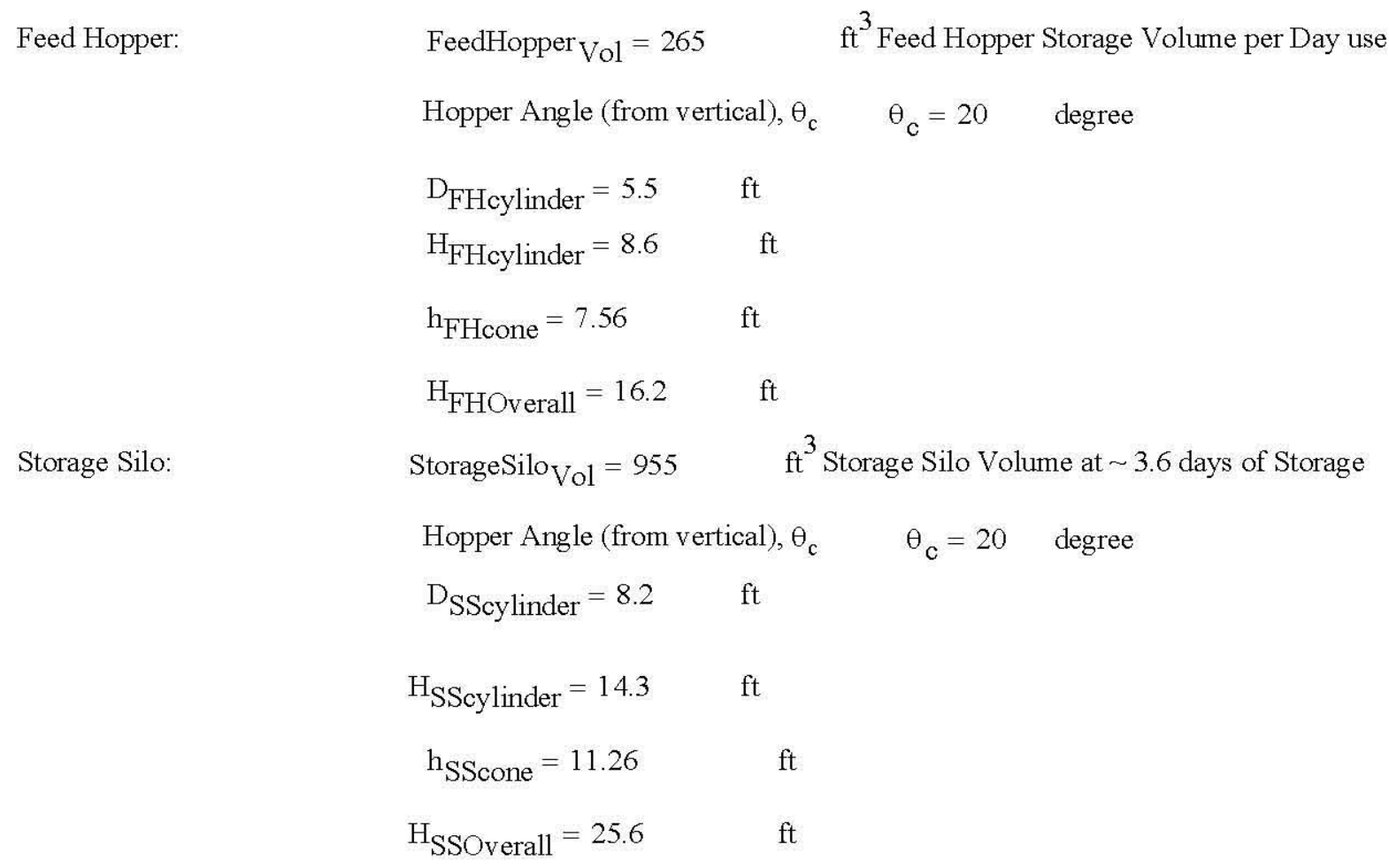

Daily mass of Petroset- $\mathrm{H}$ to be transferred from the storage silo to the feed hopper.

$$
\mathrm{M}_{\text {Stream16.Day }}=11642 \quad 1 \mathrm{~b} / \text { day }
$$

\section{Alternative 3- Pneumatic Conveying System Sizing:}

The pneumatic conveying system calculation was focused on system pipeline layout and the selection of the gas mover to provide the required gas flow rate for transporting solids at the proper velocity and pressure. The calculation assumed a positive pressure conveying system using ambient air in a dilute-phase conveying arrangement. The dry Petroset- $\mathrm{H}$ is pneumatically transferred from the storage silo to the feed hopper located above the mixer. The feed hopper is required to be filled daily a mass of $11,642 \mathrm{lbs}$ of dry Petroset-H. The conveying system is sized to transport $10.000 \mathrm{lb} / \mathrm{hr}$ of Petroset-H from storage silo to feed hopper that takes 70 minutes to be completed. The pipeline layout uses a $3.5 \mathrm{in}$. Sch. 40 pipe with an $\mathrm{ID}=3.548 \mathrm{in}$., and consist of 50 -feet of horizontal length from the storage silo solids feed-in, followed by a 30 -feet vertical elevation, and then a 50 -feet horizontal pipeline. A total pressure drop of the pneumatic conveying system was calculated to be $5.35 \mathrm{psig}$ in order to properly select the gas mover. A multistage centrifugal blower or a positive-displacement rotary lobe blower, operating at volumetric air flow rate of approximately $320 \mathrm{ft} 3 / \mathrm{min}$ (rounded) at $5.35 \mathrm{psig}$ is suitable for this application.

The Total Pressure Drop of the System:

The Volumetric air flow rate:

$$
\begin{array}{rlr}
\Delta \mathrm{P}_{\mathrm{T}} & =5.35 \quad \text { psig } \\
\mathrm{Q}_{\mathrm{g}}=317.5 \quad \mathrm{ft} 3 / \mathrm{min} \text { at } 5.35 \mathrm{psig}
\end{array}
$$




\section{Alternative 3 - Sample Load Estimated (duplicated from AEM-WRPS-2012-CN-013):}

The annual sample load estimate for the record control samples taken at the WTB for the WFE condensate tanks and WFE concentrate tanks are:

Number of RC Samples per Year per Modified Two Storage Tank WFE Concentrate Sample :

$$
\text { RoundRCSample }_{2 \mathrm{~T}}=41 \quad \text { Samples WFE Concentrate } / \mathrm{yr}
$$

Number of RC Samples per Year per Modified Two Storage Tank WFE Condensate Sample:

$$
\text { RCSample }_{\text {WFECondensate }}=142 \quad \text { Samples WFE Condensate } / \text { yr }
$$

\subsection{Conclusions}

The Alternative 3 equipment sizing was performed using the the throughput documented in SVF-2440 at 7500 gallon per day. The tanks storage capacity and volumes were modified for all three staging operations when a portion of (if needed) storage was supplied also by using ISO tanks. In this case each storage tank in a two tank storage system was sized to hold the volumetric capacity of three ISO containers and thereby identical vessels were used for all stages of the Alternative- 3 processing. An additional third storage vessel of equal capacity was included in the Feed storage configuration for blending of the off-normal downstream WFE concentrate with the feed batches if necessary.

The Wiped Film evaporator (WFE) was sized to meet the WFE condensate rate of 4.05 gpm by using 2 units of Artisan Rototherm ${ }^{\circledR}$ horizontal thin film evaporator operated in parallel. Each WFE provide 50 square feet of heat transfer area.

Horizontal Ribbon Blenders with calculated full capacity of $135 \mathrm{ft}^{3}$ or 1010 gallon that is commercially available is estimated for mixing the Petroset-H dry with the WFE concentrate.

The storage silo and feed hopper are shaped as a cylindrical top and a lower conical geometry operating in a mass flow pattern. Both hoppers angle, $\theta_{\mathfrak{c}}$, (measured from vertical) was estimated to be $20^{\circ}$. The storage silo volume is approximately $955 \mathrm{ft}^{3}$ with the dimension of $8.5 \mathrm{ft}$ in diameter, $13.9 \mathrm{ft}$ is cylindrical section height, $11.7 \mathrm{ft}$ in conical section height, and an overall $25.6 \mathrm{ft}$ tall. The feed hopper volume is approximately $265 \mathrm{ft}^{3}$ with the dimension of $5.5 \mathrm{ft}$ in diameter, $9.3 \mathrm{ft}$ is cylindrical section height, $7.6 \mathrm{ft}$ in conical section height, and an overall $16.8 \mathrm{ft}$ tall.

The pneumatic conveying system use a multistage centrifugal blower or a positive displacement rotary lobe blower, operating at volumetric air flow rate of approximately $320 \mathrm{ft} 3 / \mathrm{min}$ at $5.35 \mathrm{psig}$. The pipeline layout uses a $3.5 \mathrm{in}$. Sch. 40 pipe with an $\mathrm{ID}=3.548 \mathrm{in}$., and consist of 50-feet of horizontal length from the storage silo solids feed-in, followed by a 30 -feet vertical elevation, and then a 50 -feet horizontal pipeline. A total pressure drop of the pneumatic conveying system was calculated to be 5.35 psig.

\subsection{References}

24590-WTP-PL-PR-04-0001, 2008, Integrated Sampling and Analysis Requirements Document (ISARD), Rev 2, Bechtel National Inc., Richland, Washington.

AEM-WRPS-2012-CN-013, 2012, Alternative 2 Equipment Sizing Estimates, AEM Consulting, LLC, Richland, Washington.

File: AEM-WRPS-2012-CN-014 Rev 0.xmcd 
Cagli, A. S., 2007, Flow Property Measurement Using the Jenike Shear Cell for 7 Different Bulk Solids, Proceedings of European Congress of Chemical Engineers, Copenhagen, Denmark.

Maynard, E., 2010, Troubleshoot and Solve Pneumatic Conveying Problems, Chemical Engineering Progress, June 2010. American Institute of Chemical Engineers. New York, New York.

Mills, David, 2010, Pickup Velocity for Pneumatic Conveying, Powder/Bulk Solids Magazine, January 2010, UBM Canon Corp. Los Angeles, CA.

Mills, David, 2004, Pneumatic Conveying Design Guide, 2nd Edition, Elsevier Butterworth-Heinemann. , Oxford, United Kingdom.

Purutyan, H, 2001, Solve Solids Handling Problems by Retrofitting, Chemical Engineering Progress, June 2001. American Institute of Chemical Engineers. New York, New York.

Perry, R, 1984, Perry's Chemical Engineering Handbook, 6th edition, McGraw Book Company, New York, New York.

RPP-RPT-47443, 2011, Wiped Film Evaporator Full- Scale Demonstration System Test Report., Washington River Protection Solutions LLC, Richland, Washington.

SVF-2440, 2012, SBS Disposal PreConcept Alts. Rev 0, Washington River Protection Solutions LLC, Richland, Washington.

Welty, J. R, C. E. Wicks, R.E. Wilson, 1984, Fundamentals of Momentum, Heat, and Mass Transfer, John Wiley \& Sons, New York, New York.

White, F. M., 1986, Fluid Mechanics, 2nd edition, McGraw-Hills, Inc, New York, new York.

Woodcock, C.R., J. S. Mason, 1988, Bulk Solids Handling: An Introduction to the Practice and Technology, 1st edition, Chapman \& Hall, London, United Kingdom.

File: AEM-WRPS-2012-CN-014 Rev 0.xmcd 


\section{Appendix D \\ CALCULATION AEM-WRPS-2012-CN-015, LOW-ACTIVITY WASTE MELTER DECONTAMINATION FACTOR ADJUSTMENTS}


Subcontractor Calculation Review Checklist

Subject: AEM-WRPS-2012-CN-015, LAW Melter Decontamination Factor Adjustments

The subject document has been reviewed by the undersigned.

The reviewer reviewed and verified the following items as applicable.

Documents Reviewed: AEM-WRPS-2012-CN-015, LAW Melter Decontamination Factor Adjustments

Analysis Performed By: AEM Consulting, LLC

- Design Input

- Basic Assumption

- Approach/Design Methodology

- Consistency with item or document supported by the calculation

- Conclusion/Results Interpretation

- Impact on existing requirements

Reviewer (printed name, signature, and date) B. E. Chamberlain

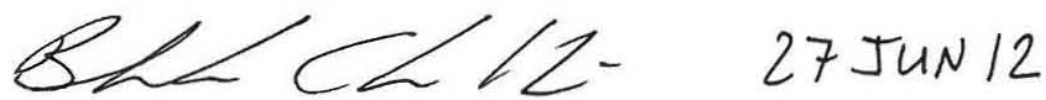

Organizational Manager (printed name, signature, and date) Martin Wheeler

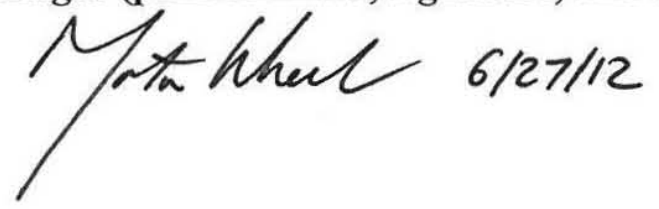




\begin{tabular}{|c|c|c|c|}
\hline \multirow{2}{*}{$\begin{array}{c}\text { A E M Consulting, LLC. } \\
\text { Calculation Note and } \\
\text { Peer Review }\end{array}$} & \multicolumn{2}{|c|}{$\begin{array}{l}\text { Calculation Sel No. } \\
\text { AEM-WRPS-2012-CN-015 }\end{array}$} & $\begin{array}{l}\text { Rev No. } \\
\quad 0\end{array}$ \\
\hline & \multicolumn{3}{|c|}{ End Use: Pre-conceptual Design } \\
\hline Project: SBS Direct Disposal Allernatives & \multicolumn{3}{|c|}{ Sheet 1 of 12} \\
\hline Discipline: Process & \multicolumn{3}{|c|}{ Contract No: WRPS 48504 Line Item 2} \\
\hline Structure or System: NA & \multicolumn{3}{|c|}{ Reserved } \\
\hline \multicolumn{4}{|l|}{ Subject: LAW Melter Decontamination Factor Adjustments } \\
\hline \multicolumn{2}{|l|}{ Completed by: A Pajunen } & Date $5 / 9$ & \\
\hline \multicolumn{2}{|l|}{ Checked by: R. Lokken tjau O Trhere } & Date $5 / 9 / 1$ & \\
\hline \multicolumn{2}{|l|}{ Approved by (LEE or Depertmert Meboger) } & Date $6 / 4$ & \\
\hline \multicolumn{4}{|l|}{ Distribution: NA } \\
\hline \multirow[t]{2}{*}{$\begin{array}{l}\text { Reason for Revision: } \\
\text { Not applicable, initial release. }\end{array}$} & & $\begin{array}{l}\text { Total numbe } \\
\text { issue: } 12\end{array}$ & ts in this \\
\hline & & $\begin{array}{l}\text { Sheets revis } \\
\text { NA }\end{array}$ & ed or deleted: \\
\hline \multicolumn{4}{|c|}{$\begin{array}{l}\text { Problem Statement: } \\
\text { Estimate the potential uncertainty of }{ }^{90} \mathrm{Sr} \text { and }{ }^{241} \mathrm{Am} \text { concentrations in SBS condensate modeling predictions }\end{array}$} \\
\hline \multicolumn{4}{|c|}{$\begin{array}{l}\text { Summary Conclusions: } \\
\text { Average values from test data used in modeling the LAW Melter decontamination factor are based on an approach } \\
\text { that produces the most conservative estimale (highest estimate) of components transmitted to the melter off gas. } \\
\text { Alternate averaging approaches indicate that feed components transmitted to the melter off gas may be a factor of } \\
10 \text { less for }{ }^{90} \mathrm{Sr} \text { and a factor of } 2 \text { less for }{ }^{241} \mathrm{Am} \text { compared to that predicted using decontamination factors used in } \\
\text { HTWOS modeling studies. }\end{array}$} \\
\hline \multicolumn{4}{|c|}{$\begin{array}{l}\text { Design Basis: } \\
\text { Primary basis begins with HTWOS modeling predictions of SBS condensate compositions and evaluates potential } \\
\text { variability that may exist in inputs used to produce the composition predictions. }\end{array}$} \\
\hline
\end{tabular}




\section{Contents}

$1.0 \quad$ Objective/Purpose

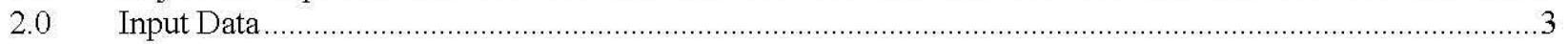

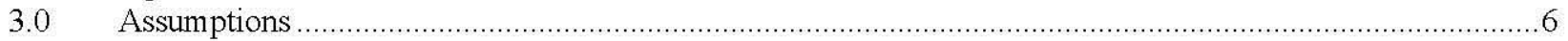

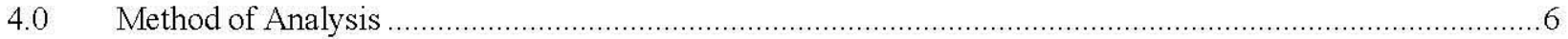

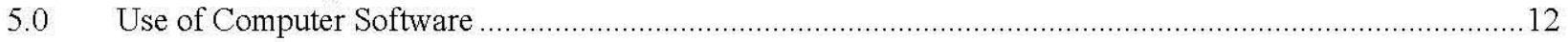

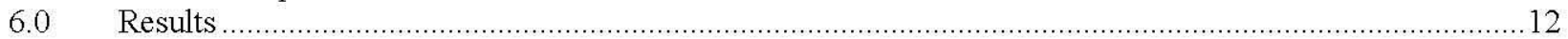

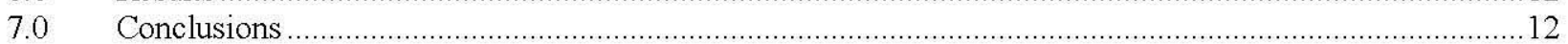

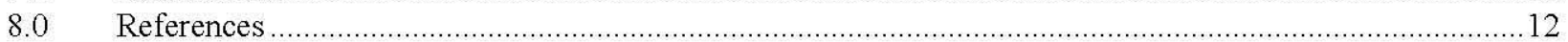

\section{List of Figures}

Figure 1-1. Description of Low Activity Glass Melter Splits Used in Material Flow Modeling .........................3 Figure 4-1. LAW Melter Non-Volatile Component Decontamination Factor Comparison to Averages.............10 Figure 4-2. LAW Melter Semi-Volatile Decontamination Factor Component Comparison to Averages. ..........11

\section{List of Tables}

Table 2-1. Summary of ${ }^{90} \mathrm{Sr}$ and ${ }^{241} \mathrm{Am}$ LAW Melter Decontamination Factors in Alternative Modeling

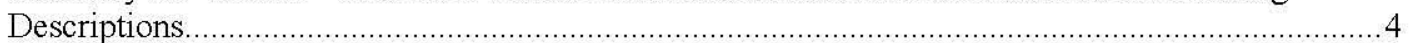

Table 2-2. Average LAW Melter Decontamination Factors from Simulant Test Data. ...................................5

Table 2-3. Calculated Average Non-Volatile, Semi-Volatile, and Volatile LAW Melter Decontamination

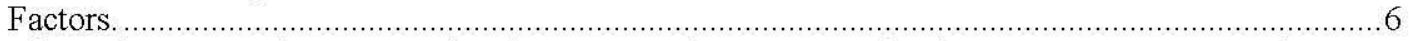

Table 4-1. Alternative Averaging Approaches for LAW Melter Decontamination Factor Component Bins.......9 Table 6-1. Summary of Potential Changes to ${ }^{90} \mathrm{Sr}$ and ${ }^{241} \mathrm{Am}$ LAW Melter Decontamination Factors..............12

\subsection{Objective/Purpose}

Preliminary calculations indicate that the predicted concentration of ${ }^{90} \mathrm{Sr}$ (and possibly ${ }^{241} \mathrm{Am}$ ) potentially limits the volume reduction of as-generated Submerged Bed Scrubber (SBS) condensate that could be achieved in a direct offsite disposal scenario based on limiting the transported material characteristics to Class A radionuclide characteristics. The condensate of interest is generated in the Waste Treatment and Immobilization Plant (WTP) Low Activity Waste (LAW) vitrification facility. The SBS condensate is produced during treatment of off gas from an LAW melter. Therefore, the mass rate of feed components transmitted to the melter off gas during glass production directly influences the mass rate of components captured by the off gas treatment equipment and resulting contaminate concentrations in SBS condensate. The purpose of this calculation is to estimate the potential uncertainty of ${ }^{90} \mathrm{Sr}$ and ${ }^{241} \mathrm{Am}$ concentrations in SBS condensate modeling predictions.

Figure 1-1 provides a simplified sketch of a glass melter material balance, where each feed component entering a glass melter is distributed between the glass product and off gas. The mass rate of contaminants transmitted to the melter off gas is predicted by computer models that use split factors to estimate the path of components through a LAW melter and a major fraction of the contaminants transmitted to the off gas are subsequently captured in the SBS condensate. 


\section{Figure 1-1. Description of Low Activity Glass Melter Splits Used in Material Flow Modeling.}

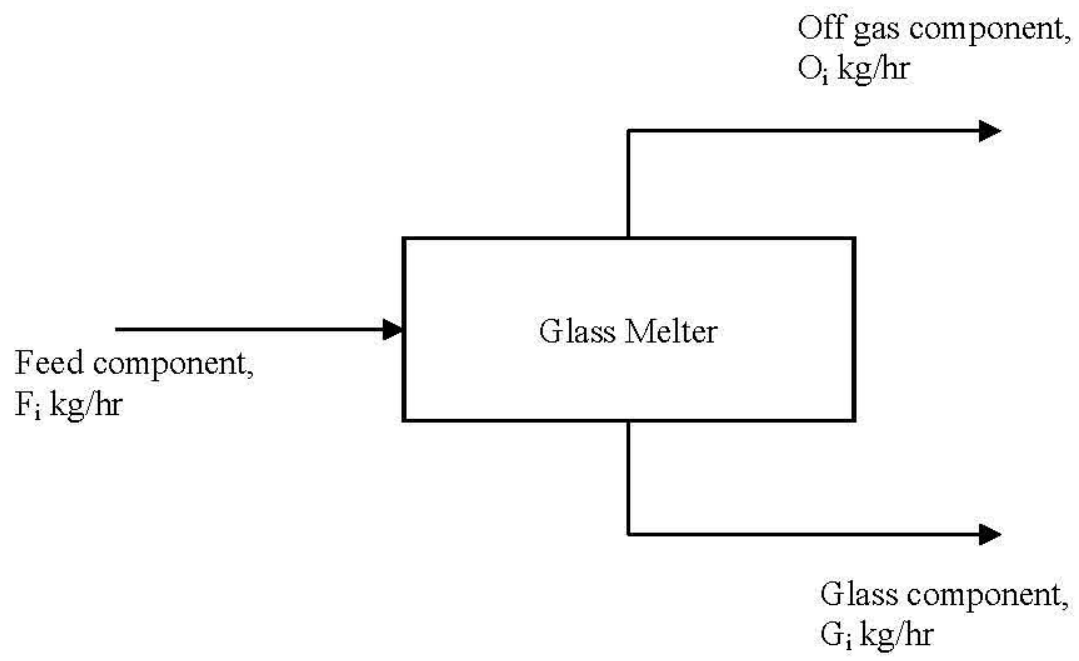

Equation (1-1) provides the definition of a decontamination factor based on the nomenclature shown in Figure 1-1. Separate decontamination factors are defined for each component tracked by material balance models. It should also be recognized that some models track the path of components through unit operations using a "fraction of feed to vapor" definition, which is equivalent to the inverse of the decontamination factor (1/DFi) shown in Equation (1-1).

$$
D F_{i}=\frac{F_{i}}{O_{i}}
$$

where: $F_{i} \quad=$ mass rate of component $i$ entering the glass melter, $\mathrm{kg} / \mathrm{hr}$

$\mathrm{O}_{\mathrm{i}} \quad=$ mass rate of component $\mathrm{i}$ leaving the glass melter in the off gas, $\mathrm{kg} / \mathrm{hr}$

$\mathrm{DF}_{\mathrm{i}} \quad=$ decontamination factor describing the path of component $\mathrm{i}$ through the melter, dimensionless

\subsection{Input Data}

Table 2-1 provides a summary of LAW melter decontamination factors used as a basis for modeling ${ }^{90} \mathrm{Sr}$ and ${ }^{241} \mathrm{Am}$ material flows through a LAW melter. Three alternatives are shown in Table 2-1. The first source is based on the model design document for HTWOS (RPP-17152, Hanford Tank Waste Operations Simulator (HTWOS)Version 6.6.1 Model Design Document) and represents the basis for system planning model runs used to predict SBS condensate compositions for evaluating the SBS condensate direct disposal alternatives. The RPP-17152 decontamination factors are referenced to the Envelope A values described in Revision 5 of 24590-WTP-RPT-PT005, Flowsheet Bases, Assumptions, and Requirements. The decontamination factors listed in 24590-WTP-RPTPT-005 were updated in 2011 (Revision 6) and have not yet been incorporated in the basis for system planning documents. Table 2-1 indicates that the latest estimates for ${ }^{90} \mathrm{Sr}$ and ${ }^{241} \mathrm{Am}$ decontamination factors were not significantly modified between Revision 5 and 6 of 24590-WTP-RPT-PT-02-005. 
Table 2-1. Summary of ${ }^{90} \mathrm{Sr}$ and ${ }^{241} \mathrm{Am}$ LAW Melter Decontamination Factors in Alternative Modeling Descriptions.

\begin{tabular}{|c|c|c|c|}
\hline Component & \multicolumn{2}{|c|}{ Fraction of Feed to Vapor } & Decontamination Factor \\
\hline${ }^{90} \mathrm{Sr}, \mathrm{Sr}^{+2}$ & \multicolumn{2}{|c|}{0.00909} & 110 \\
\hline${ }^{241} \mathrm{Am}$ & \multicolumn{2}{|c|}{0.01754} & 57 \\
\hline \multicolumn{4}{|c|}{$\begin{array}{l}\text { Source: Table A-3 of RPP-17152, Hanford Tank Waste Operations Simulator (HTWOS)Version 6.6.1 Model } \\
\text { Design Document, Rev } 6 .\end{array}$} \\
\hline \multirow{2}{*}{ Component } & \multicolumn{3}{|c|}{ Decontamination Factors } \\
\hline & Envelope A & Envelope B & Envelope C \\
\hline${ }^{90} \mathrm{Sr}, \mathrm{Sr}^{+2}$ & 110 & 660 & 170 \\
\hline${ }^{241} \mathrm{Am}, \mathrm{Am}^{+3}$ & 57 & 110 & 88 \\
\hline \multicolumn{4}{|c|}{ Source: Table 3.2-2 of 24590-WTP-RPT-PT-02-005, Flowsheet Bases, Assumptions, and Requirements, Rev } \\
\hline \multirow{2}{*}{ Component } & \multicolumn{3}{|c|}{ Decontamination Factors } \\
\hline & Envelope A & Envelope B & Envelope C \\
\hline${ }^{90} \mathrm{Sr}, \mathrm{Sr}^{+2}$ & 106 & 570 & 136 \\
\hline${ }^{241} \mathrm{Am}, \mathrm{Am}^{+3}$ & 54 & 103 & 77 \\
\hline
\end{tabular}

The basis for the latest estimates of LAW melter decontamination factors is described in 24590-WTP-M4C-V37T00008, Reconciliation of HLW and LAW Melter Decontamination Factors. 2490-WTP-M4C-V37T-00008 begins with recognizing that simulant test data do not contain all the components predicted to be present in melter feed by computer models. An averaging approach is described in 24590-WTP-M4C-V37T-00008 which is used as a basis for decontamination factor estimates for components where no specific test data are available (neither $\mathrm{Sr}$ or Am data are available from LAW melter tests).

The averaging approach begins by assigning components to one of three volatility bins: non-volatile (NV), semivolatile (SV), or volatile (V). Components are assigned to volatility bins based on element melting point and boiling points, relative to an average melter pool temperature of $\sim 1150^{\circ} \mathrm{C}$. 24590 -WTP-M4C-V37T-00008 uses the following basis for volatility bin assignment:

- Non-volatile bin - $T_{m p}^{\text {comp }}>T_{\text {pool temp }}$

- Semi-volatile bin - $T_{m p}^{\text {comp }}<T_{\text {pool temp }}$ and $T_{b p}^{\text {comp }}>T_{\text {pool temp }}$

- Volatile bin - $T_{b p}^{\text {comp }}<T_{\text {pool temp }}$

Table 2-2 summarizes components included in LAW glass melter test data. Based on the 24590-WTP-M4C-V37T00008 evaluation, the test data components were assigned to the following bins:

- Non-volatile (NV) bin components: $\mathrm{Al}, \mathrm{Ca}, \mathrm{Cd}, \mathrm{Cr}, \mathrm{Fe}, \mathrm{Li}, \mathrm{Mg}, \mathrm{Ni}, \mathrm{Se}, \mathrm{Te}, \mathrm{Zn}, \mathrm{Zr}$.

- Semi-volatile (SV) bin components: B, B(s), K, Na, P, Pb.

- Volatile (V) bin components: Cl(s), Cl, Cs, F(s), F, I(s), I, Re, S(s), S, Se(s), Se, $\mathrm{NH}_{4}$.

Listings in Table 3.2-2 of 24590-WTP-RPT-PT-02-005, Rev 6, indicate that the components ${ }^{90} \mathrm{Sr} / \mathrm{Sr}^{+2}$ were assigned to the non-volatile decontamination factor bin and ${ }^{241} \mathrm{Am} / \mathrm{Am}^{+3}$ were assigned to the semi-volatile bin. 
A E M Consulting, LLC.

Calculation Set No. AEM-WRPS-2012-CN-015 Rev No. 0

Sheet 5 of 12

Table 2-2. Average LAW Melter Decontamination Factors from Simulant Test Data.

\begin{tabular}{|c|c|c|c|c|c|c|c|c|c|c|c|c|c|c|c|}
\hline & GW & GX & GY & $\mathrm{GZ}$ & HA & $\mathrm{HB}$ & $\mathrm{HC}$ & $\mathrm{HD}$ & HE & HF & $\mathrm{HG}$ & $\mathrm{HH}$ & Hil & $\mathrm{H}_{3}$ & $H K$ \\
\hline 1 & & & & EnvA & EnV B & EnvC & & & & & & & & & \\
\hline 2 & & Volability & & Ave DF & Ave DF & Ave DF & & Volatility & Envelope $A$ & & Ervelope B & & Envelape C & & \\
\hline 3 & & & & $=U 4$, et al & $\mathrm{FQ4}$, ot. al & GQ4, ot al. & & & DF & $1 / \mathrm{DF}$ & DF & $1 / \mathrm{DF}$ & DF & 1/DF & \\
\hline 4 & & NV & Al & 523.7 & 2754.5 & 1382.0 & & NV & 13.64 & 0.0733388 & 85.3 & 0.011722 & 15.81 & 0.0632466 & \\
\hline 5 & & SV & $B(5)$ & 133.8 & 347.0 & 202.3 & & NV & 106.33 & 0.0094048 & 651.17 & 0.001536 & 188.35 & 0.0053093 & \\
\hline 6 & & $\mathrm{NV}$ & $\mathrm{Ca}$ & 803.8 & 2045.7 & 1135.5 & & NV & 104,9 & 0.0095372 & 7819 & 0.001279 & 253.56 & 0.0039438 & \\
\hline 7 & & NV & $\mathrm{Cd}$ & 117.0 & & & & NV & 117.0 & 0.008547 & 1009.0 & 0.000991 & 434.3 & 0.0023026 & \\
\hline 8 & & 60 & $\mathrm{Cl}(\mathrm{s})$ & 2.1 & 3.9 & 27 & & NV & 537.3 & 0.0018613 & 1504.2 & 0.000639 & 511,3 & 0.0019556 & \\
\hline 9 & & $\mathrm{NV}$ & $\mathrm{Cr}$ & 13.6 & 85.3 & 15.8 & & NV & 338.9 & 0.0029505 & 20457 & 0.000489 & 675.94 & 0.0014794 & \\
\hline 10 & & $v$ & Cs & 6.6 & 42.6 & 13.9 & & NV & 350,1 & 0.0028565 & 2754.5 & 0.000363 & 1135.5 & 0,0008807 & \\
\hline 11 & & vo & $F(s)$ & 2.8 & 9.0 & 8,1 & & NV & 523.7 & 0,0019095 & 2833.8 & 0.000353 & 1382.0 & 0,0007236 & \\
\hline 12 & & $\mathrm{NV}$ & $\mathrm{Fe}$ & 537.3 & 1564.2 & 675.9 & & NV & 858.1 & 0.0011654 & 11619.4 & $8.61 \mathrm{E}-05$ & 1750.6 & 0.0005712 & \\
\hline 13 & & wo & I(s) & 63.0 & 2035.6 & 185.5 & & NV & 803.8 & 0.0012441 & 11395.2 & $878 \mathrm{E}-05$ & 5632.4 & 0.0001775 & \\
\hline 14 & & SV & $\mathrm{K}$ & 19.6 & 67.6 & 22.1 & & NV & 6352.1 & 0.0001574 & & & 6191.5 & 0,0001615 & \\
\hline 15 & & $\overline{N N}$ & 4 & 104.9 & 6512 & 253.6 & & NV & 4600.7 & 0.0002174 & & & NA & & \\
\hline 16 & & N & $\mathrm{Mg}$ & 6352.1 & 11395.2 & 6181.5 & & SV & 19.61 & 0.0509914 & 50.42 & 0.019835 & 22.05 & 0.045348 & \\
\hline 17 & & SV & $\mathrm{Na}$ & 77.5 & 256.1 & 129.9 & & SV & 39.77 & 0.0251438 & 67.64 & 0.014784 & 103.42 & 0.0096697 & \\
\hline 18 & & N & $\mathrm{Ni}$ & 106.3 & & 188.3 & & SV & 84.19 & 0.0118774 & 114.46 & 0.008737 & 156.69 & 0.0063822 & \\
\hline 19 & & SV & $P$ & 84.2 & 114.5 & 156.7 & & SV & 77.47 & 0.0129087 & 119.84 & 0.008345 & 129.93 & 0.0076965 & \\
\hline 20 & & SV & $\mathrm{Pb}$ & 39.8 & 50.4 & 103.4 & & SV & 133.76 & 0.0074758 & 347.02 & 0.002882 & 282.31 & 0.0035422 & \\
\hline 21 & & V & Re & 2.1 & 18 & 1.4 & & SV & 326.72 & 0.0030608 & 256.07 & 0.003905 & 195.71 & 0.0051097 & \\
\hline 22 & & $\mathrm{v}$ & $\mathbf{S}(\mathbf{s})$ & 7.7 & 16.2 & 7.7 & & V & 1.6 & 0.625 & 1.75 & 0.570846 & 1.44 & 0.6924603 & \multirow{13}{*}{$\mathrm{V}+\mathrm{v} 0$} \\
\hline 23 & & V & $\mathrm{Se}(\mathrm{s})$ & 3.4 & & & & $\mathrm{~V}$ & 2.11 & 0.4730426 & 4.5 & 0.223112 & 7.72 & 0.1295591 & \\
\hline 24 & & NW & Si & 858.1 & 283338 & 1750.6 & & $\mathrm{~V}$ & 3.40 & 0.2941176 & 16.16 & 0,061885 & 13.90 & 0.0719203 & \\
\hline 25 & & WV & $\pi$ & 338.9 & 1009.0 & 4343 & & V & 6.59 & 0.1518207 & 42.55 & 0.023501 & 29.56 & 0.0338251 & \\
\hline 26 & & N & $\mathrm{Zn}$ & 350.1 & 781.9 & 511.3 & & V & 7.67 & 0.1304364 & & & & & \\
\hline 27 & & $\mathrm{NW}$ & $\mathrm{Zr}$ & 4600.7 & 11619.4 & 5632.4 & & V & 56 & 0.0178623 & & & & & \\
\hline 28 & & SV & $\mathrm{B}$ & 326.7 & 119.8 & 195.7 & & $\mathrm{~V}$ & 667.0 & 0.0014993 & & & & & \\
\hline 29 & & vo & $\mathrm{Cl}$ & 38.2 & 1.7 & 10.4 & & Vo & 284 & 0.3525705 & 3.90 & 0.25611 & 2.75 & 0.3642936 & \\
\hline 30 & & $\mathrm{V0}$ & $F$ & 5.7 & 3.1 & 73 & & Vo & 2.13 & 0.4687932 & 9.0 & 0.110696 & 8.1 & 0.1234759 & \\
\hline 31 & & vo & 1 & 2.5 & 1.4 & 1.6 & & vo & 63.01 & 0.0158695 & 2035.6 & 0.000491 & 185.5 & 0.0053919 & \\
\hline 32 & & V & $\mathbf{s}$ & 56.0 & 4.5 & 29.6 & & vo & 2.46 & 0.4062843 & 1.42 & 0.704439 & 1.61 & 0.6216317 & \\
\hline 33 & & $\mathrm{~V}$ & $\mathrm{Se}$ & 667.0 & & & & V0 & 5.70 & 0.1755737 & 1.66 & 0.603889 & 10.45 & 00956939 & \\
\hline 34 & & V & $\mathrm{NH}_{4}$ & 1.6 & & & & V0 & 38.19 & 0.0261818 & 3,13 & 0.319118 & 7.30 & 0.1370012 & \\
\hline
\end{tabular}

Source: 24590-WTP-M4C-V37T-00008, Rev 0, Sheet No. D-9.

24590-WTP-M4C-V37T-00008 describes an averaging approach used to determine an average decontamination factor for each bin. Individual component decontamination factors are obtained from LAW melter simul ant test data. The component decontamination factors assigned to one of the three bins are averaged and the resulting average is assumed to represent the decontamination factor for components included in the same bin, but not included in simulant test feed.

Equation (2-1) indicates the equation used by 24590 -WTP-M4C-V37T-00008 to approximate non-volatile, semivolatile, and volatile component average decontaminati on factors. The bin decontamination factors are based on averaging the fractions of a feed component transmitted to the off gas observed during tests.

$$
D F_{\text {avg }}=\frac{N}{\sum_{i=1}^{N}\left(\frac{1}{D F_{i}}\right)}
$$

where: $\mathrm{DF}_{\mathrm{i}} \quad=$ the successive $\mathrm{DF}$ 's to be averaged, dimensionless

$\mathrm{N}=$ net number of DF's to be counted, dimensi onless

$\mathrm{DF}_{\mathrm{avg}}=$ average decontamination factor, dimensionless 
It shoul $\mathrm{d}$ be noted that Equation (2-1) is gener ally applied to most components in the component list. Some special case evaluations were performed in 24590-WTP-M4C-V37T-00008 for selected volatile components. In addition, the averaging approach is applied at multiple points in the evaluation. When a particular test contains multiple runs, the decontamination factor observed for each component is averaged usingE quation (2-1) to calculate a test average for each test. The decontamination factors are then averaged over multiple tests using Equation (2-1) to produce an owerall average from test data for each component. The components are then binned and the decontamination factors for the multiple components in a bin aver aged using Equation (2-1) to determine decontamination factors for the non-vol atile, semi-volatile, and vol atile components. Table 2-3 summ arizes the results from the averaging procedures.

Table 2-3. Calculated Average Non- Volatile, Semi-Vobtile, and Volatile LAW Melter Decontamimation Factors.

\begin{tabular}{|c|c|c|c|}
\hline $\mathrm{HL}$ & HM & HN & $\mathrm{HO}$ \\
\hline & Average of & Average of & Average of \\
\hline & Env A & Env B & Envc \\
\hline \multicolumn{4}{|c|}{ Species } \\
\hline NV & 106 & 570 & 136 \\
\hline SV & 54 & 103 & 77 \\
\hline V & 4.1 & 3.5 & 4.4 \\
\hline & & & \\
\hline & & & \\
\hline & & & \\
\hline NV & Non-volatile & & \\
\hline SV & Semi-volatile & & \\
\hline V & Volasile & & \\
\hline
\end{tabular}

Source: 24590-WTP-M4C-V 37T-00008, Rev0, Sheet No. D-9.

24590-WTP-M4C-V37T-00008 also describes an awerage Sr decontamination factor of $\sim 90$ derived from HLW melter test observations, where individual tests ranged fr om 55 to 438 .

\subsection{Assumptions}

1. Alternative methods of averaging test data bimed by 24590 -WTP-M4C-V37T-00008 approx im ate the potential range of individual component decontamination factors that may be observed churing operation of anLAW melter.

\subsection{Method of Analysis}

Individual component decontamination factors within each bin identified by 24590-WTP-M4C-V37T-00008 can vary over multiple orders of magnitude. Therefore, the approach used to determine an average of decontamination factors can influence the value used to estim ate factors applied to other components in a volatility bin. Three alternative methods of aver aging decontamination factors are considered below. The alternate averages are then 
used as a guide for the potential range of decontamination factor for components in a bin that may be observed for an individual component that was not included in test simulant.

Averaging Alternative 1 is shown by Equation (4-1) and describes a typical arithmetic average of the observed decontamination factors for components in a bin. In this case, the arithmetic average is shown to represent an average value that minimizes the sum of the squares of differences between the single average value and the various values being averaged.

$$
\begin{gathered}
\text { Sum } 1=\sum_{i=1}^{N}\left(X_{i}-\bar{X}\right)^{2} \\
\frac{d(\operatorname{Sum} 1)}{d \bar{X}}=2\left(X_{1}-\bar{X}\right)(-1)+\cdots+2\left(X_{N}-\bar{X}\right)(-1) \\
=-2 \sum_{i=1}^{N}\left(X_{i}-\bar{X}\right)
\end{gathered}
$$

Sum 1 is at a minimum when $\left|\frac{d(\text { Sum } 1)}{d \bar{X}}\right|=0$, which occurs when:

$$
\begin{gathered}
0=\sum_{i=1}^{N}\left(X_{i}-\bar{X}\right) \\
0=\sum_{i=1}^{N}\left(X_{i}\right)-N \bar{X} \\
N \bar{X}=\sum_{i=1}^{N}\left(X_{i}\right) \\
\bar{X}=\frac{\sum_{i=1}^{N}\left(X_{i}\right)}{N}
\end{gathered}
$$

where: Sum $1=$ the sum of the squares of the indicated differences

$\mathrm{N} \quad=$ the number of points being averaged

$\bar{X} \quad=$ average value of a series of numbers

$\mathrm{X}_{\mathrm{i}} \quad=$ series of numbers to $\mathrm{b}$ e averaged

Averaging Alternative 2 is shown by Equation (4-2) and describes an arithmetic average of the inverse of observed decontamination factors for components in a bin. This averaging approach is equivalent to the method used in 24590-WTP-M4C-V37T-00008 and produces a result consistent with Equation (2-1). In this case, the result is consistent with an arithmetic average for the fraction of a feed component transmitted to the melter off gas and minimizes the sum of the squares of differences between the single average inverse of the decontamination factor and the various inverse values being averaged. An average decontamination factor is then found by inverting the average inverse value. 


$$
\begin{gathered}
\text { Sum } 2=\sum_{i=1}^{N}\left(\frac{1}{X_{i}}-\frac{1}{\bar{X}}\right)^{2} \\
\text { Sum2 is at a minimum when }\left|\frac{d(\operatorname{sum} 2)}{d \bar{X}}\right|=0, \text { which occurs when: } \\
0=\sum_{i=1}^{N}\left(\frac{1}{X_{i}}-\frac{1}{\bar{X}}\right) \\
0=\sum_{i=1}^{N}\left(\frac{1}{X_{i}}\right)-N\left(\frac{1}{\bar{X}}\right) \\
N\left(\frac{1}{\bar{X}}\right)=\sum_{i=1}^{N}\left(\frac{1}{X_{i}}\right) \\
\left(\frac{1}{\bar{X}}\right)=\frac{\sum_{i=1}^{N}\left(\frac{1}{X_{i}}\right)}{N} \\
\bar{X}=\frac{N}{\sum_{i=1}^{N}\left(\frac{1}{X_{i}}\right)}
\end{gathered}
$$

Averaging Alternative 3 is based on the weighting function shown by Equation (4-3). In this case, an average is found by minimizing the sum of the squares of a difference based on the value logarithms. This is typically determined using a numerical procedure, or trial and error calculation.

$$
\text { Sum } 3=\sum_{i=1}^{N}\left(\operatorname{Ln}\left(X_{i}\right)-\operatorname{Ln}(\bar{X})\right)^{2}
$$

Table 4-1 provides a summary of the LAW melter decontamination factors reported in 24590-WTP-M4C-V37T00008 for the non-volatile and semi-volatile bins used as the basis for average decontamination factors in modeling studies. Average decontamination factors were calculated for the volatility bins using each of the three averaging approaches. Note that non-volatile and semi-volatile average decontamination factors reported in 24590-WTPM4C-V37T-00008 were duplicated using Averaging Alternative 2.

Figure 4-1 provides a plot of the non-volatile component values and compares the individual decontamination factors with the three alternative averaging approaches. The plots are shown based on both linear and logarithmic scales to emphasize the comparison characteristics. The comparison indicates that higher numerical values dominate the calculated average decontamination factor using Averaging Alternative 1. Lower numerical values dominate the calculated average decontamination factor using Averaging Alternative 2 and produces the most conservative estimate of an average decontamination factor. Averaging Alternative 3 produces an average that is intermediate between the Averaging Alternatives 1 and 2. Averaging Alternative 3 is similar to approximating a median value as the decontamination factor average.

Figure 4-2 provides a similar comparison between the semi-volatile component values and the alternative averaging approaches. 
A E M Consulting, LLC.

Calculation Set No. AEM-WRPS-2012-CN-015 Rev No. 0

Sheet 9 of 12

Table 4-1. Alternative Averaging Approaches for LAW Melter Decontamination Factor Component Bins.

\begin{tabular}{|c|c|c|c|}
\hline Bin & Component & $\mathrm{DF}$ & $1 / \mathrm{DF}$ \\
\hline \multirow{15}{*}{ Non-volatile } & $\mathrm{Cr}$ & 13.64 & 0.073314 \\
\hline & $\mathrm{Ni}$ & 106.33 & 0.009405 \\
\hline & $\mathrm{Li}$ & 104.9 & 0.009533 \\
\hline & $\mathrm{Cd}$ & 117 & 0.008547 \\
\hline & $\mathrm{Fe}$ & 537.3 & 0.001861 \\
\hline & $\mathrm{Ti}$ & 338.9 & 0.002951 \\
\hline & $\mathrm{Zn}$ & 350.1 & 0.002856 \\
\hline & $\mathrm{Al}$ & 523.7 & 0.001909 \\
\hline & $\mathrm{Si}$ & 858.1 & 0.001165 \\
\hline & $\mathrm{Ca}$ & 803.8 & 0.001244 \\
\hline & $\mathrm{Mg}$ & 6352.1 & 0.000157 \\
\hline & $\mathrm{Zr}$ & 4600.7 & 0.000217 \\
\hline & \multirow{3}{*}{ Alternative Bin Averages } & Equation (4-1) & 1225 \\
\hline & & Equation (4-2) & 106 \\
\hline & & Equation (4-3) & 389 \\
\hline \multirow{9}{*}{ Semi-Volatile } & $\mathrm{K}$ & 19.61 & 0.050994 \\
\hline & $\mathrm{Pb}$ & 39.77 & 0.025145 \\
\hline & $\mathrm{P}$ & 84.19 & 0.011878 \\
\hline & $\mathrm{Na}$ & 77.47 & 0.012908 \\
\hline & $B(s)$ & 133.76 & 0.007476 \\
\hline & $\mathrm{B}$ & 326.72 & 0.003061 \\
\hline & \multirow{3}{*}{ Alternative Bin Averages } & Equation (4-1) & 114 \\
\hline & & Equation (4-2) & 54 \\
\hline & & Equation (4-3) & 78 \\
\hline
\end{tabular}

Notes:

1. $\mathrm{DF}=$ Decontamination Factor

2. Component bins, component list, and DF values from Table 2-2. 
A E M Consulting, LLC.

Calculation Set No. AEM-WRPS-2012-CN-015 Rev No. 0

Sheet 10 of 12

Figure 4-1. LAW Melter Non-Volatile Component Decontam ination Factor Comparison to Averages.

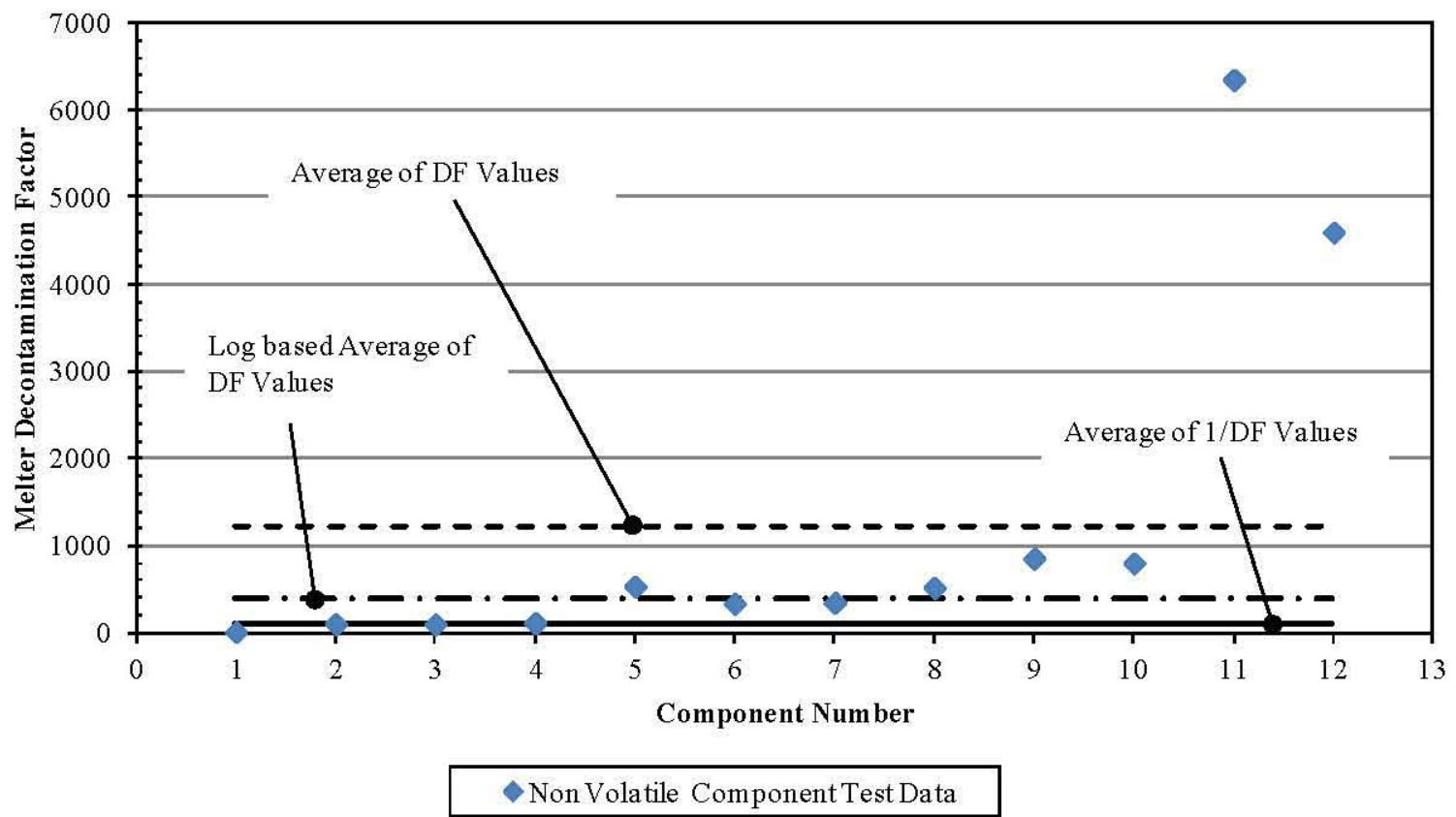

(a) Linear Scale

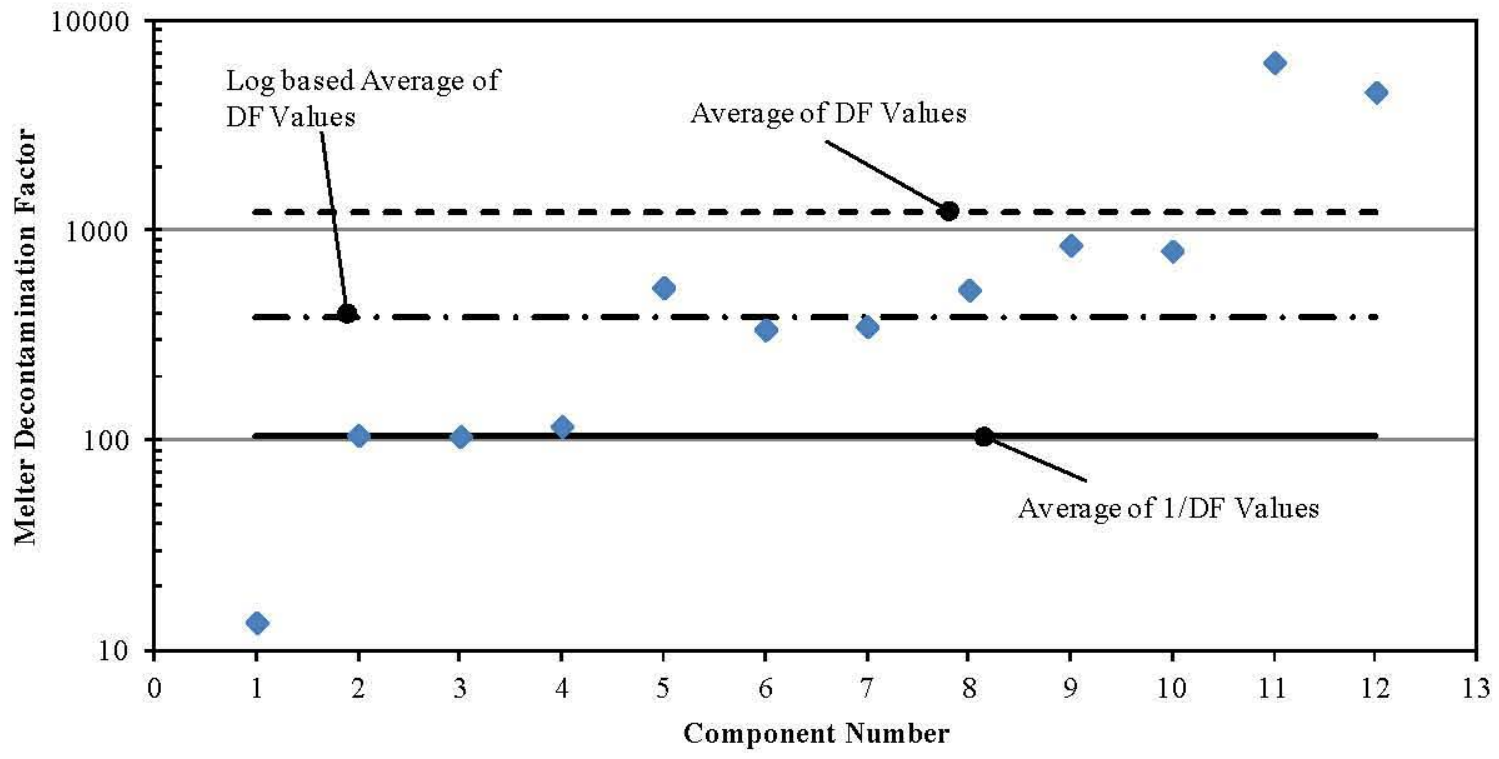

Non Volatile Component Test Data

(b) Logarithmic Scale

Key:

\begin{tabular}{|r|c|c|c|c|c|c|c|c|c|c|c|c|}
\hline Component Number & 1 & 2 & 3 & 4 & 5 & 6 & 7 & 8 & 9 & 10 & 11 & 12 \\
\hline Chemical & $\mathrm{O}$ & $\mathrm{Ni}$ & $\mathrm{Li}$ & $\mathrm{Cd}$ & $\mathrm{Fe}$ & $\mathrm{Ti}$ & $\mathrm{Zn}$ & $\mathrm{Al}$ & $\mathrm{Si}$ & $\mathrm{Ca}$ & $\mathrm{Mg}$ & $\mathrm{Zr}$ \\
\hline
\end{tabular}


A E M Consulting, LLC.

Calculation Set No. AEM-WRPS-2012-CN-015 Rev No. 0

Sheet 11 of 12

Figure 4-2. LAW Melter Semi-Volatile Decontamination Factor Component Comparison to Averages.

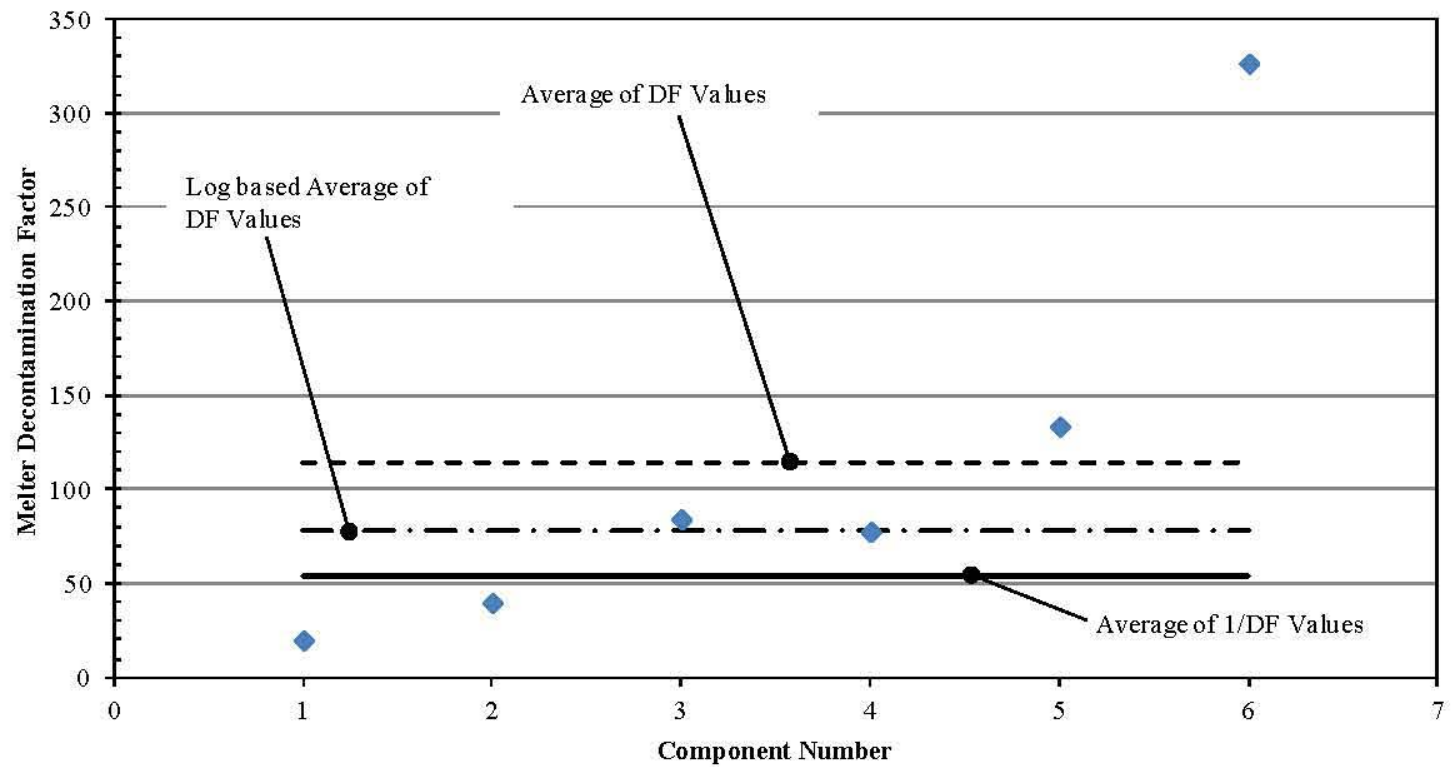

Semi-Volatile Component TestData

(a) Linear Scale

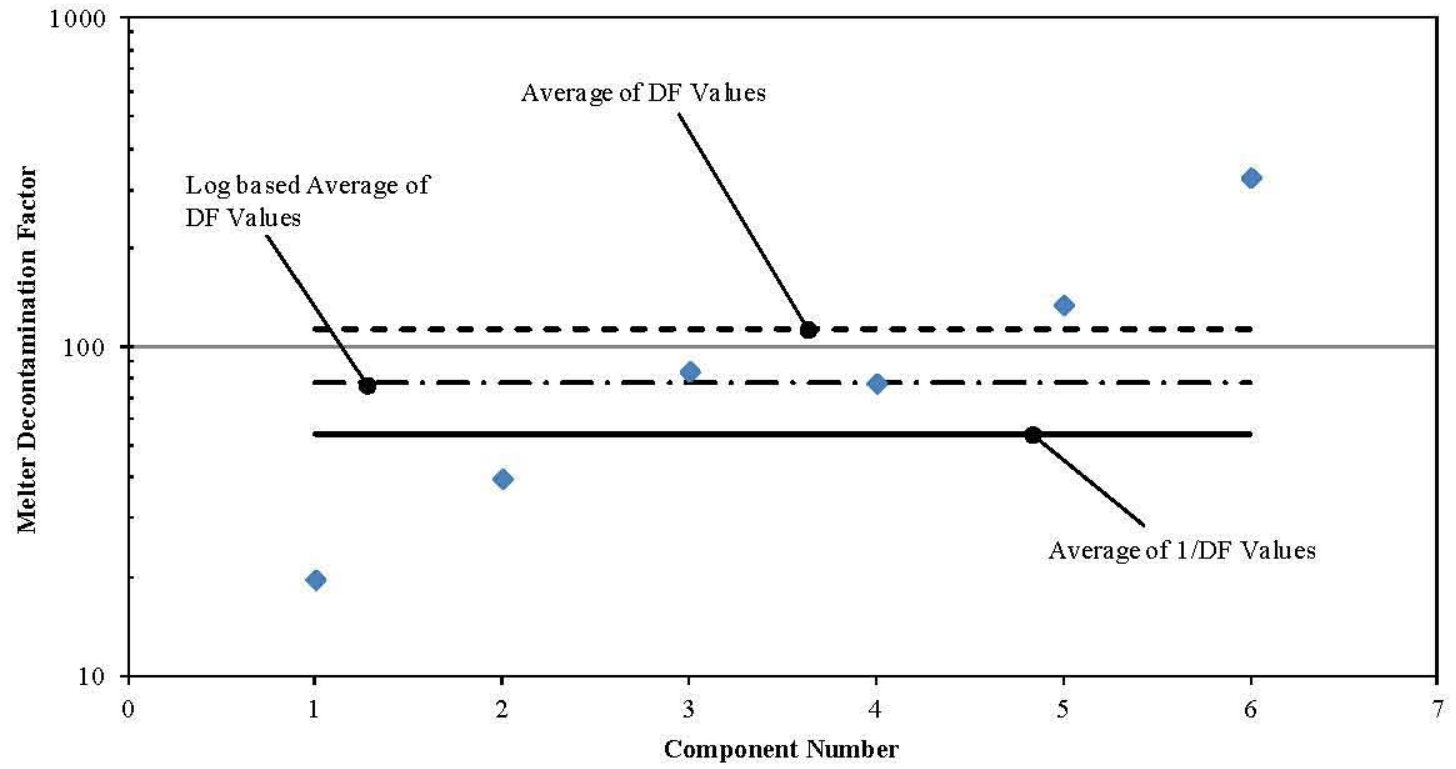

- Semi-Volatile Component TestData

(b) Logarithmic Scale

Key:

\begin{tabular}{|r|c|c|c|c|c|c|}
\hline Component Number & 1 & 2 & 3 & 4 & 5 & 6 \\
\hline Chemical & $\mathrm{K}$ & $\mathrm{Pb}$ & $\mathrm{P}$ & $\mathrm{Na}$ & $\mathrm{B}(\mathrm{s})$ & $\mathrm{B}$ \\
\hline
\end{tabular}


RPP-RPT-52796, Rev. 0

\section{A E M Consulting, LLC.}

Calculation Set No. AEM-WRPS-2012-CN-015 Rev No. 0

Sheet 12 of 12

\subsection{Use of Computer Software}

Calculations in this work have been treated as hand calculations. The actual values reported were calculated using Microsoft Excel 2007 spreadsheet. However, all values in calculations are included in tabular information such that the calculations can be independently duplicated. Calculation formulas were considered simple enough such that inclusion of a spreadsheet file was not considered warranted. Plots were also created using a spreadsheet and can be verified by comparison with tabular input.

\subsection{Results}

Section 4.0 describes three alternative approaches for calculating an average decontamination factor from LAW melter test observations for components in the non-volatile and semi-volatile bins. Current HTWOS modeling is essentially based on ${ }^{90} \mathrm{Sr}$ and ${ }^{241} \mathrm{Am}$ decontamination factor bins described in 24590-WTP-M4C-V37T-00008, which uses the most conservative approach for averaging test observations. Averaging Alternative 1 is used as an estimate of the upper bound for a bin averaged derived from the same test observations. Table 6-1 indicates that LAW melter decontamination factors could be as much as a factor of 10 higher for $90 \mathrm{Sr}$ and factor of 2 higher for $241 \mathrm{Am}$ using the same binning approach from 24590-WTP-M4C-V37T-00008. The increased decontamination factors imply that the mass rate of ${ }^{90} \mathrm{Sr}$ transmitted to the melter off gas system could potentially be a factor of 10 less than current predictions by HTWOS, while ${ }^{241}$ Am could be reduced by a factor of 2 .

Table 6-1. Summary of Potential Changes to ${ }^{90} \mathrm{Sr}$ and ${ }^{241} \mathrm{Am}$ LAW Melter Decontamination Factors.

\begin{tabular}{|c|c|c|c|c|}
\hline Component & Bin & Model Run DF & Potential DF & DF Ratio (rounded) \\
\hline${ }^{90} \mathrm{Sr} / \mathrm{Sr}^{+2}$ & Non-Volatile & 110 & 1225 & 10 \\
\hline${ }^{241} \mathrm{Am} / \mathrm{Am}^{+3}$ & Semi-Volatile & 57 & 114 & 2 \\
\hline
\end{tabular}

Notes:

1. $\mathrm{DF}=$ Decontamination Factor

2. Model Run DF from Table 2-1.

3. Potential DF from Table 4-1 based on Averaging Alternative 1.

4. DF Ratio represents potential reduction factor of component transmitted to the LAW melter off gas based on ratio of (Potential DF)/(Model Run DF). Value is rounded.

\subsection{Conclusions}

Average values from test data used in modeling the LAW Melter decontamination factor are based on an approach that produces the most conservative estimate of components transmitted to the melter off gas. Alternate averaging approaches indicate that feed components transmitted to the melter off gas may be a factor of 10 less for ${ }^{90} \mathrm{Sr}$ and a factor of 2 less for ${ }^{241} \mathrm{Am}$ compared to that predicted using decontamination factors used in HTWOS modeling studies.

\subsection{References}

24590-WTP-M4C-V37T-00008, 2011, Reconciliation of HLW and LAW Melter Decontamination Factors, Rev 0, Bechtel National, Inc., Richland, Washington.

24590-WTP-RPT-PT-02-005, 2009, Flowsheet Bases, Assumptions, and Requirements, Rev 5, Bechtel National Inc., Richland, Washington.

24590-WTP-RPT-PT-02-005, 2011, Flowsheet Bases, Assumptions, and Requirements, Rev 6, Bechtel National Inc., Richland, Washington.

RPP-17152, 2011, Hanford Tank Waste Operations Simulator (HTWOS)Version 6.6.1 Model Design Document, Rev 6, Washington River Protection Solutions, LLC., Richland, Washington. 


\author{
Appendix E \\ CALCULATION AEM-WRPS-2012-CN-017 \\ HAZARD CATEGORY CALCULATION FOR \\ SUBMERGED BED SCRUBBER CONDENSATE DIRECT DISPOSAL
}


Subcontractor Calculation Review Checklist

Subject: AEM-WRPS-2012-CN-017, Hazard Category Calculation for SBS Condensate Direct Disposal

The subject document has been reviewed by the undersigned.

The reviewer reviewed and verified the following items as applicable.

Documents Reviewed: AEM-WRPS-2012-CN-017, Hazard Category Calculation for SBS Condensate Direct Disposal

Analysis Performed By: AEM Consulting, LLC

- Design Input

- Basic Assumption

- Approach/Design Methodology

- Consistency with item or document supported by the calculation

- Conclusion/Results Interpretation

- Impact on existing requirements

Reviewer (printed name, signature, and date) T. G. Goetz $6 / 28 / 12$

Organizational Manager (printed name, signature, and date) Martin Wheeler

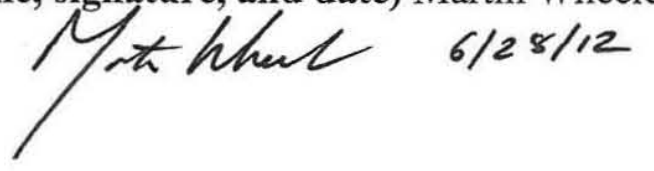




\begin{tabular}{|c|c|c|c|}
\hline A E M Consulting, LLC. & \multicolumn{2}{|c|}{$\begin{array}{l}\text { Calculation Set No. } \\
\text { AEM-WRPS-2012-CN-017 }\end{array}$} & $\begin{array}{c}\text { Rev No. } \\
0\end{array}$ \\
\hline Peer Review & \multicolumn{3}{|c|}{ End Use: Pre-conceptual Design } \\
\hline $\begin{array}{l}\text { Project: WRPS } 48504 \text { Line Item 2-SBS Direct Disposal } \\
\text { Alternatives }\end{array}$ & \multicolumn{3}{|c|}{ Sheet 1 of 18} \\
\hline Discipline: Process & \multicolumn{3}{|c|}{ Contract No: WRPS 48504 Line Item 2} \\
\hline Structure or System: Not applicable & \multicolumn{3}{|c|}{ Reserved } \\
\hline \multicolumn{4}{|c|}{ Subject: Hazard Category Calculalion for SBS Condensate Direct Disposal } \\
\hline \multicolumn{2}{|l|}{ Completed by: P. G. Johnson tater. } & \multicolumn{2}{|c|}{ Date $6 / 26 / 12$} \\
\hline \multicolumn{2}{|l|}{ Checked by: R. O. Lokken RuawO. Lothen } & \multicolumn{2}{|c|}{ Date $6 / 26 / 12$} \\
\hline \multicolumn{2}{|l|}{ Approved by: G. L. Dunford } & \multicolumn{2}{|c|}{ Date $8 / 27 / 12$} \\
\hline \multicolumn{4}{|l|}{ Distribution: NA } \\
\hline \multirow[t]{2}{*}{$\begin{array}{l}\text { Reason for Revision: } \\
\text { Not applicable, initial release }\end{array}$} & & \multicolumn{2}{|c|}{$\begin{array}{l}\text { Total number of sheets in this } \\
\text { issue: } 18\end{array}$} \\
\hline & & \multicolumn{2}{|c|}{$\begin{array}{l}\text { Sheets revised, added or deleted: } \\
\text { NA }\end{array}$} \\
\hline \multicolumn{4}{|c|}{$\begin{array}{l}\text { Problem Statement: } \\
\text { Assess the hazard category for the SBS direct disposal alternative processes: } \\
\text { - Alternative } 1 \text { - Containerize the unconcentrated SBS condensate for offsite disposal. } \\
\text { Alternative } 2 \text { - Concentrate the SBS condensate and containerize the resultant wiped film evaporator (WFE) } \\
\text { concentrate for offsite disposal. } \\
\text { Alternative } 3 \text { - Concentrate the SBS condensate, solidify the WFE concentrate, and containerize the resultant } \\
\text { solidified WFE concentrate for offite disposal. }\end{array}$} \\
\hline \multicolumn{4}{|c|}{$\begin{array}{l}\text { Summary Conclusions: } \\
\text { All process altematives would be classified as Hazard Category } 3 \text { facilities and are well below the Hazard Category } \\
2 \text { threshold. }\end{array}$} \\
\hline \multicolumn{4}{|c|}{$\begin{array}{l}\text { Design Basis: } \\
\text { SBS condensate feed composition and peak SBS condensate flow rate are taken from SVF-2440, SBS Disposal } \\
\text { PreConcept Alts. }\end{array}$} \\
\hline
\end{tabular}




\section{Contents}

1.0

\subsection{Objective/Purpose}

The purpose of this calculation is to assess the hazard category for the following Submerged Bed Scrubber (SBS) direct disposal alternative processes:

- Alternative 1 - Containerize the unconcentrated SBS condensate for offsite disposal.

- Alternative 2 - Concentrate the SBS condensate and containerize the resultant wiped film evaporator (WFE) concentrate for offsite disposal.

- Alternative 3 - Concentrate the SBS condensate, solidify the WFE concentrate, and containerize the resultant solidified WFE concentrate for offite disposal.

The process flow diagram for the three alternatives is shown in Attachment A.

\subsection{Input Data}

The input data associated with this calculation are as follows:

- The SBS condensate average composition is taken from SVF-2440, SBS Disposal PreConcept Alts, "Feed Stream" worksheet. The average concentrations rounded to three significant figures are shown in Table 4-1.

- The composition of the SBS condensate batch with the lowest volume to reach the Hazard Category 3 threshold, batch date $1 / 10 / 2020$, is taken from SVF-2440, "Ci per L Decayed" worksheet. The concentrations for this batch rounded to three significant figures are shown in Table 4-1.

- Class A, Table 1 waste disposal limits are taken from SVF-2440, "Class A" worksheet, which converts the 10 CFR 61.55, Table 1 units of $\mathrm{Ci} / \mathrm{m}^{3}$ and $\mathrm{nCi} / \mathrm{g}$ to $\mathrm{Ci} / \mathrm{L}$. The Class A, Table 1 limits are shown in Table $4-2$ of this calculation.

- The peak SBS condensate flow rate of 7500 gal/day is taken from SVF-2440, "Liquid Flow" worksheet. This flow rate is used to calculate the waste volumes for each alternative in Table 4-3.

- Tank capacities are taken from calculations AEM-WRPS-2012-CN-012, Alternative 1 Equipment Sizing Estimates, AEM-WRPS-2012-CN-013, Alternative 2 Equipment Sizing Estimates, and AEM-WRPS-2012-CN-014, Alternative 3 Equipment Sizing Estimates in RPP-RPT-52796, Supporting Calculations for Submerged Bed Scrubber Condensate Disposal Pre-Conceptual Study. Tank capacities are shown in Table 4-3. 
- Hazard Category 3 threshold values are taken from LA-12981-MS, Table of DOE-STD-1027-92 Hazard Category 3 Threshold Quantities for the ICRP-30 List of 757 Radionuclides, LANL Fact Sheet, as allowed by DOE-STD-1027-92, Hazard Categorization and Accident Analysis Techniques for Compliance with DOE Order 5480.23, Nuclear Safety Analysis Reports, Table A.1, footnote 2. LA-12981-MS provides a much more comprehensive listing of Hazard Category 3 threshold values than DOE-STD-1027-92. The applicable Hazard Category 3 threshold values are shown in Table 4-4.

- Hazard Category 2 threshold values are taken from DOE-STD-1027-92. The applicable Hazard Category 2 threshold values are shown in Table 4-4.

\subsection{Assumptions}

The assumptions associated with this calculation are as follows:

- The composition of the SBS condensate is based on the components tracked by the Hanford Tank Waste Operations Simulation (HTWOS) model. Components not tracked by the HTWOS model are not considered in this evaluation.

- The hazard category determination for Case 1 of all alternatives is based on the average SBS condensate concentrated to the Class A, Table 1 waste disposal limits.

- The hazard category determination for Alternative 1, Case 2 is based on the unconcentrated SBS condensate batch with the lowest volume to reach the Hazard Category 3 threshold.

- The hazard category determination for Alternatives 2 and 3, Case 2 is based on the SBS condensate batch with the lowest volume to reach the Hazard Category 3 threshold concentrated to the Class A, Table 1 waste disposal limits.

- Class A waste disposal limits are applied to the waste in liquid form rather than the as-disposed solidified form.

- Tanks are assumed filled to $100 \%$ tank volume.

- The incoming SBS condensate feed shipping containers and outgoing WFE concentrate shipping containers staged at the facility are considered part of the facility for the hazard category calculations.

- Incoming shipping container lag storage is needed to allow continued delivery of SBS condensate from the Waste Treatment and Immobilization Plant if SBS condensate processing operations are disrupted. Similarly, outgoing shipping container lag storage is needed to allow continued SBS condensate processing operations if offsite shipping is disrupted. For Alternative 1, combined incoming/outgoing lag storage equivalent to 7 days of SBS condensate generation is assumed due to the minimal processing associated with this alternative. For Alternatives 2 and 3, incoming lag storage equivalent to 7 days of SBS condensate generation and outgoing lag storage equivalent to 7 days of SBS concentrate generation are assumed.

- The tanks and shipping containers for WFE condensate are disregarded in this evaluation because the SBS condensate feed tanks and WFE concentrate tanks are assumed to contain the same concentrations. Including the WFE condensate tanks and shipping containers would result in double counting of inventory originating in the feed tanks.

- The mixing tanks for the Alternative 3 solidification process are disregarded in this evaluation because the solidification process involves small batch transfers from the concentrate tanks to the solidification mixing tanks.

- Contaminated in-service HEPA filters are disregarded in this evaluation because this contamination is insignificant compared to the tank inventories. 
RPP-RPT-52796, Rev. 0

A E M Consulting, LLC.

Calculation Set No. AEM-WRPS-2012-CN-017 Rev No. 0

Sheet 4 of 18

\subsection{Method of Analysis}

The hazard category for each alternative is determined for two different SBS condensate compositions. Case 1 for all alternatives is based on average SBS condensate concentrated to the Class A, Table 1 waste disposal limits. This approach is based on the following rationale:

- The planned disposal path for the SBS condensate is as Class A waste.

- SVF-2440, "Class A" worksheet demonstrates that long-lived radionuclides (Table 1), rather than short-lived radionuclides (Table 2), are always limiting for the SBS condensate to meet Class A waste disposal limits.

This approach could be overly conservative for determining the hazard category for Alternative 1 because the SBS condensate is not concentrated in the Alternative 1 process. To assess whether this approach is indeed overly conservative, Case 2 for Alternative 1 determines the hazard category based on the unconcentrated SBS condensate batch with the lowest volume to reach the Hazard Category 3 threshold.

Case 2 results in a higher Hazard Category 3 sum-of-fractions than Case 1 based on comparing the results shown in Tables 4-5 and 4-6. Therefore, to confirm the hazard category determination, Case 2 for Alternatives 2 and 3 determines the hazard category based on the SBS condensate batch with the lowest volume to reach the Hazard Category 3 threshold concentrated to the Class A, Table 1 waste disposal limits.

Sections 4.1 through 4.5 discuss the hazard category calculation results shown in Tables 4-1 through 4-8. Section 4.6 discusses operational and design changes that would be needed for a less-than-Hazard-Category-3 categorization for Alternative 1.

\subsection{SBS Condensate Composition}

Table 4-1 shows the SBS condensate composition data used in this calculation. Each column in Table 4-1 is described below.

- The "Average Feed" composition represents the average SBS condensate feed composition over the 25-year mission. This composition is taken from SVF-2440, "Feed Stream" worksheet and is used to calculate the "Average Feed at Class A Limits" composition.

- The "Average Feed at Class A Limits" composition represents the average SBS condensate feed concentrated to the Class A, Table 1 waste disposal limits. This composition is used to determine the hazard category for Case 1 for all alternatives. The concentration factor of 6.0 derived in Section 4.2 is used to calculate the "Average Feed at Class A Limits" composition:

$$
\begin{gathered}
\text { Average Feed at Class } A \\
\text { Limits" column }
\end{gathered}=\begin{gathered}
\text { Average Feed" } \\
\text { column }
\end{gathered} \times \begin{gathered}
\text { Concentration } \\
\text { Factor (6.0) }
\end{gathered}
$$

- The "Worst-Case Batch" composition represents the unconcentrated SBS condensate batch with the lowest volume to reach the Hazard Category 3 threshold, as calculated in SVF-2440, "HazCat" worksheet. This composition is used to determine the hazard category for Alternative 1, Case 2. This composition is the 1/10/2020 batch, the fourth batch of the 25-year mission from SVF-2440, "Ci Per L Decayed" worksheet. The worst-case batch can be seen graphically as the lowest point in Figure 4-1, which shows the volume to reach the Hazard Category 3 threshold for each SBS condensate feed batch over the 25-year mission. The implications of this figure are discussed in more detail in Section 4.6. 
- The "Worst-Case Batch at Class A Limits" composition represents the SBS condensate batch with the lowest volume to reach Hazard Category 3 threshold concentrated to the Class A, Table 1 waste disposal limits. This composition is used to determine the hazard category for Alternatives 2 and 3, Case 2. SVF-2440, "Class A" worksheet calculates a concentration factor of 1.48 to concentrate the "Worst-Case Batch" to the Class A, Table 1 waste disposal limits. A rounded up concentration factor of 1.5 is used to calculate the "Worst-Case Batch at Class A Limits" composition:

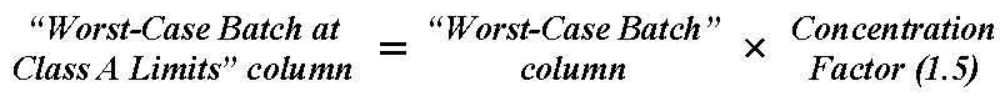

\subsection{Concentration Factor}

The calculation of the concentration factor to concentrate the average SBS condensate feed to the Class A, Table 1 waste disposal limits is described below. Table 4-2 shows the calculation results.

- The "Average Feed" column shows the average SBS condensate feed concentrations from Table 4-1 for the radionuclides that are subject to Class $\mathrm{A}$, Table 1 waste disposal limits.

- The "Class A, Table 1 Limit" column shows the Class A, Table 1 limits in Ci/L taken from SVF-2440, "Class A" worksheet. Note that 237-Np, 238-Pu, 239-Pu, 240-Pu, 241-Am, 242-Pu, 243-Am, 243-Cm, and Cm-244 (alpha-emitting radionuclides with a half-life greater than 5 years) have a composite limit, whereas the other radionuclides have individual limits.

- The values in the "Table 1 Fraction" column are calculated as:

$$
\begin{gathered}
\text { Table } 1 \text { Fraction" } \\
\text { column }
\end{gathered}=\begin{gathered}
\text { Average Feed" } \\
\text { column }
\end{gathered} \div \text { "Class A, Table 1 Limit" }
$$

- The "Sum-of-Fractions" line is calculated as:

$$
\begin{gathered}
\text { Sum-of-Fractions" } \\
\text { line }
\end{gathered}=\sum \begin{gathered}
\text { "Table } 1 \text { Fraction" } \\
\text { column }
\end{gathered}
$$

- The "Concentration Factor" line is the reciprocal of the "Sum-of-Fractions" line.

- The concentration factor is rounded up to 6.0. This rounded concentration factor provides conservative hazard category determination.

\subsection{Waste Volumes}

Table 4-3 shows the calculation results for the waste volumes for each process alternative. The waste volumes are calculated as the sum of the in-facility tank capacities and the total volume of incoming and outgoing shipping containers. The total volumes for incoming and outgoing shipping containers are calculated based on 7 days of feed at the peak SBS condensate flow rate of $7500 \mathrm{gal} / \mathrm{day}$, rounded up to a multiple of 5000 gallons, the anticipated shipping container volume from AEM-WRPS-2012-CN-012. The waste volumes for each process alternative are shown in the "Total" column of Table 4-3. A single calculation is shown for Alternatives 2 and 3 because these alternatives have the same applicable tank capacities as calculated in AEM-WRPS-2012-CN-013 and AEM-WRPS-2012-CN-014. Note that the outgoing waste form is different for Alternatives 2 and 3 but the liquid 
waste volume basis is the same. The solid product form for Alternative 3 is represented in its equivalent liquid volume.

The total volume for each alternative is converted from units of gallons to liters using a conversion factor of 3.785 and rounded to three significant figures. The rounded total volumes in liters are used in the calculations described in Section 4.5.

\subsection{Hazard Category Threshold Values}

The applicable Hazard Category 3 and Hazard Category 2 threshold values, taken from LA-12981-MS and DOE-STD-1027-92, respectively, are shown in Table 4-4.

\subsection{Hazard Category Sum-of-Fractions}

Tables 4-5 through 4-8 show the calculation results for hazard category sum-of-fractions for the four cases. The "Inventory" column in each table is calculated as follows:

- Alternative 1, Case 1 -Average SBS Condensate Feed Concentrated to Class A, Table 1 Limits:

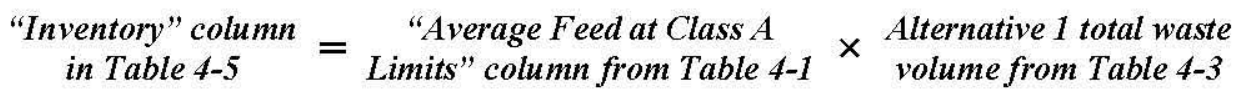

- Alternative 1, Case 2 -Worst-Case Batch of Unconcentrated SBS Condensate Feed:

$$
\begin{gathered}
\text { "Inventory" column } \\
\text { in Table 4-6 }
\end{gathered}=\begin{gathered}
\text { "Worst-Case Batch" } \\
\text { column from Table 4-1 }
\end{gathered} \times \begin{gathered}
\text { Alternative } 1 \text { total waste } \\
\text { volume from Table 4-3 }
\end{gathered}
$$

- Alternatives 2 and 3, Case 1 - Average SBS Condensate Feed Concentrated to Class A, Table 1 Limits:

$$
\begin{gathered}
\text { "Inventory" column } \\
\text { in Table 4-7 }
\end{gathered}=\begin{gathered}
\text { "Average Feed at Class } A \\
\text { Limits" column from Table 4-1 }
\end{gathered} \times \begin{gathered}
\text { Alternative } 2 / 3 \text { total waste } \\
\text { volume from Table 4-3 }
\end{gathered}
$$

- Alternatives 2 and 3, Case 2 - Worst-Case Batch of SBS Condensate Feed Concentrated to Class A, Table 1 Limits:

$$
\begin{gathered}
\text { "Inventory" column } \\
\text { in Table 4-8 }
\end{gathered}=\begin{gathered}
\text { "Worst-Case Batch at Class } A \\
\text { Limits" column from Table 4-1 }
\end{gathered} \times \begin{gathered}
\text { Alternative 2/3 total waste } \\
\text { volume from Table 4-3 }
\end{gathered}
$$

The remainder of the calculations in Tables 4-5 through 4-8 is identical for each case:

- The values in the Hazard Category 3 threshold fraction columns are calculated as:

$$
\begin{gathered}
\text { Category } 3 \text { Threshold } \\
\text { Fraction" column }
\end{gathered}=\begin{gathered}
\text { "Inventory" } \\
\text { column }
\end{gathered} \div \text { "Hazard Category } 3 \text { Threshold" }
$$

- The values in the Hazard Category 2 threshold fraction columns are calculated as:

$$
\begin{gathered}
\text { Category } 2 \text { Threshold } \\
\text { Fraction" column }
\end{gathered}=\begin{gathered}
\text { "Inventory" } \\
\text { column }
\end{gathered} \div \begin{gathered}
\text { "Hazard Category } 2 \text { Threshold" } \\
\text { column from Table 4-4 }
\end{gathered}
$$


- The "Sum-of-Fractions" lines are calculated as:

$$
\begin{gathered}
\begin{array}{c}
\text { Category } 3 \text { "Sum-of- } \\
\text { Fractions" }
\end{array}=\sum \begin{array}{c}
\text { "Category } 3 \text { Threshold } \\
\text { Fraction" column }
\end{array} \\
\begin{array}{c}
\text { Category } 2 \text { "Sum-of- } \\
\text { Fractions" }
\end{array}=\sum \begin{array}{c}
\text { "Category } 2 \text { Threshold } \\
\text { Fraction" column }
\end{array}
\end{gathered}
$$

The predominant radionuclide in the Hazard Category 3 sum-of-fractions calculations for all cases is 129-I. The 129-I contributions to the Hazard Category 3 sum-of-fractions on a percentage basis are as follows:

- Alternative 1 , Case $1-66 \% 129-\mathrm{I}$

- Alternative 1, Case $2-91 \% 129-\mathrm{I}$

- Alternative 2 and 3, Case $1-66 \% 129-\mathrm{I}$

- Alternative 2 and 3, Case 2-91\% 129-I

For Alternative 1, Case 1 and Alternatives 2 and 3, Case 1, 137-Cs, 239-Pu, 241-Am, 90-Sr, and 99-Tc are secondary contributors, accounting for at least one percent of the sum-of-fractions. For Alternative 1, Case 2 and Alternatives 2 and 3, Case 2, 137-Cs, 151-Sm, 90-Sr, and 99-Tc are secondary contributors. These radionuclides are shaded in Tables 4-5 through 4-8.

\subsection{Further Evaluation of Alternative 1 Hazard Category}

The waste volume to reach the Hazard Category 3 threshold for each SBS condensate feed batch over the 25 -year mission is shown in Figure 4-1. Figure 4-2 shows these waste volumes for the first 400 SBS condensate feed batches, approximately the first third of the 25-year mission. These data are taken from SVF-2440, "HazCat" worksheet. For comparison the Alternative 1 total waste volume and in-facility tank volume from Table 4-3, 117,500 and 62,500 gallons, respectively, are shown on the figures. The total waste volume includes both the infacility tanks and the shipping containers. The waste volume shown in Figures 4-1 and 4-2 is less than the total waste volume of 117,500 gallons for 266 SBS condensate batches, or $23 \%$ of the 1165 batches, and is less than the in-facility tank volume of 62,500 gallons for 24 batches, or $\sim 2 \%$ of the 1165 batches. These statistics are shown in tabular form below.

\begin{tabular}{|l|c|c|}
\hline \multicolumn{1}{|c|}{ SBS Condensate Volume } & $\begin{array}{c}\text { Number of Batches } \\
\text { Below Volume }\end{array}$ & $\begin{array}{c}\text { Percentage of Batches } \\
\text { Below Volume }\end{array}$ \\
\hline Total waste volume, 117,500 gallons & 266 batches & $23 \%$ \\
\hline In-facility tank volume, 62,500 gallons & 24 batches & $2 \%$ \\
\hline
\end{tabular}

The lowest waste volume in Figures 4-1 and 4-2, which corresponds to the Case 2 worst-case batch, is $~ 23,200$ gallons. For those batches where the waste volume shown in Figures 4-1 and 4-2 is between 62,500 and 117,500 gallons, the inventory of filled shipping containers at the facility would have to be administratively limited to remain below Hazard Category 3. For those batches where the waste volume shown in Figures 4-1 and 4-2 is less than 62,500 gallons, the waste volume in the in-facility tanks would have to be reduced to remain below Hazard Category 3. 
\begin{tabular}{|l|l|r} 
A E M Consulting, LLC. & Calculation Set No. AEM-WRPS-2012-CN-017 Rev No. 0 & Sheet 8 of 18
\end{tabular}

Table 4-1. SBS Condensate Composition.

\begin{tabular}{|c|c|c|c|c|}
\hline Radionuclide & $\begin{array}{c}\text { Average Feed } \\
(\mathrm{Ci} / \mathrm{L})\end{array}$ & $\begin{array}{c}\text { Average Feed at } \\
\text { Class A Limits }(\mathrm{Ci} / \mathrm{L})\end{array}$ & $\begin{array}{l}\text { Worst-Case Batch } \\
(\mathrm{Ci} / \mathrm{L})\end{array}$ & $\begin{array}{l}\text { Worst-Case Batch at } \\
\text { Class A Limits }(\mathrm{Ci} / \mathrm{L})\end{array}$ \\
\hline $106-\mathrm{Ru}$ & $1.86 \mathrm{E}-14$ & $1.12 \mathrm{E}-13$ & $8.03 \mathrm{E}-18$ & $1.20 \mathrm{E}-17$ \\
\hline $113 \mathrm{~m}-\mathrm{Cd}$ & $2.31 \mathrm{E}-08$ & $1.39 \mathrm{E}-07$ & $3.26 \mathrm{E}-07$ & $4.89 \mathrm{E}-07$ \\
\hline $125-\mathrm{Sb}$ & $5.07 \mathrm{E}-08$ & $3.04 \mathrm{E}-07$ & $9.05 \mathrm{E}-08$ & $1.36 \mathrm{E}-07$ \\
\hline $126-\mathrm{Sn}$ & $5.64 \mathrm{E}-09$ & $3.38 \mathrm{E}-08$ & $5.97 \mathrm{E}-08$ & $8.96 \mathrm{E}-08$ \\
\hline $129-\mathrm{I}$ & $6.32 \mathrm{E}-08$ & $3.79 \mathrm{E}-07$ & $6.23 \mathrm{E}-07$ & $9.35 \mathrm{E}-07$ \\
\hline 134-Cs & $1.16 \mathrm{E}-12$ & $6.96 \mathrm{E}-12$ & $2.23 \mathrm{E}-11$ & $3.35 \mathrm{E}-11$ \\
\hline $137-\mathrm{Cs}$ & $3.37 \mathrm{E}-06$ & $2.02 \mathrm{E}-05$ & $2.47 \mathrm{E}-05$ & $3.71 \mathrm{E}-05$ \\
\hline $137 \mathrm{~m}-\mathrm{Ba}$ & $3.19 \mathrm{E}-06$ & $1.91 \mathrm{E}-05$ & $2.33 \mathrm{E}-05$ & $3.50 \mathrm{E}-05$ \\
\hline $14-\mathrm{C}$ & $0.00 \mathrm{E}+00$ & $0.00 \mathrm{E}+00$ & $0.00 \mathrm{E}+00$ & $0.00 \mathrm{E}+00$ \\
\hline 151-Sm & $9.41 \mathrm{E}-06$ & $5.65 \mathrm{E}-05$ & $1.35 \mathrm{E}-04$ & $2.03 \mathrm{E}-04$ \\
\hline $152-\mathrm{Eu}$ & $9.42 \mathrm{E}-10$ & $5.65 \mathrm{E}-09$ & $9.55 \mathrm{E}-09$ & $1.43 \mathrm{E}-08$ \\
\hline 154-Eu & $1.18 \mathrm{E}-08$ & 7.08E-08 & 8.39E-08 & $1.26 \mathrm{E}-07$ \\
\hline $155-\mathrm{Eu}$ & $3.26 \mathrm{E}-09$ & $1.96 \mathrm{E}-08$ & $5.20 \mathrm{E}-08$ & $7.80 \mathrm{E}-08$ \\
\hline $226-\mathrm{Ra}$ & $4.36 \mathrm{E}-12$ & $2.62 \mathrm{E}-11$ & $4.42 \mathrm{E}-11$ & $6.63 \mathrm{E}-11$ \\
\hline $227-\mathrm{Ac}$ & $3.34 \mathrm{E}-12$ & $2.00 \mathrm{E}-11$ & $2.15 \mathrm{E}-10$ & $3.23 \mathrm{E}-10$ \\
\hline $228-\mathrm{Ra}$ & $1.86 \mathrm{E}-10$ & $1.12 \mathrm{E}-09$ & $4.89 \mathrm{E}-12$ & $7.34 \mathrm{E}-12$ \\
\hline 229-Th & $2.65 \mathrm{E}-12$ & $1.59 \mathrm{E}-11$ & $6.78 \mathrm{E}-13$ & $1.02 \mathrm{E}-12$ \\
\hline 231-Pa & $4.62 \mathrm{E}-11$ & $2.77 \mathrm{E}-10$ & $1.78 \mathrm{E}-09$ & 2.67E-09 \\
\hline 232-Th & $6.05 \mathrm{E}-12$ & $3.63 \mathrm{E}-11$ & $1.30 \mathrm{E}-12$ & $1.95 \mathrm{E}-12$ \\
\hline $232-U$ & $1.08 \mathrm{E}-11$ & $6.48 \mathrm{E}-11$ & $2.88 \mathrm{E}-11$ & $4.32 \mathrm{E}-11$ \\
\hline $233-\mathrm{U}$ & $7.56 \mathrm{E}-10$ & $4.54 \mathrm{E}-09$ & $2.64 \mathrm{E}-09$ & $3.96 \mathrm{E}-09$ \\
\hline $234-U$ & $3.38 \mathrm{E}-10$ & $2.03 \mathrm{E}-09$ & $3.73 \mathrm{E}-09$ & $5.60 \mathrm{E}-09$ \\
\hline $235-U$ & $1.39 \mathrm{E}-11$ & $8.34 \mathrm{E}-11$ & $1.47 \mathrm{E}-10$ & $2.21 \mathrm{E}-10$ \\
\hline $236-\mathrm{U}$ & $1.10 \mathrm{E}-11$ & $6.60 \mathrm{E}-11$ & $1.94 \mathrm{E}-10$ & $2.91 \mathrm{E}-10$ \\
\hline $237-\mathrm{Np}$ & $5.48 \mathrm{E}-10$ & $3.29 \mathrm{E}-09$ & $4.37 \mathrm{E}-09$ & $6.56 \mathrm{E}-09$ \\
\hline $238-\mathrm{Pu}$ & $1.48 \mathrm{E}-09$ & $8.88 \mathrm{E}-09$ & $2.14 \mathrm{E}-09$ & $3.21 \mathrm{E}-09$ \\
\hline $238-\mathrm{U}$ & $3.15 \mathrm{E}-10$ & $1.89 \mathrm{E}-09$ & $3.00 \mathrm{E}-09$ & $4.50 \mathrm{E}-09$ \\
\hline $239-\mathrm{Pu}$ & $2.90 \mathrm{E}-08$ & $1.74 \mathrm{E}-07$ & $1.32 \mathrm{E}-08$ & $1.98 \mathrm{E}-08$ \\
\hline $240-\mathrm{Pu}$ & $6.28 \mathrm{E}-09$ & $3.77 \mathrm{E}-08$ & $7.58 \mathrm{E}-09$ & $1.14 \mathrm{E}-08$ \\
\hline 241-Am & $1.49 \mathrm{E}-07$ & $8.94 \mathrm{E}-07$ & $1.24 \mathrm{E}-08$ & $1.86 \mathrm{E}-08$ \\
\hline $241-\mathrm{Pu}$ & $2.43 \mathrm{E}-08$ & $1.46 \mathrm{E}-07$ & $3.78 \mathrm{E}-08$ & $5.67 \mathrm{E}-08$ \\
\hline $242-\mathrm{Cm}$ & $3.14 \mathrm{E}-10$ & $1.88 \mathrm{E}-09$ & $2.09 \mathrm{E}-11$ & $3.14 \mathrm{E}-11$ \\
\hline $242-\mathrm{Pu}$ & $4.98 \mathrm{E}-13$ & $2.99 \mathrm{E}-12$ & $6.60 \mathrm{E}-13$ & $9.90 \mathrm{E}-13$ \\
\hline 243-Am & $1.56 \mathrm{E}-10$ & $9.36 \mathrm{E}-10$ & $1.36 \mathrm{E}-11$ & $2.04 \mathrm{E}-11$ \\
\hline $243-\mathrm{Cm}$ & $2.03 \mathrm{E}-11$ & $1.22 \mathrm{E}-10$ & $9.02 \mathrm{E}-13$ & $1.35 \mathrm{E}-12$ \\
\hline $244-\mathrm{Cm}$ & $3.41 \mathrm{E}-10$ & $2.05 \mathrm{E}-09$ & $1.66 \mathrm{E}-11$ & $2.49 \mathrm{E}-11$ \\
\hline $3-\mathrm{H}$ & $0.00 \mathrm{E}+00$ & $0.00 \mathrm{E}+00$ & $0.00 \mathrm{E}+00$ & $0.00 \mathrm{E}+00$ \\
\hline $59-\mathrm{Ni}$ & $6.08 \mathrm{E}-09$ & $3.65 \mathrm{E}-08$ & $1.21 \mathrm{E}-08$ & $1.82 \mathrm{E}-08$ \\
\hline $60-\mathrm{Co}$ & $1.69 \mathrm{E}-09$ & $1.01 \mathrm{E}-08$ & $2.01 \mathrm{E}-08$ & $3.02 \mathrm{E}-08$ \\
\hline $63-\mathrm{Ni}$ & $4.43 \mathrm{E}-07$ & $2.66 \mathrm{E}-06$ & $1.01 \mathrm{E}-06$ & $1.52 \mathrm{E}-06$ \\
\hline $79-\mathrm{Se}$ & $9.51 \mathrm{E}-08$ & $5.71 \mathrm{E}-07$ & $1.52 \mathrm{E}-07$ & $2.28 \mathrm{E}-07$ \\
\hline $90-\mathrm{Sr}$ & $1.30 \mathrm{E}-06$ & $7.80 \mathrm{E}-06$ & $3.45 \mathrm{E}-06$ & $5.18 \mathrm{E}-06$ \\
\hline $90-Y$ & $1.30 \mathrm{E}-06$ & $7.80 \mathrm{E}-06$ & $3.45 \mathrm{E}-06$ & $5.18 \mathrm{E}-06$ \\
\hline $93-\mathrm{Zr}$ & $1.01 \mathrm{E}-09$ & $6.06 \mathrm{E}-09$ & $2.00 \mathrm{E}-08$ & $3.00 \mathrm{E}-08$ \\
\hline $93 \mathrm{~m}-\mathrm{Nb}$ & $4.27 \mathrm{E}-08$ & $2.56 \mathrm{E}-07$ & $8.81 \mathrm{E}-07$ & $1.32 \mathrm{E}-06$ \\
\hline 99-Tc & $4.35 \mathrm{E}-05$ & $2.61 \mathrm{E}-04$ & $1.78 \mathrm{E}-04$ & $2.67 \mathrm{E}-04$ \\
\hline
\end{tabular}


Table 4-2. Concentration Factor.

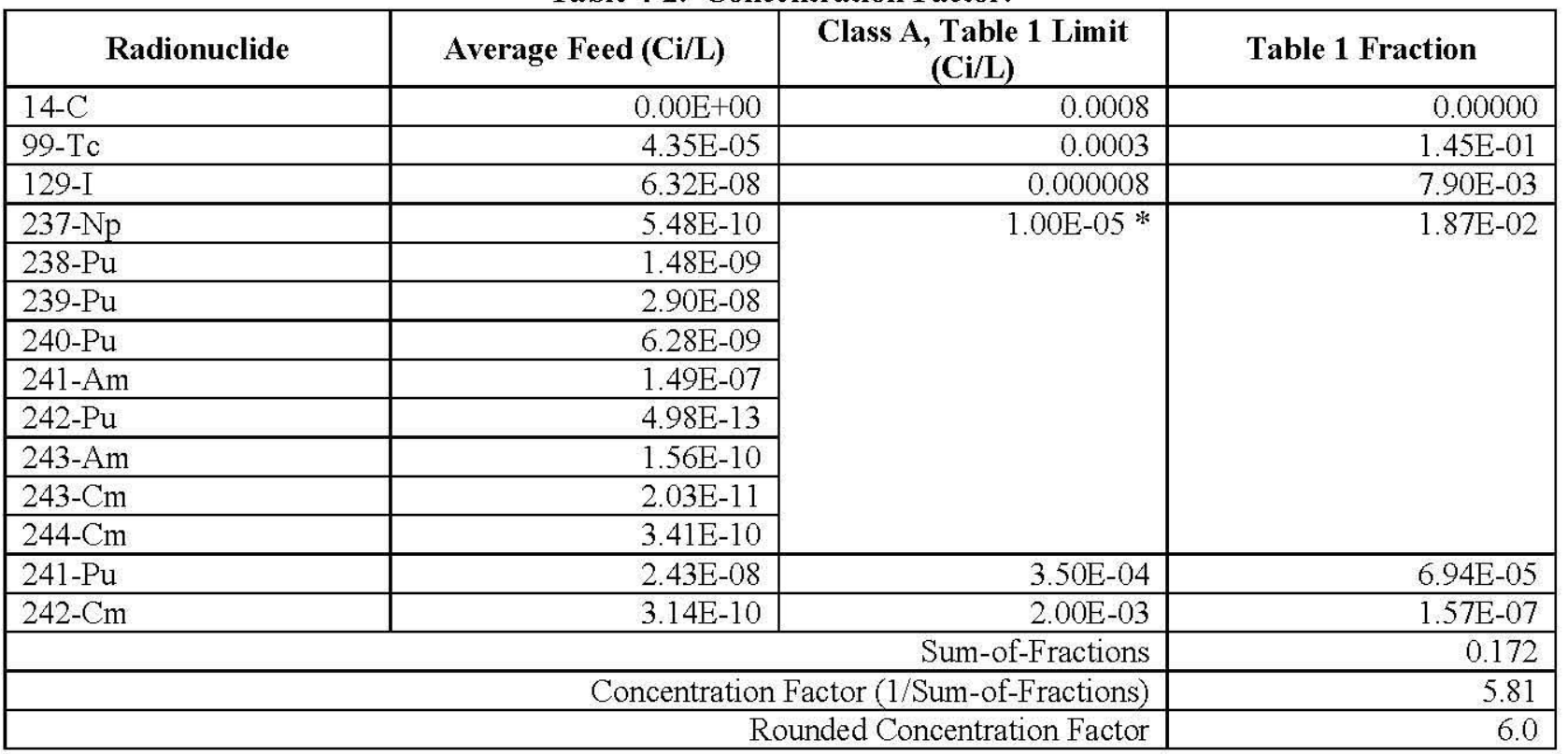

* composite limit for alpha-emitting radionuclides with a half-life greater than 5 years.

Table 4-3. Waste Volumes.

\begin{tabular}{|c|c|c|c|}
\hline Alternative & Tank & Tank Volume & Total \\
\hline \multirow{4}{*}{1} & Feed & $2 \times 31,250 \mathrm{gal}$ & $62,500 \mathrm{gal}$ \\
\hline & Incoming/Outgoing Shipping & 7 day $\times 7500 \mathrm{gal} / \mathrm{day}=52,500 \mathrm{gal} \approx 55,000 \mathrm{gal} *$ & $55,000 \mathrm{gal}$ \\
\hline & \multirow{2}{*}{\multicolumn{2}{|c|}{ Total }} & $117,500 \mathrm{gal}$ \\
\hline & & & $445,000 \mathrm{~L}$ \\
\hline \multirow{5}{*}{2 and 3} & Feed & $3 \times 18,750 \mathrm{gal}$ & $56,250 \mathrm{gal}$ \\
\hline & Concentrate & $2 \times 18,750 \mathrm{gal}$ & $37,500 \mathrm{gal}$ \\
\hline & Incoming Shipping & 7 day $\times 7500 \mathrm{gal} /$ day $=52,500 \mathrm{gal} \approx 55,000 \mathrm{gal} *$ & $55,000 \mathrm{gal}$ \\
\hline & Outgoing Shipping & 7 day $\times 7500$ gal $/$ day $=52,500$ gal $\approx 55,000$ gal $*$ & $55,000 \mathrm{gal}$ \\
\hline & \multicolumn{2}{|r|}{ Total } & $203,750 \mathrm{gal}$ \\
\hline
\end{tabular}

* rounded up to an even increment of 5000 gallons, the anticipated shipping container volume. 
Table 4-4. Hazard Category Threshold Values.

\begin{tabular}{|c|c|c|}
\hline Radionuclide & $\begin{array}{c}\text { Hazard Category } 3 \\
\text { Threshold (Ci) } \\
\end{array}$ & $\begin{array}{c}\text { Hazard Category } 2 \\
\text { Threshold (Ci) }\end{array}$ \\
\hline 106-Ru & $1.00 \mathrm{E}+02$ & $6.5 \mathrm{E}+03$ \\
\hline $113 \mathrm{~m}-\mathrm{Cd}$ & $1.18 \mathrm{E}+01$ & $\mathrm{~N} / \mathrm{A}$ \\
\hline $125-\mathrm{Sb}$ & $1.20 \mathrm{E}+03$ & $\mathrm{~N} / \mathrm{A}$ \\
\hline 126-Sn & $1.70 \mathrm{E}+02$ & $3.3 \mathrm{E}+05$ \\
\hline $129-\mathrm{I}$ & $6.00 \mathrm{E}-02$ & N/A \\
\hline 134-Cs & $4.20 \mathrm{E}+01$ & $6.0 \mathrm{E}+04$ \\
\hline 137-Cs & $6.00 \mathrm{E}+01$ & $8.9 \mathrm{E}+04$ \\
\hline $137 \mathrm{~m}-\mathrm{Ba}$ & N/A & N/A \\
\hline $14-\mathrm{C}$ & $4.20 \mathrm{E}+02$ & $1.4 \mathrm{E}+06$ \\
\hline 151-Sm & $1.00 \mathrm{E}+03$ & $9.9 \mathrm{E}+05$ \\
\hline 152-Eu & $2.00 \mathrm{E}+02$ & $1.3 \mathrm{E}+05$ \\
\hline 154-Eu & $2.00 \mathrm{E}+02$ & $1.1 \mathrm{E}+05$ \\
\hline 155-Eu & $9.40 \mathrm{E}+02$ & $7.3 \mathrm{E}+05$ \\
\hline $226-\mathrm{Ra}$ & $1.20 \mathrm{E}+01$ & N/A \\
\hline $227-A c$ & $4.20 \mathrm{E}-02$ & $4.3 \mathrm{E}+00$ \\
\hline $228-\mathrm{Ra}$ & $1.20 \mathrm{E}+01$ & N/A \\
\hline 229-Th & $9.40 \mathrm{E}-02$ & N/A \\
\hline $231-\mathrm{Pa}$ & $2.00 \mathrm{E}-01$ & N/A \\
\hline 232-Th & $1.00 \mathrm{E}-01$ & $1.8 \mathrm{E}+01$ \\
\hline $232-U$ & $8.20 \mathrm{E}-01$ & N/A \\
\hline $233-\mathrm{U}$ & $4.20 \mathrm{E}+00$ & $2.2 \mathrm{E}+02$ \\
\hline $234-\mathrm{U}$ & $4.20 \mathrm{E}+00$ & $2.2 \mathrm{E}+02$ \\
\hline $235-\mathrm{U}$ & $4.20 \mathrm{E}+00$ & $2.4 \mathrm{E}+02$ \\
\hline $236-\mathrm{U}$ & $4.20 \mathrm{E}+00$ & N/A \\
\hline $237-\mathrm{Np}$ & $4.20 \mathrm{E}-01$ & $5.8 \mathrm{E}+01$ \\
\hline $238-\mathrm{Pu}$ & $6.20 \mathrm{E}-01$ & $6.2 \mathrm{E}+01$ \\
\hline $238-U$ & $4.20 \mathrm{E}+00$ & $2.4 \mathrm{E}+02$ \\
\hline 239-Pu & $5.20 \mathrm{E}-01$ & $5.6 \mathrm{E}+01$ \\
\hline $240-\mathrm{Pu}$ & $5.20 \mathrm{E}-01$ & N/A \\
\hline 241-Am & $5.20 \mathrm{E}-01$ & $5.5 \mathrm{E}+01$ \\
\hline 241-Pu & $3.20 \mathrm{E}+01$ & $2.9 \mathrm{E}+03$ \\
\hline $242-\mathrm{Cm}$ & $3.20 \mathrm{E}+01$ & $1.7 \mathrm{E}+03$ \\
\hline $242-\mathrm{Pu}$ & $6.20 \mathrm{E}-01$ & N/A \\
\hline 243-Am & $5.20 \mathrm{E}-01$ & $5.5 \mathrm{E}+01$ \\
\hline $243-\mathrm{Cm}$ & $8.20 \mathrm{E}-01$ & N/A \\
\hline 244-Cm & $1.04 \mathrm{E}+00$ & N/A \\
\hline $3-\mathrm{H}$ & $1.66 \mathrm{E}+04$ & $3.0 \mathrm{E}+05$ \\
\hline 59-Ni & $1.18 \mathrm{E}+04$ & N/A \\
\hline $60-\mathrm{Co}$ & $2.80 \mathrm{E}+02$ & $1.9 \mathrm{E}+05$ \\
\hline $63-\mathrm{Ni}$ & $5.40 \mathrm{E}+03$ & $4.5 \mathrm{E}+06$ \\
\hline 79-Se & $3.60 \mathrm{E}+02$ & N/A \\
\hline $90-\mathrm{Sr}$ & $1.60 \mathrm{E}+01$ & $2.2 \mathrm{E}+04$ \\
\hline $90-\mathrm{Y}$ & $1.42 \mathrm{E}+03$ & N/A \\
\hline $93-\mathrm{Zr}$ & $6.20 \mathrm{E}+01$ & $8.9 \mathrm{E}+04$ \\
\hline $93 \mathrm{~m}-\mathrm{Nb}$ & $2.00 \mathrm{E}+03$ & N/A \\
\hline 99-Tc & $1.70 \mathrm{E}+03$ & $3.8 \mathrm{E}+06$ \\
\hline
\end{tabular}


Table 4-5. Alternative 1, Case 1 Hazard Category Sum-of-Fractions.

\begin{tabular}{|c|c|c|c|}
\hline Radionuclide & Inventory $(\mathrm{Ci})$ & Category 3 Threshold Fraction & Category 2 Threshold Fraction \\
\hline 106-Ru & $4.98 \mathrm{E}-08$ & $4.98 \mathrm{E}-10$ & $7.66 \mathrm{E}-12$ \\
\hline $113 \mathrm{~m}-\mathrm{Cd}$ & $6.19 \mathrm{E}-02$ & $5.25 \mathrm{E}-03$ & $\mathrm{~N} / \mathrm{A}$ \\
\hline $125-\mathrm{Sb}$ & $1.35 \mathrm{E}-01$ & $1.13 \mathrm{E}-04$ & N/A \\
\hline $126-\mathrm{Sn}$ & $1.50 \mathrm{E}-02$ & $8.82 \mathrm{E}-05$ & $4.55 \mathrm{E}-08$ \\
\hline $129-\mathrm{I}$ & $1.69 \mathrm{E}-01$ & $2.82 \mathrm{E}+00$ & $\mathrm{~N} / \mathrm{A}$ \\
\hline 134-Cs & $3.10 \mathrm{E}-06$ & $7.38 \mathrm{E}-08$ & $5.17 \mathrm{E}-11$ \\
\hline $137-\mathrm{Cs}$ & $8.99 \mathrm{E}+00$ & $1.50 \mathrm{E}-01$ & $1.01 \mathrm{E}-04$ \\
\hline $137 \mathrm{~m}-\mathrm{Ba}$ & $8.50 \mathrm{E}+00$ & N/A & $\mathrm{N} / \mathrm{A}$ \\
\hline $14-\mathrm{C}$ & $0.00 \mathrm{E}+00$ & $0.00 \mathrm{E}+00$ & $0.00 \mathrm{E}+00$ \\
\hline $151-\mathrm{Sm}$ & $2.51 \mathrm{E}+01$ & $2.51 \mathrm{E}-02$ & $2.54 \mathrm{E}-05$ \\
\hline $152-\mathrm{Eu}$ & $2.51 \mathrm{E}-03$ & $1.26 \mathrm{E}-05$ & $1.93 \mathrm{E}-08$ \\
\hline 154-Eu & $3.15 \mathrm{E}-02$ & $1.58 \mathrm{E}-04$ & $2.86 \mathrm{E}-07$ \\
\hline $155-\mathrm{Eu}$ & $8.72 \mathrm{E}-03$ & $9.28 \mathrm{E}-06$ & $1.19 \mathrm{E}-08$ \\
\hline $226-\mathrm{Ra}$ & $1.17 \mathrm{E}-05$ & $9.75 \mathrm{E}-07$ & $\mathrm{~N} / \mathrm{A}$ \\
\hline $227-A c$ & $8.90 \mathrm{E}-06$ & $2.12 \mathrm{E}-04$ & $2.07 \mathrm{E}-06$ \\
\hline $228-\mathrm{Ra}$ & $4.98 \mathrm{E}-04$ & $4.15 \mathrm{E}-05$ & N/A \\
\hline 229-Th & $7.08 \mathrm{E}-06$ & $7.53 \mathrm{E}-05$ & N/A \\
\hline $231-\mathrm{Pa}$ & $1.23 \mathrm{E}-04$ & $6.15 \mathrm{E}-04$ & N/A \\
\hline 232-Th & $1.62 \mathrm{E}-05$ & $1.62 \mathrm{E}-04$ & $9.00 \mathrm{E}-07$ \\
\hline $232-U$ & $2.88 \mathrm{E}-05$ & $3.51 \mathrm{E}-05$ & N/A \\
\hline $233-\mathrm{U}$ & $2.02 \mathrm{E}-03$ & $4.81 \mathrm{E}-04$ & $9.18 \mathrm{E}-06$ \\
\hline $234-U$ & $9.03 \mathrm{E}-04$ & $2.15 \mathrm{E}-04$ & $4.10 \mathrm{E}-06$ \\
\hline $235-\mathrm{U}$ & $3.71 \mathrm{E}-05$ & $8.83 \mathrm{E}-06$ & $1.55 \mathrm{E}-07$ \\
\hline $236-\mathrm{U}$ & $2.94 \mathrm{E}-05$ & $7.00 \mathrm{E}-06$ & N/A \\
\hline $237-\mathrm{Np}$ & $1.46 \mathrm{E}-03$ & $3.48 \mathrm{E}-03$ & $2.52 \mathrm{E}-05$ \\
\hline $238-\mathrm{Pu}$ & $3.95 \mathrm{E}-03$ & $6.37 \mathrm{E}-03$ & $6.37 \mathrm{E}-05$ \\
\hline $238-U$ & $8.41 \mathrm{E}-04$ & $2.00 \mathrm{E}-04$ & $3.50 \mathrm{E}-06$ \\
\hline $239-\mathrm{Pu}$ & $7.74 \mathrm{E}-02$ & $1.49 \mathrm{E}-01$ & $1.38 \mathrm{E}-03$ \\
\hline $240-\mathrm{Pu}$ & $1.68 \mathrm{E}-02$ & $3.23 \mathrm{E}-02$ & N/A \\
\hline 241-Am & $3.98 \mathrm{E}-01$ & $7.65 \mathrm{E}-01$ & $7.24 \mathrm{E}-03$ \\
\hline $241-\mathrm{Pu}$ & $6.50 \mathrm{E}-02$ & $2.03 \mathrm{E}-03$ & $2.24 \mathrm{E}-05$ \\
\hline $242-\mathrm{Cm}$ & $8.37 \mathrm{E}-04$ & $2.62 \mathrm{E}-05$ & $4.92 \mathrm{E}-07$ \\
\hline $242-\mathrm{Pu}$ & $1.33 \mathrm{E}-06$ & $2.15 \mathrm{E}-06$ & N/A \\
\hline 243-Am & $4.17 \mathrm{E}-04$ & $8.02 \mathrm{E}-04$ & $7.58 \mathrm{E}-06$ \\
\hline $243-\mathrm{Cm}$ & $5.43 \mathrm{E}-05$ & $6.62 \mathrm{E}-05$ & N/A \\
\hline 244-Cm & $9.12 \mathrm{E}-04$ & $8.77 \mathrm{E}-04$ & N/A \\
\hline $3-\mathrm{H}$ & $0.00 \mathrm{E}+00$ & $0.00 \mathrm{E}+00$ & $0.00 \mathrm{E}+00$ \\
\hline $59-\mathrm{Ni}$ & $1.62 \mathrm{E}-02$ & $1.37 \mathrm{E}-06$ & N/A \\
\hline $60-\mathrm{Co}$ & $4.49 \mathrm{E}-03$ & $1.60 \mathrm{E}-05$ & $2.36 \mathrm{E}-08$ \\
\hline 63-Ni & $1.18 \mathrm{E}+00$ & $2.19 \mathrm{E}-04$ & $2.62 \mathrm{E}-07$ \\
\hline 79-Se & $2.54 \mathrm{E}-01$ & $7.06 \mathrm{E}-04$ & N/A \\
\hline $90-\mathrm{Sr}$ & $3.47 \mathrm{E}+00$ & $2.17 \mathrm{E}-01$ & $1.58 \mathrm{E}-04$ \\
\hline $90-Y$ & $3.47 \mathrm{E}+00$ & $2.44 \mathrm{E}-03$ & $\mathrm{~N} / \mathrm{A}$ \\
\hline $93-\mathrm{Zr}$ & $2.70 \mathrm{E}-03$ & $4.35 \mathrm{E}-05$ & $3.03 \mathrm{E}-08$ \\
\hline $93 \mathrm{~m}-\mathrm{Nb}$ & $1.14 \mathrm{E}-01$ & $5.70 \mathrm{E}-05$ & N/A \\
\hline 99-Tc & $1.16 \mathrm{E}+02$ & $6.82 \mathrm{E}-02$ & $3.05 \mathrm{E}-05$ \\
\hline & Sum-of-Fractions & 4.3 & $9.1 \mathrm{E}-03$ \\
\hline
\end{tabular}


Table 4-6. Alternative 1, Case 2 Hazard Category Sum-of-Fractions.

\begin{tabular}{|c|c|c|c|}
\hline Radionuclide & Inventory (Ci) & Category 3 Threshold Fraction & Category 2 Threshold Fraction \\
\hline 106-Ru & $3.57 \mathrm{E}-12$ & $3.57 \mathrm{E}-14$ & $5.49 \mathrm{E}-16$ \\
\hline $113 \mathrm{~m}-\mathrm{Cd}$ & $1.45 \mathrm{E}-01$ & $1.23 \mathrm{E}-02$ & N/A \\
\hline $125-\mathrm{Sb}$ & 4.03E-02 & $3.36 \mathrm{E}-05$ & N/A \\
\hline $126-\mathrm{Sn}$ & $2.66 \mathrm{E}-02$ & $1.56 \mathrm{E}-04$ & $8.06 \mathrm{E}-08$ \\
\hline $129-\mathrm{I}$ & $2.77 \mathrm{E}-01$ & $4.62 \mathrm{E}+00$ & N/A \\
\hline $134-\mathrm{Cs}$ & $9.92 \mathrm{E}-06$ & $2.36 \mathrm{E}-07$ & $1.65 \mathrm{E}-10$ \\
\hline 137-Cs & $1.10 \mathrm{E}+01$ & $1.83 \mathrm{E}-01$ & $1.24 \mathrm{E}-04$ \\
\hline $137 \mathrm{~m}-\mathrm{Ba}$ & $1.04 \mathrm{E}+01$ & N/A & N/A \\
\hline 14-C & $0.00 \mathrm{E}+00$ & $0.00 \mathrm{E}+00$ & $0.00 \mathrm{E}+00$ \\
\hline 151-Sm & $6.01 \mathrm{E}+01$ & $6.01 \mathrm{E}-02$ & $6.07 \mathrm{E}-05$ \\
\hline 152-Eu & $4.25 \mathrm{E}-03$ & $2.13 \mathrm{E}-05$ & $3.27 \mathrm{E}-08$ \\
\hline 154-Eu & $3.73 \mathrm{E}-02$ & $1.87 \mathrm{E}-04$ & $3.39 \mathrm{E}-07$ \\
\hline 155-Eu & $2.31 \mathrm{E}-02$ & $2.46 \mathrm{E}-05$ & $3.16 \mathrm{E}-08$ \\
\hline 226-Ra & $1.97 \mathrm{E}-05$ & $1.64 \mathrm{E}-06$ & N/A \\
\hline $227-A c$ & $9.57 \mathrm{E}-05$ & $2.28 \mathrm{E}-03$ & $2.23 \mathrm{E}-05$ \\
\hline 228-Ra & $2.18 \mathrm{E}-06$ & $1.82 \mathrm{E}-07$ & N/A \\
\hline 229-Th & $3.02 \mathrm{E}-07$ & $3.21 \mathrm{E}-06$ & N/A \\
\hline $231-\mathrm{Pa}$ & $7.92 \mathrm{E}-04$ & $3.96 \mathrm{E}-03$ & N/A \\
\hline 232-Th & $5.79 \mathrm{E}-07$ & $5.79 \mathrm{E}-06$ & $3.22 \mathrm{E}-08$ \\
\hline $232-U$ & $1.28 \mathrm{E}-05$ & $1.56 \mathrm{E}-05$ & N/A \\
\hline $233-\mathrm{U}$ & $1.17 \mathrm{E}-03$ & $2.79 \mathrm{E}-04$ & $5.32 \mathrm{E}-06$ \\
\hline $234-\mathrm{U}$ & $1.66 \mathrm{E}-03$ & $3.95 \mathrm{E}-04$ & $7.55 \mathrm{E}-06$ \\
\hline $235-\mathrm{U}$ & $6.54 \mathrm{E}-05$ & $1.56 \mathrm{E}-05$ & $2.73 \mathrm{E}-07$ \\
\hline $236-\mathrm{U}$ & $8.63 \mathrm{E}-05$ & $2.05 \mathrm{E}-05$ & N/A \\
\hline 237-Np & $1.94 \mathrm{E}-03$ & $4.62 \mathrm{E}-03$ & $3.34 \mathrm{E}-05$ \\
\hline $238-\mathrm{Pu}$ & $9.52 \mathrm{E}-04$ & $1.54 \mathrm{E}-03$ & $1.54 \mathrm{E}-05$ \\
\hline $238-\mathrm{U}$ & $1.34 \mathrm{E}-03$ & $3.19 \mathrm{E}-04$ & $5.58 \mathrm{E}-06$ \\
\hline $239-\mathrm{Pu}$ & $5.87 \mathrm{E}-03$ & $1.13 \mathrm{E}-02$ & $1.05 \mathrm{E}-04$ \\
\hline $240-\mathrm{Pu}$ & $3.37 \mathrm{E}-03$ & $6.48 \mathrm{E}-03$ & N/A \\
\hline 241-Am & $5.52 \mathrm{E}-03$ & $1.06 \mathrm{E}-02$ & $1.00 \mathrm{E}-04$ \\
\hline $241-\mathrm{Pu}$ & $1.68 \mathrm{E}-02$ & $5.25 \mathrm{E}-04$ & $5.79 \mathrm{E}-06$ \\
\hline $242-\mathrm{Cm}$ & $9.30 \mathrm{E}-06$ & $2.91 \mathrm{E}-07$ & $5.47 \mathrm{E}-09$ \\
\hline $242-\mathrm{Pu}$ & $2.94 \mathrm{E}-07$ & 4.74E-07 & N/A \\
\hline 243-Am & $6.05 \mathrm{E}-06$ & $1.16 \mathrm{E}-05$ & $1.10 \mathrm{E}-07$ \\
\hline 243-Cm & $4.01 \mathrm{E}-07$ & $4.89 \mathrm{E}-07$ & N/A \\
\hline 244-Cm & $7.39 \mathrm{E}-06$ & 7.11E-06 & N/A \\
\hline $3-\mathrm{H}$ & $0.00 \mathrm{E}+00$ & $0.00 \mathrm{E}+00$ & $0.00 \mathrm{E}+00$ \\
\hline 59-Ni & $5.38 \mathrm{E}-03$ & $4.56 \mathrm{E}-07$ & N/A \\
\hline $60-\mathrm{Co}$ & $8.94 \mathrm{E}-03$ & 3.19E-05 & $4.71 \mathrm{E}-08$ \\
\hline $63-\mathrm{Ni}$ & $4.49 \mathrm{E}-01$ & $8.31 \mathrm{E}-05$ & $9.98 \mathrm{E}-08$ \\
\hline $79-\mathrm{Se}$ & $6.76 \mathrm{E}-02$ & $1.88 \mathrm{E}-04$ & N/A \\
\hline $90-\mathrm{Sr}$ & $1.54 \mathrm{E}+00$ & $9.63 \mathrm{E}-02$ & $7.00 \mathrm{E}-05$ \\
\hline $90-Y$ & $1.54 \mathrm{E}+00$ & $1.08 \mathrm{E}-03$ & N/A \\
\hline $93-\mathrm{Zr}$ & $8.90 \mathrm{E}-03$ & $1.44 \mathrm{E}-04$ & $1.00 \mathrm{E}-07$ \\
\hline $93 \mathrm{~m}-\mathrm{Nb}$ & $3.92 \mathrm{E}-01$ & $1.96 \mathrm{E}-04$ & N/A \\
\hline 99-Tc & $7.92 \mathrm{E}+01$ & $4.66 \mathrm{E}-02$ & $2.08 \mathrm{E}-05$ \\
\hline & Sum-of-Fractions & 5.1 & $5.8 \mathrm{E}-04$ \\
\hline
\end{tabular}


\begin{tabular}{|l|l|r}
\hline A E M Consulting, LLC. & Calculation Set No. AEM-WRPS-2012-CN-017 Rev No. 0 & Sheet 13 of 18
\end{tabular}

Table 4-7. Alternatives 2 and 3, Case 1 Hazard Category Sum-of-Fractions.

\begin{tabular}{|c|c|c|c|}
\hline Radionuclide & Inventory $(\mathrm{Ci})$ & Category 3 Threshold Fraction & Category 2 Threshold Fraction \\
\hline 106-Ru & $8.64 \mathrm{E}-08$ & $8.64 \mathrm{E}-10$ & $1.33 \mathrm{E}-11$ \\
\hline $113 \mathrm{~m}-\mathrm{Cd}$ & $1.07 \mathrm{E}-01$ & $9.07 \mathrm{E}-03$ & $\mathrm{~N} / \mathrm{A}$ \\
\hline $125-\mathrm{Sb}$ & $2.34 \mathrm{E}-01$ & $1.95 \mathrm{E}-04$ & N/A \\
\hline $126-\mathrm{Sn}$ & $2.61 \mathrm{E}-02$ & $1.54 \mathrm{E}-04$ & $7.91 \mathrm{E}-08$ \\
\hline $129-\mathrm{I}$ & $2.92 \mathrm{E}-01$ & $4.87 \mathrm{E}+00$ & $\mathrm{~N} / \mathrm{A}$ \\
\hline 134-Cs & $5.37 \mathrm{E}-06$ & $1.28 \mathrm{E}-07$ & $8.95 \mathrm{E}-11$ \\
\hline $137-\mathrm{Cs}$ & $1.56 \mathrm{E}+01$ & $2.60 \mathrm{E}-01$ & $1.75 \mathrm{E}-04$ \\
\hline $137 \mathrm{~m}-\mathrm{Ba}$ & $1.47 \mathrm{E}+01$ & N/A & $\mathrm{N} / \mathrm{A}$ \\
\hline $14-\mathrm{C}$ & $0.00 \mathrm{E}+00$ & $0.00 \mathrm{E}+00$ & $0.00 \mathrm{E}+00$ \\
\hline $151-\mathrm{Sm}$ & $4.36 \mathrm{E}+01$ & $4.36 \mathrm{E}-02$ & $4.40 \mathrm{E}-05$ \\
\hline 152-Eu & $4.36 \mathrm{E}-03$ & $2.18 \mathrm{E}-05$ & $3.35 \mathrm{E}-08$ \\
\hline 154-Eu & $5.46 \mathrm{E}-02$ & $2.73 \mathrm{E}-04$ & $4.96 \mathrm{E}-07$ \\
\hline $155-\mathrm{Eu}$ & $1.51 \mathrm{E}-02$ & $1.61 \mathrm{E}-05$ & $2.07 \mathrm{E}-08$ \\
\hline $226-\mathrm{Ra}$ & $2.02 \mathrm{E}-05$ & $1.68 \mathrm{E}-06$ & N/A \\
\hline $227-A c$ & $1.54 \mathrm{E}-05$ & $3.67 \mathrm{E}-04$ & $3.58 \mathrm{E}-06$ \\
\hline $228-\mathrm{Ra}$ & $8.64 \mathrm{E}-04$ & $7.20 \mathrm{E}-05$ & N/A \\
\hline 229-Th & $1.23 \mathrm{E}-05$ & $1.31 \mathrm{E}-04$ & N/A \\
\hline $231-\mathrm{Pa}$ & $2.14 \mathrm{E}-04$ & $1.07 \mathrm{E}-03$ & N/A \\
\hline 232-Th & $2.80 \mathrm{E}-05$ & $2.80 \mathrm{E}-04$ & $1.56 \mathrm{E}-06$ \\
\hline $232-U$ & $5.00 \mathrm{E}-05$ & $6.10 \mathrm{E}-05$ & N/A \\
\hline $233-\mathrm{U}$ & $3.50 \mathrm{E}-03$ & $8.33 \mathrm{E}-04$ & $1.59 \mathrm{E}-05$ \\
\hline $234-U$ & $1.57 \mathrm{E}-03$ & $3.74 \mathrm{E}-04$ & $7.14 \mathrm{E}-06$ \\
\hline $235-\mathrm{U}$ & $6.43 \mathrm{E}-05$ & $1.53 \mathrm{E}-05$ & $2.68 \mathrm{E}-07$ \\
\hline $236-\mathrm{U}$ & $5.09 \mathrm{E}-05$ & $1.21 \mathrm{E}-05$ & N/A \\
\hline $237-\mathrm{Np}$ & $2.54 \mathrm{E}-03$ & $6.05 \mathrm{E}-03$ & $4.38 \mathrm{E}-05$ \\
\hline $238-\mathrm{Pu}$ & $6.85 \mathrm{E}-03$ & $1.10 \mathrm{E}-02$ & $1.10 \mathrm{E}-04$ \\
\hline $238-U$ & $1.46 \mathrm{E}-03$ & $3.48 \mathrm{E}-04$ & $6.08 \mathrm{E}-06$ \\
\hline $239-\mathrm{Pu}$ & $1.34 \mathrm{E}-01$ & $2.58 \mathrm{E}-01$ & $2.39 \mathrm{E}-03$ \\
\hline $240-\mathrm{Pu}$ & $2.91 \mathrm{E}-02$ & $5.60 \mathrm{E}-02$ & N/A \\
\hline 241-Am & $6.89 \mathrm{E}-01$ & $1.33 \mathrm{E}+00$ & $1.25 \mathrm{E}-02$ \\
\hline $241-\mathrm{Pu}$ & $1.13 \mathrm{E}-01$ & $3.53 \mathrm{E}-03$ & $3.90 \mathrm{E}-05$ \\
\hline $242-\mathrm{Cm}$ & $1.45 \mathrm{E}-03$ & $4.53 \mathrm{E}-05$ & $8.53 \mathrm{E}-07$ \\
\hline $242-\mathrm{Pu}$ & $2.31 \mathrm{E}-06$ & $3.73 \mathrm{E}-06$ & N/A \\
\hline 243-Am & $7.22 \mathrm{E}-04$ & $1.39 \mathrm{E}-03$ & $1.31 \mathrm{E}-05$ \\
\hline $243-\mathrm{Cm}$ & $9.41 \mathrm{E}-05$ & $1.15 \mathrm{E}-04$ & N/A \\
\hline 244-Cm & $1.58 \mathrm{E}-03$ & $1.52 \mathrm{E}-03$ & N/A \\
\hline $3-\mathrm{H}$ & $0.00 \mathrm{E}+00$ & $0.00 \mathrm{E}+00$ & $0.00 \mathrm{E}+00$ \\
\hline $59-\mathrm{Ni}$ & $2.81 \mathrm{E}-02$ & $2.38 \mathrm{E}-06$ & N/A \\
\hline $60-\mathrm{Co}$ & $7.79 \mathrm{E}-03$ & $2.78 \mathrm{E}-05$ & $4.10 \mathrm{E}-08$ \\
\hline 63-Ni & $2.05 \mathrm{E}+00$ & $3.80 \mathrm{E}-04$ & $4.56 \mathrm{E}-07$ \\
\hline 79-Se & $4.40 \mathrm{E}-01$ & $1.22 \mathrm{E}-03$ & N/A \\
\hline $90-\mathrm{Sr}$ & $6.01 \mathrm{E}+00$ & $3.76 \mathrm{E}-01$ & $2.73 \mathrm{E}-04$ \\
\hline $90-Y$ & $6.01 \mathrm{E}+00$ & $4.23 \mathrm{E}-03$ & N/A \\
\hline $93-\mathrm{Zr}$ & $4.67 \mathrm{E}-03$ & $7.53 \mathrm{E}-05$ & $5.25 \mathrm{E}-08$ \\
\hline $93 \mathrm{~m}-\mathrm{Nb}$ & $1.97 \mathrm{E}-01$ & $9.85 \mathrm{E}-05$ & N/A \\
\hline 99-Tc & $2.01 \mathrm{E}+02$ & $1.18 \mathrm{E}-01$ & $5.29 \mathrm{E}-05$ \\
\hline & Sum-of-Fractions & 7.4 & $1.6 \mathrm{E}-02$ \\
\hline
\end{tabular}


\begin{tabular}{|l|l|r}
\hline A E M Consulting, LLC. & Calculation Set No. AEM-WRPS-2012-CN-017 Rev No. 0 & Sheet 14 of 18
\end{tabular}

Table 4-8. Alternatives 2 and 3, Case 2 Hazard Category Sum-of-Fractions.

\begin{tabular}{|c|c|c|c|}
\hline Radionuclide & Inventory $(\mathrm{Ci})$ & Category 3 Threshold Fraction & Category 2 Threshold Fraction \\
\hline 106-Ru & $9.25 \mathrm{E}-12$ & $9.25 \mathrm{E}-14$ & $1.42 \mathrm{E}-15$ \\
\hline $113 \mathrm{~m}-\mathrm{Cd}$ & $3.77 \mathrm{E}-01$ & $3.19 \mathrm{E}-02$ & $\mathrm{~N} / \mathrm{A}$ \\
\hline $125-\mathrm{Sb}$ & $1.05 \mathrm{E}-01$ & $8.75 \mathrm{E}-05$ & N/A \\
\hline $126-\mathrm{Sn}$ & $6.91 \mathrm{E}-02$ & $4.06 \mathrm{E}-04$ & $2.09 \mathrm{E}-07$ \\
\hline $129-\mathrm{I}$ & $7.21 \mathrm{E}-01$ & $1.20 \mathrm{E}+01$ & N/A \\
\hline 134-Cs & $2.58 \mathrm{E}-05$ & $6.14 \mathrm{E}-07$ & $4.30 \mathrm{E}-10$ \\
\hline $137-\mathrm{Cs}$ & $2.86 \mathrm{E}+01$ & $4.77 \mathrm{E}-01$ & $3.21 \mathrm{E}-04$ \\
\hline $137 \mathrm{~m}-\mathrm{Ba}$ & $2.70 \mathrm{E}+01$ & N/A & $\mathrm{N} / \mathrm{A}$ \\
\hline $14-\mathrm{C}$ & $0.00 \mathrm{E}+00$ & $0.00 \mathrm{E}+00$ & $0.00 \mathrm{E}+00$ \\
\hline $151-\mathrm{Sm}$ & $1.57 \mathrm{E}+02$ & $1.57 \mathrm{E}-01$ & $1.59 \mathrm{E}-04$ \\
\hline $152-\mathrm{Eu}$ & $1.10 \mathrm{E}-02$ & $5.50 \mathrm{E}-05$ & $8.46 \mathrm{E}-08$ \\
\hline 154-Eu & $9.71 \mathrm{E}-02$ & $4.86 \mathrm{E}-04$ & $8.83 \mathrm{E}-07$ \\
\hline $155-\mathrm{Eu}$ & $6.01 \mathrm{E}-02$ & $6.39 \mathrm{E}-05$ & $8.23 \mathrm{E}-08$ \\
\hline $226-\mathrm{Ra}$ & $5.11 \mathrm{E}-05$ & $4.26 \mathrm{E}-06$ & N/A \\
\hline $227-A c$ & $2.49 \mathrm{E}-04$ & $5.93 \mathrm{E}-03$ & $5.79 \mathrm{E}-05$ \\
\hline $228-\mathrm{Ra}$ & $5.66 \mathrm{E}-06$ & $4.72 \mathrm{E}-07$ & N/A \\
\hline 229-Th & $7.86 \mathrm{E}-07$ & $8.36 \mathrm{E}-06$ & N/A \\
\hline $231-\mathrm{Pa}$ & $2.06 \mathrm{E}-03$ & $1.03 \mathrm{E}-02$ & N/A \\
\hline 232-Th & $1.50 \mathrm{E}-06$ & $1.50 \mathrm{E}-05$ & $8.33 \mathrm{E}-08$ \\
\hline $232-U$ & $3.33 \mathrm{E}-05$ & $4.06 \mathrm{E}-05$ & N/A \\
\hline $233-\mathrm{U}$ & $3.05 \mathrm{E}-03$ & $7.26 \mathrm{E}-04$ & $1.39 \mathrm{E}-05$ \\
\hline $234-U$ & $4.32 \mathrm{E}-03$ & $1.03 \mathrm{E}-03$ & $1.96 \mathrm{E}-05$ \\
\hline $235-\mathrm{U}$ & $1.70 \mathrm{E}-04$ & $4.05 \mathrm{E}-05$ & $7.08 \mathrm{E}-07$ \\
\hline $236-\mathrm{U}$ & $2.24 \mathrm{E}-04$ & $5.33 \mathrm{E}-05$ & N/A \\
\hline $237-\mathrm{Np}$ & $5.06 \mathrm{E}-03$ & $1.20 \mathrm{E}-02$ & $8.72 \mathrm{E}-05$ \\
\hline $238-\mathrm{Pu}$ & $2.47 \mathrm{E}-03$ & $3.98 \mathrm{E}-03$ & $3.98 \mathrm{E}-05$ \\
\hline $238-U$ & $3.47 \mathrm{E}-03$ & $8.26 \mathrm{E}-04$ & $1.45 \mathrm{E}-05$ \\
\hline $239-\mathrm{Pu}$ & $1.53 \mathrm{E}-02$ & $2.94 \mathrm{E}-02$ & $2.73 \mathrm{E}-04$ \\
\hline $240-\mathrm{Pu}$ & $8.79 \mathrm{E}-03$ & $1.69 \mathrm{E}-02$ & N/A \\
\hline 241-Am & $1.43 \mathrm{E}-02$ & $2.75 \mathrm{E}-02$ & $2.60 \mathrm{E}-04$ \\
\hline $241-\mathrm{Pu}$ & $4.37 \mathrm{E}-02$ & $1.37 \mathrm{E}-03$ & $1.51 \mathrm{E}-05$ \\
\hline $242-\mathrm{Cm}$ & $2.42 \mathrm{E}-05$ & $7.56 \mathrm{E}-07$ & $1.42 \mathrm{E}-08$ \\
\hline $242-\mathrm{Pu}$ & $7.63 \mathrm{E}-07$ & $1.23 \mathrm{E}-06$ & N/A \\
\hline 243-Am & $1.57 \mathrm{E}-05$ & $3.02 \mathrm{E}-05$ & $2.85 \mathrm{E}-07$ \\
\hline $243-\mathrm{Cm}$ & $1.04 \mathrm{E}-06$ & $1.27 \mathrm{E}-06$ & N/A \\
\hline 244-Cm & $1.92 \mathrm{E}-05$ & $1.85 \mathrm{E}-05$ & N/A \\
\hline $3-\mathrm{H}$ & $0.00 \mathrm{E}+00$ & $0.00 \mathrm{E}+00$ & $0.00 \mathrm{E}+00$ \\
\hline $59-\mathrm{Ni}$ & $1.40 \mathrm{E}-02$ & $1.19 \mathrm{E}-06$ & N/A \\
\hline $60-\mathrm{Co}$ & $2.33 \mathrm{E}-02$ & $8.32 \mathrm{E}-05$ & $1.23 \mathrm{E}-07$ \\
\hline 63-Ni & $1.17 \mathrm{E}+00$ & $2.17 \mathrm{E}-04$ & $2.60 \mathrm{E}-07$ \\
\hline $79-\mathrm{Se}$ & $1.76 \mathrm{E}-01$ & $4.89 \mathrm{E}-04$ & N/A \\
\hline $90-\mathrm{Sr}$ & $3.99 \mathrm{E}+00$ & $2.49 \mathrm{E}-01$ & $1.81 \mathrm{E}-04$ \\
\hline $90-Y$ & $3.99 \mathrm{E}+00$ & $2.81 \mathrm{E}-03$ & $\mathrm{~N} / \mathrm{A}$ \\
\hline $93-\mathrm{Zr}$ & $2.31 \mathrm{E}-02$ & $3.73 \mathrm{E}-04$ & $2.60 \mathrm{E}-07$ \\
\hline $93 \mathrm{~m}-\mathrm{Nb}$ & $1.02 \mathrm{E}+00$ & $5.10 \mathrm{E}-04$ & $\mathrm{~N} / \mathrm{A}$ \\
\hline 99-Tc & $2.06 \mathrm{E}+02$ & $1.21 \mathrm{E}-01$ & $5.42 \mathrm{E}-05$ \\
\hline & Sum-of-Fractions & 13.2 & $1.5 \mathrm{E}-03$ \\
\hline
\end{tabular}


\begin{tabular}{|l|l|r}
\hline A E M Consulting, LLC. & Calculation Set No. AEM-WRPS-2012-CN-017 Rev No. 0 & Sheet 15 of 18
\end{tabular}

Figure 4-1. Waste Volume to Reach Hazard Category 3 Threshold Over Entire 25-Year Mission.

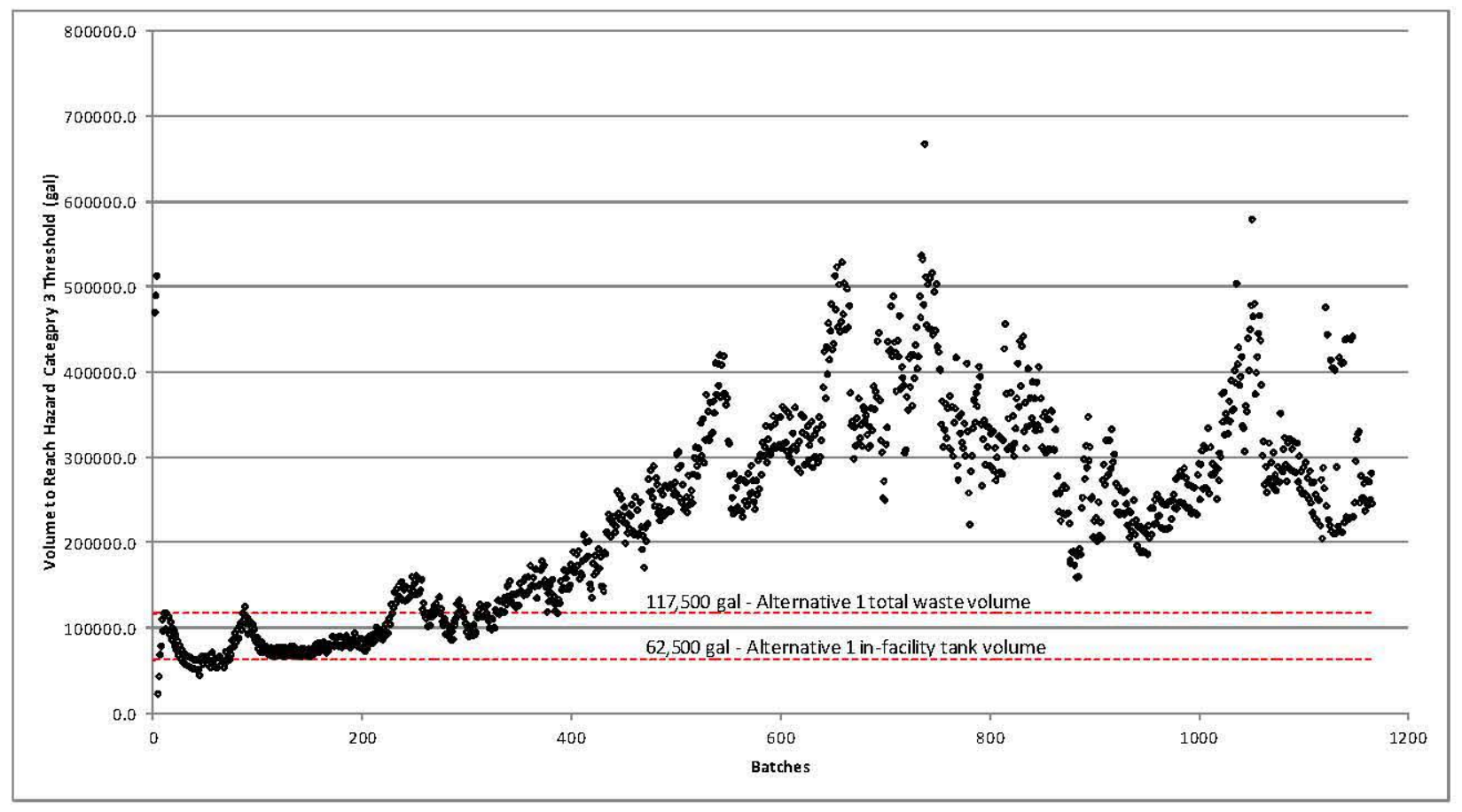

Figure 4-2. Waste Volume to Reach Hazard Category 3 Threshold for First Third of 25-Year Mission.

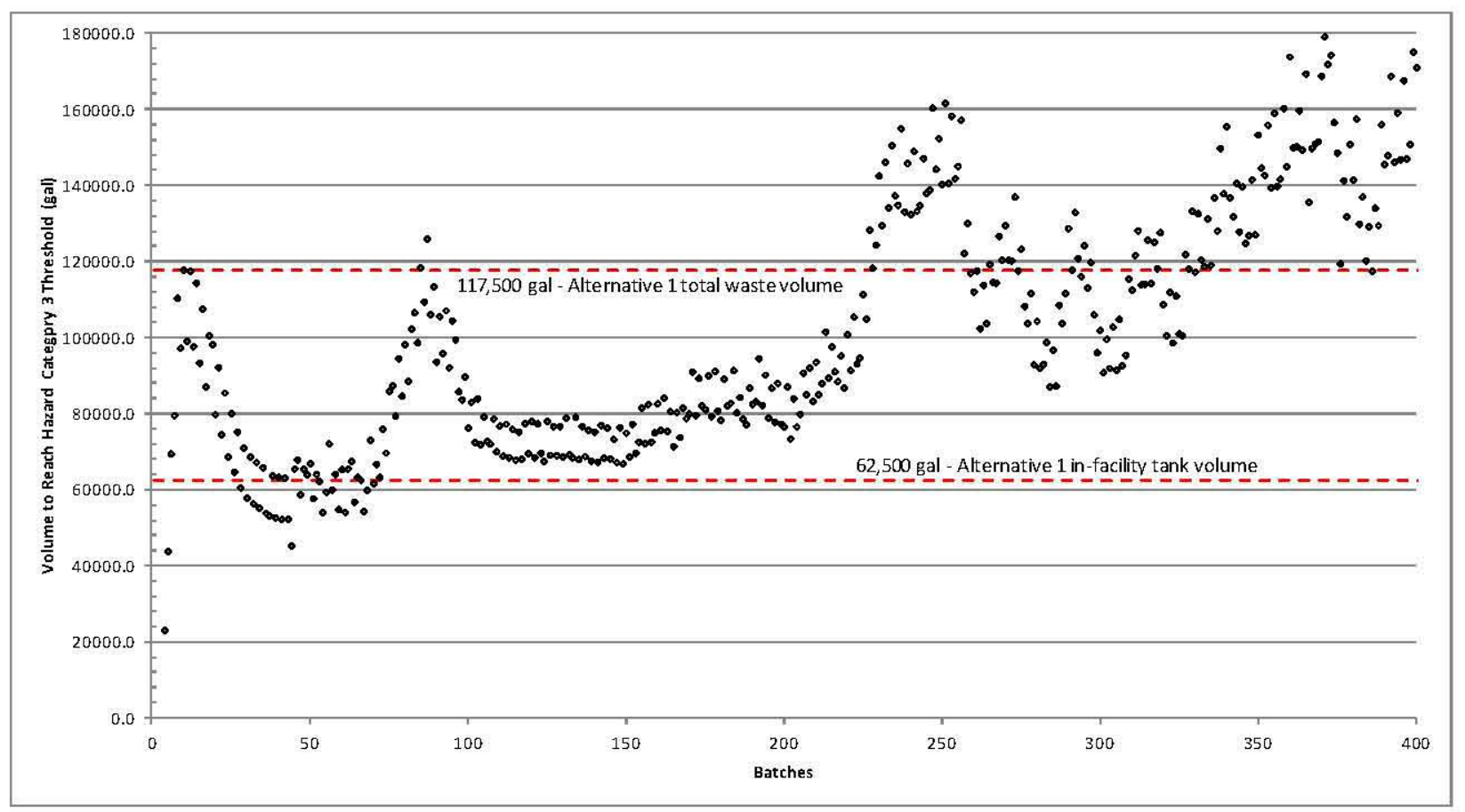




\section{$5.0 \quad$ Use of Computer Software}

None.

\subsection{Results}

Table 6-1 summarizes the hazard category threshold sum-of-fractions calculated in Section 4.0.

Table 6-1. Hazard Category Threshold Sum-of-Fractions Summary.

\begin{tabular}{|c|l|c|c|}
\hline Alternative & \multicolumn{1}{|c|}{ Case } & $\begin{array}{c}\text { Hazard Category 3 } \\
\text { Threshold } \\
\text { Sum-of-Fractions }\end{array}$ & $\begin{array}{c}\text { Hazard Category 2 } \\
\text { Threshold } \\
\text { Sum-of-Fractions }\end{array}$ \\
\hline \multirow{2}{*}{1} & 1. Concentrated Average Feed & 4.3 & $9.1 \mathrm{E}-03$ \\
\cline { 2 - 4 } & 2. Unconcentrated Worst-Case Batch & 5.1 & $5.8 \mathrm{E}-04$ \\
\hline \multirow{2}{*}{2 and 3} & 1. Concentrated Average Feed & 7.4 & $1.6 \mathrm{E}-02$ \\
\cline { 2 - 4 } & 2. Concentrated Worst-Case Batch & 13.2 & $1.5 \mathrm{E}-03$ \\
\hline
\end{tabular}

The Hazard Category 3 threshold sum-of-fractions are greater than one and the Hazard Category 2 threshold sum-offractions are less than one. Therefore, all of the process alternatives would be classified as Hazard Category 3 facilities.

The Alternative 1 cases are based on a total waste volume of 117,500 gallons. The Alternative 1 process could stay below Hazard Category 3 by restricting the total waste volume inventory in the first third of the 25 -year mission, to as low as 23,200 gallons. Refer to Section 4.6 for additional information.

\subsection{Conclusions}

All three process alternatives would be classified as Hazard Category 3 facilities and are well below the Hazard Category 2 threshold. 


\subsection{References}

10 CFR 61.55, Part 61, "Licensing Requirements for Land Disposal of Radioactive Waste," 61.55, "Waste Classification".

DOE-STD-1027-92, 1997, Hazard Categorization and Accident Analysis Techniques for Compliance with DOE Order 5480.23, Nuclear Safety Analysis Reports, Change Notice 1, U.S. Department of Energy, Washington, D.C.

LA-12981-MS, 2002, Table of DOE-STD-1027-92 Hazard Category 3 Threshold Quantities for the ICRP-30 List of 757 Radionuclides, LANL Fact Sheet, Rev. 1, Los Alamos National Laboratory, Los Alamos, New Mexico.

RPP-RPT-52796, 2012, Supporting Calculations for Submerged Bed Scrubber Condensate Disposal Pre-Conceptual Study, Rev. 0, Washington River Protection Solutions, LLC, Richland, Washington.

SVF-2440, 2012, SBS Disposal PreConcept Alts, Draft, Washington River Protection Solutions, LLC, Richland, Washington. 


\section{\begin{tabular}{|l|l|r}
\hline A E M Consulting, LLC. & Calculation Set No. AEM-WRPS-2012-CN-017 Rev No. 0 & Sheet 18 of 18
\end{tabular}}

Attachment A. Process Flow Diagram from SVF-2440, SBS Disposal PreConcept Alts.

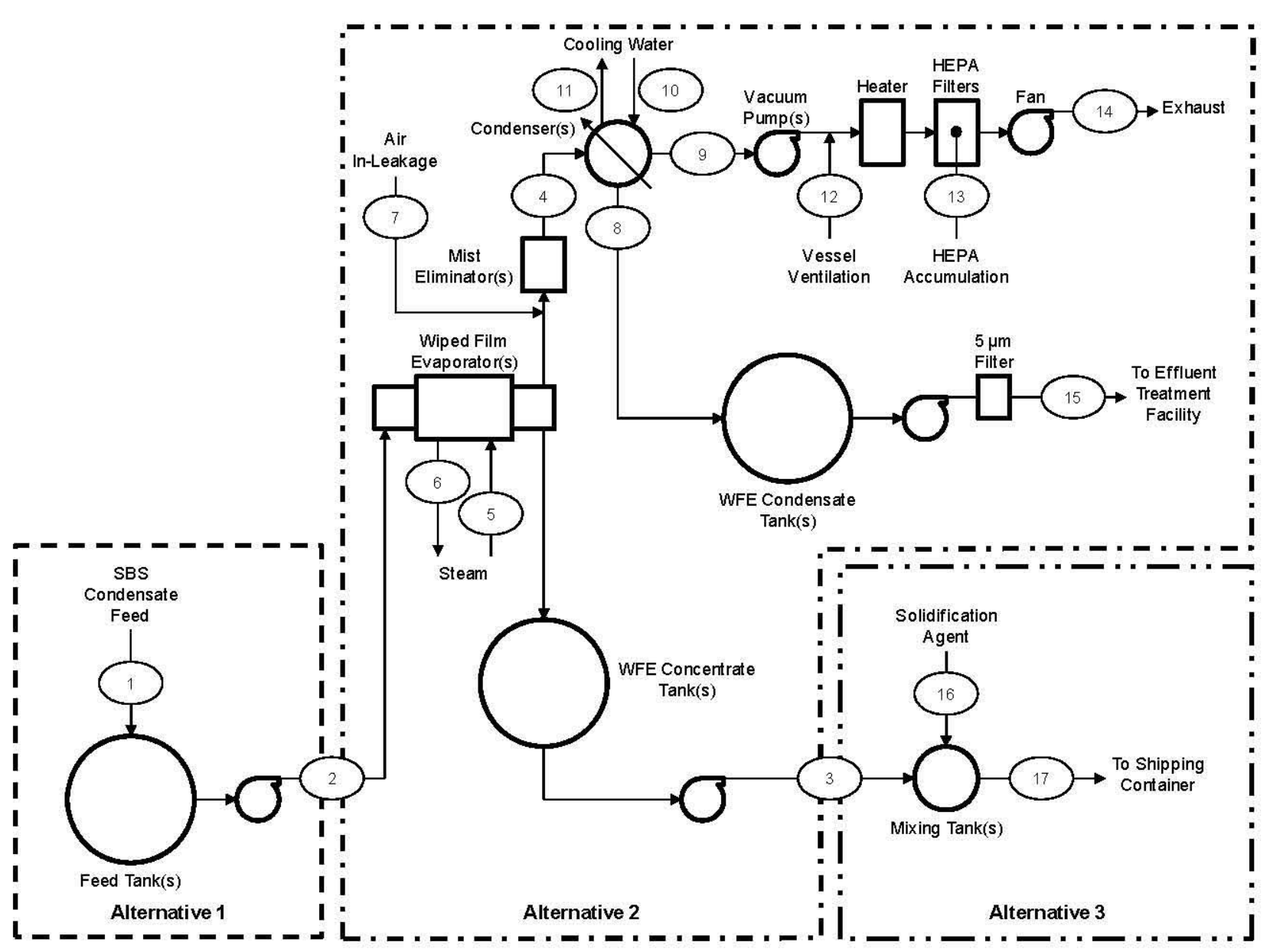

